\title{
Valorisation of plastic waste via metal-catalysed depolymerisation
}

\author{
Francesca Liguori, Carmen Moreno-Marrodán and Pierluigi Barbaro*
}

\author{
Review \\ Address: \\ Consiglio Nazionale delle Ricerche, Istituto di Chimica dei Composti \\ Organo Metallici, Via Madonna del Piano 10, 50019 Sesto Fiorentino, \\ Firenze, Italy \\ Email: \\ Pierluigi Barbaro* - pierluigi.barbaro@iccom.cnr.it \\ * Corresponding author \\ Keywords: \\ catalysis; depolymerisation; plastic; recycling; sustainable
}

\author{
Beilstein J. Org. Chem. 2021, 17, 589-621. \\ https://doi.org/10.3762/bjoc.17.53 \\ Received: 23 November 2020 \\ Accepted: 05 February 2021 \\ Published: 02 March 2021 \\ This article is part of the thematic issue "Green chemistry II". \\ Associate Editor: L. Vaccaro \\ (c) 2021 Liguori et al.; licensee Beilstein-Institut. \\ License and terms: see end of document.
}

\begin{abstract}
Metal-catalysed depolymerisation of plastics to reusable building blocks, including monomers, oligomers or added-value chemicals, is an attractive tool for the recycling and valorisation of these materials. The present manuscript shortly reviews the most significant contributions that appeared in the field within the period January 2010-January 2020 describing selective depolymerisation methods of plastics. Achievements are broken down according to the plastic material, namely polyolefins, polyesters, polycarbonates and polyamides. The focus is on recent advancements targeting sustainable and environmentally friendly processes. Biocatalytic or unselective processes, acid-base treatments as well as the production of fuels are not discussed, nor are the methods for the further upgrade of the depolymerisation products.
\end{abstract}

\section{Review}

\section{Introduction}

In a circular-economy perspective, wastes are deemed precious feedstock usable in the production of fertilisers, fuels, chemicals and a variety of materials for packaging, housing, transport and clothing [1,2]. A considerable fraction of the waste currently produced by our society is due to plastics, which is a major problem $[3,4]$. Plastics are usually synthetic polymers recalcitrant to decomposition, and hence liable to accumulate in landfills or the environment when discarded $[5,6]$. Not all plastics can be reused, and thus having limited economic value $[7,8]$. Plastics may release toxic compounds dangerous to human health and the habitat $[9,10]$. Plastic materials are ubiquitous in our everyday life, which accounts for a global production of plastics of around 360 million tons in 2018 [11], of which more than $60 \%$ are disposed $[12,13]$. As a consequence, pollution from plastics is impressive, resulting in the diffusion of microplastics into soil $[14,15]$, oceans $[16,17]$, crustaceans [18] and rain [19].

Valorisation of plastic waste, via chemical conversion into reusable building blocks, may contribute to solving these prob- 
lems while representing a strategy to reduce the carbon footprint of the chemical industry [20,21]. The approach deepens the concept of plastic recycling [22,23], first of all requiring a careful design of efficient and controlled depolymerisation processes. Despite of this hurdle, the implementation of effective plastics value chains through recovery, reprocessing and upgrade would be a tangible mean to turn a challenge into an opportunity $[24,25]$. The waste-to-products strategy is already in place for both animal $[26,27]$ and plant biomass polymeric waste $[28,29]$, for which mature technologies are operative [30].

When referring to polymers in general, there is often a lack of univocal definitions, which may lead to confusion between terminologies used as synonyms, though they are not $[31,32]$ The IUPAC recommendations provide a useful reference to this aim [33]. Thus, "degradation" is a broad term describing the "progressive loss of the performance or of the characteristics of a substance" due to the action of chemical (acids, air, halogens, solvents) or physical agents (heat, light). For polymers, the properties involved are, for instance, tensile strength, colour or shape, the change of which is usually associated with a modification of the chemical composition (e.g., as a consequence of oxidation, cross-linkage, bond cleavage). The term "biodegradation" indicates a "degradation caused by enzymatic processes resulting from the action of cells". Although commonly used, also for artificial polymers, the term "biodegradable" specifically refers to biorelated polymers (i.e., proteins, nucleic acids, polysaccharides), which are "susceptible to degradation by biological activity by lowering of the molar masses of macromolecules". Therefore, in this situation, "chain cleavage" and "degradation" are used interchangeably. To avoid confusion, instead of "(bio)degradation", in the present review, we will use the term "depolymerisation" to identify the "process of converting a macromolecule into (recoverable) monomers or a mixture of monomers". Another relevant definition is that of "bioplastic", meaning "biobased polymer derived from the biomass or issued from monomers derived from the biomass", wherein "biobased" indicates "composed or derived in whole or in part of biological products issued from the biomass". Also, there is no universally accepted definition for "compostable", as it differs between diverse issuers [34]. The criteria indicated by the European Commission through the standard EN 13432 "Packaging-Requirements for packaging recoverable through composting and biodegradation" include disintegration (i.e., breakdown of material to particles of a defined size), biodegradability, absence of negative effects on the composting process and amount of heavy metals below given maximum values $[35,36]$.

"Recycling" itself is a general term for which multiple definitions exist, depending on the year and the author [37]. Plastics manufacturers have also delivered their own guidelines under the name "Design for Recycling" [38,39]. A generally accepted definition for plastic recycling is "the process of recovering scrap or waste plastics and reprocessing the material into useful products, sometimes completely different in form from their original state" $[40,41]$. A possible classification of reported plastic recycling techniques is schematically shown in Figure 1 [42], wherein breakdown by the recycled polymer, the final product or the process involved further differentiates between methods, which may lead to occasional overlaps and inconsistencies $[43,44]$.

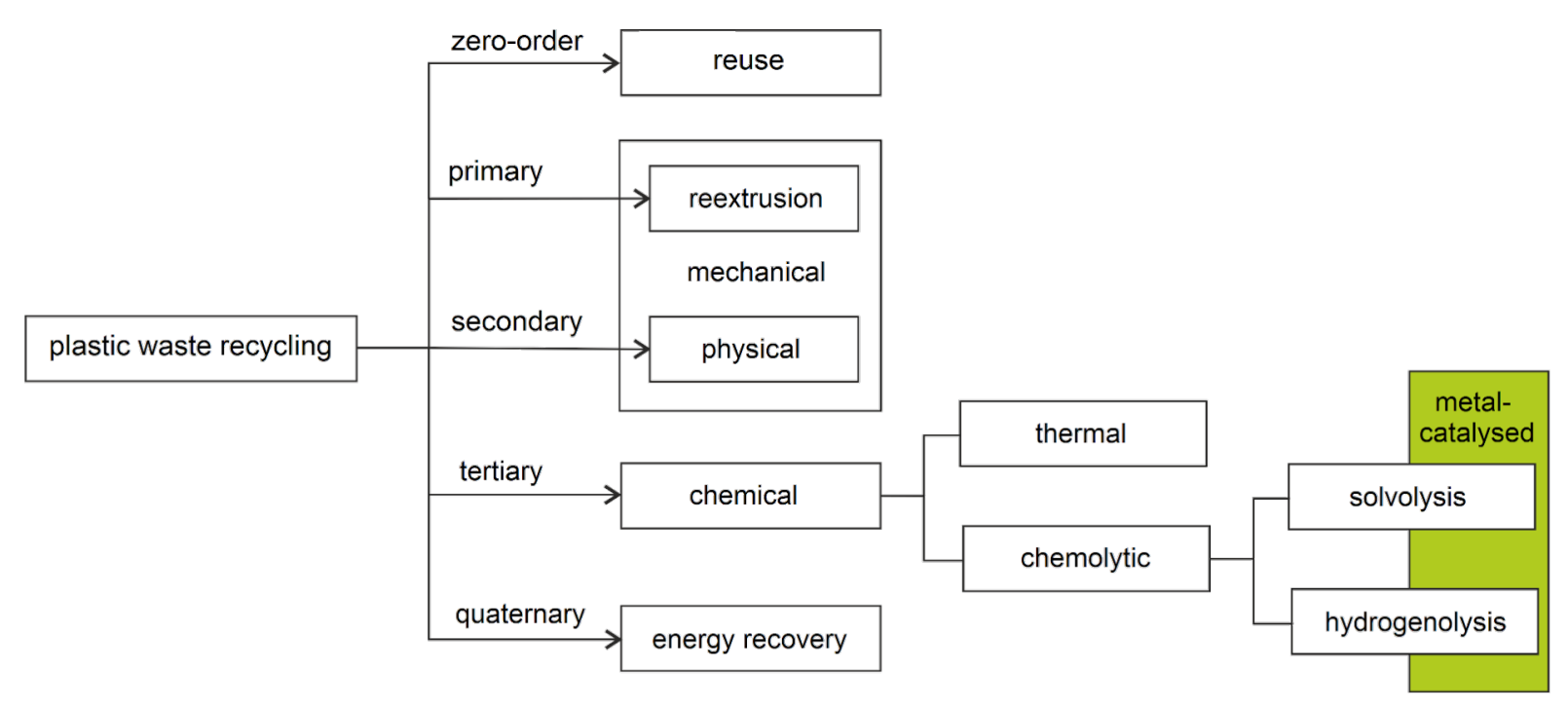

Figure 1: Potential classification of plastic recycling processes. The area covered by the present review is highlighted in green. 
"Reuse" is considered a zero-order recycling option, meaning "any operation by which products or components that are not waste are used again for the same purpose for which they were conceived" [45]. A typical example are plastic containers that are washed and reused as they are [46]. True recycling includes "any recovery operation by which waste materials are reprocessed into products, materials or substances whether for the original or other purposes. It includes the reprocessing of organic material but does not include energy recovery and the reprocessing into materials that are to be used as fuels" [45] Therein, three options can be distinguished. "Reextrusion" (also known as closed-loop recycling) refers to the recycling of clean, uncontaminated single-polymer materials to give products with analogous performance and applications [47]. For example, polyethylene bottles are recycled into new bottles. Similarly, in "physical recycling", the polymeric structure of the original material is maintained, although purification steps, the addition of additives or blending with fresh polymers may be included [48]. For this reason, both reextrusion and physical recycling are also referred to as "mechanical recycling", primary and secondary, respectively $[49,50]$. However, materials of lower quality and economic value can be obtained [51,52]. By contrast, the term "chemical recycling" (or feedstock recycling) refers to those processes involving an alteration of the polymeric chain due to breakage of chemical bonds [53,54]. This definition may be confusing since chain scission may actually occur using either physical (heat) or chemical agents. Indeed, chemical recycling processes can be divided into two main categories: thermochemical and chemolytic routes. All of these processes may result in a variety of valuable products and the mixture thereof, including $\mathrm{C} 1$ molecules $\left(\mathrm{CO}, \mathrm{CO}_{2}, \mathrm{CH}_{4}\right), \mathrm{H}_{2} \mathrm{O}$ and $\mathrm{H}_{2}$ due to complete decomposition of the polymeric chain, monomers or oligomers, depending on the waste polymer and the process. The as-obtained compounds can be reused as raw materials for the process industry (hence the term feedstock) to produce chemicals, fuels or other polymers. Thermochemical processes include pyrolysis [55], catalytic cracking [56] and gasification [57]. These are usually unselective, high-temperature treatments $\left(300-1000{ }^{\circ} \mathrm{C}\right)$ that may efficiently provide light hydrocarbons or small molecules [58,59]. Chemolytic processes, wherein a chemical reagent is used to achieve depolymerisation, mainly involve solvolysis (a solvent is the reagent and solvolyses include hydrolysis, glycolysis, alcoholysis and aminolysis) and hydrogenolysis reactions $\left(\mathrm{H}_{2}\right.$ as reagent). Hydrolysis (sometimes called hydrocracking) is in between thermochemical and chemolytic processing, basically consisting of depolymerisation by the combined action of heat and dihydrogen [60]. Chemolytic processes may or may not be catalytic. They will be discussed in detail in the following section. A fourth option is "energy recovery". Strictly speaking, this cannot be considered as recycling, consisting in the recovery of the energy contained in a material rather than the material itself, and it is usually achieved by combustion or incineration [61,62]. This method is generally used for plastics that cannot be economically recycled by other means $[63,64]$. However, it often entails the emission of toxic volatile compounds (furans, dioxins) [65]. The tar obtained may be used for road construction [66].

The present paper shortly reviews the most significant contributions that appeared in the literature, from January 2010 to January 2020, in the field of metal-catalysed selective depolymerisation of plastics to reusable monomers, oligomers or added-value chemicals (see Figure 1). Scientific achievements will be described according to the plastic substrate, irrespective of the metal catalyst. Uncatalysed depolymerisations, full chaincracking or unselective processes, acid-base treatments, as well as the production of fuels from plastics, will not be covered. Conversion of plastic waste to fuels $[67,68]$ and biocatalytic depolymerisation methods $[69,70]$ have been extensively and recently reviewed elsewhere, hence they will not be considered herein.

\section{Depolymerisation of plastics}

As outlined above, depolymerisation of plastic waste to reusable building blocks is an attractive option for effective recycling and valorisation. This is most conveniently achieved through chemolytic processes because of the higher selectivity and lower energy inputs compared to thermochemical approaches [71]. This is a "hot" research topic, mainly due to the few industrial applications developed in the field so far, despite the urgent need for innovative technologies that overcome the high costs of recycling, the legal constraints for dumping, the accumulation of plastic scraps and the dependence on nonrenewable (fossil) sources [72,73]. A reason for this underdevelopment is that chemolysis of plastics is still challenging due to multiple critical factors: i) the achievement of selective depolymerisation is only possible by carefully controlled reaction conditions, ii) the related processes must be "green" and economically viable and, iii) tailored solutions are required to overcome the chemical inertness for, and the thermodynamic limitations of the reversal of each polymer. Indeed, the ease (and outcome) of chain scission does not depend on the origin of the polymer but on its chemical structure [74,75]. For instance, plastics derived from biomass are not necessarily biodegradable, particularly if similar to those obtained from petroleum sources [76,77]. For depolymerisation to be effective at reasonable operating temperature and selective, the plastic substrate should in principle originate from low-exergonic polymerisation reactions [78]. This justifies for the easier depolymerisation of polyesters and polycarbonates compared to polyolefins $[79,80]$. By contrast, poor selectivity and slow kinetics of depolymerisation can be circumvented using a catalyst. 


\subsection{Chemolysis}

Several catalytic depolymerisation processes of plastics have been developed, using a solvent or molecular hydrogen as cleaving agents [81]. The main solvolytic process include:

- hydrolysis (water)

- alcoholysis (methanol, ethanol, 1-butanol, 2-ethyl-1hexanol, phenol)

- glycolysis (ethylene glycol (EG), 1,2-propanediol (PD), 1,3- and 1,4-butanediol (BD)), diethylene glycol (DEG), dipropylene glycol (DPG))

- aminolysis (2-aminoethanol, 3-amino-1-propanol, ethylenediamine).

Advantages of catalytic processes are obvious and can be witnessed in the hydrolysis and the glycolysis reactions of poly(ethylene terephthalate) (PET) $[82,83]$. Representative data are reported in graphical format in Figure 2 for the glycolysis reaction of PET, using titanium(IV) $n$-butoxide as the catalyst. Compared to the uncatalysed process, benefits include milder reaction conditions, higher selectivity and productivity and reduced generation of waste; in short, improved sustainability $[84,85]$. However, solvolytic methods are usually not costcompetitive and energy-intensive [86], while they may involve the management of large amounts of noxious solvents and a variety of (decomposition) byproducts [87,88]. Depolymerisation products of course depend on the polymer, the solvent and the reaction conditions. For instance, for polyesters, alcoholysis may provide mixed monomers formally derived from transesterification reactions $[89,90]$, while aminolysis provides amides and alcohols [91,92].

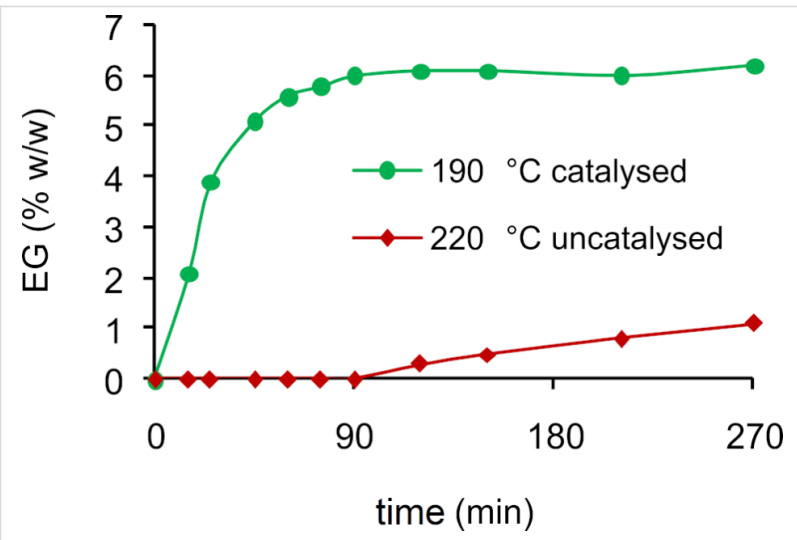

Figure 2: EG produced during glycolytic depolymerisation of PET using DEG + DPG as solvent and titanium(IV) $n$-butoxide as catalyst. Data from reference [92].

In the search of "greener" technologies for plastic recycling, catalytic hydrogenolysis processes have been developed that benefit from the use of $\mathrm{H}_{2}$ as clean reagent and that usually result in a limited number of secondary products $[93,94]$. The excess of $\mathrm{H}_{2}$ reagent can also be easily removed from the reaction mixture. The approach, referred to as hydrodeoxygenation $[95,96]$, is already in use for the valorisation of naturally-occurring polymeric waste, i.e., lignocellulosic biomass [97,98], particularly lignin $[99,100]$ and cellulose [101], to monomers or added-value platform molecules [102,103]. Here the main drawbacks concern safety hazards, supply, transport and storage costs of hydrogen. Catalytic transfer hydrogenation (CTH) methods from safer reagents have thus been developed and successfully applied to lignocellulose polymers [104,105].

\subsection{Catalysts}

Catalysts of various types, including homogeneous and heterogeneous, have been reported for the above-mentioned depolymerisation processes of plastics. Heterogeneous systems are preferred by industry due to the easier separation from the reaction mixture, reuse and integration into existing reactor equipment [106,107]. Metal-based catalysts have been used for both solvolytic and hydrogenolytic methods, wherein the latter are usually achieved by supported metal species (Ru, Ir), due to the ability to activate molecular hydrogen, functioning as redox centres. The mechanisms of the metal-catalysed solvolytic reactions of plastics are all very similar and typical of conventional organic processes: a metal ion acts as Lewis acid centre for the activation of the chain-linking group of the polymer (either an ester, carbonate, ketone or amide) toward the nucleophilic attack of the various solvents. Specific examples, broken down according to the nature of the polymer and the process, will be reported in the next sections, in which metal catalysts are described in detail. Solvolytic depolymerisations can also be promoted by metal-free soluble acid or base catalysts. However, concentrated solutions, quasistoichiometric amounts or strong mineral acids $\left(\mathrm{HNO}_{3}, \mathrm{H}_{2} \mathrm{SO}_{4}, \mathrm{H}_{3} \mathrm{PO}_{4}\right)$ or bases $(\mathrm{NaOH}, \mathrm{KOH}$, potassium butoxide) are often required, particularly for hydrolysis reactions [108,109], which may result in corrosion problems, troublesome neutralisation and purification procedures as well as a considerable generation of waste, which makes these process economically and environmentally unappealing [110,111]. These systems are not considered in the present review.

Biological catalysts for the deconstruction of plastics were extensively studied in the past years, and several hydrolytic-enzymes-containing microorganisms have been shown to be usable for this purpose [112,113]. However, enzymatic depolymerisation is hampered by high molecular weight and crystallinity, reduced chain mobility and hydrophobicity of polymers $[114,115]$, which makes biodegradation often ineffective and time-consuming, particularly for polyolefins, such as polyethylene, polyvinyl chloride (PVC), polystyrene or PET 
[116,117]. Thus, abiotic pretreatments may be required, including UV irradiation [118], oxidation [119] or acidic degradation [120].

It is worth mentioning that organocatalytic depolymerisation methods have also been reported [121,122]. Despite these systems represent promising "greener" options, they still are in an early development stage. Uses are mainly limited to nitrogen-based catalysts, ionic liquids $[123,124]$ and alcoholysis of oxygen-containing polymers, such as polyesters, polycarbonates and polyamides, i.e., glycolysis of PET, wherein high temperatures and nearly stoichiometric amounts of catalysts are often required to achieve moderate yields of monomers $[125,126]$.

\section{Selective depolymerisation of plastics via metal catalysis}

Research in depolymerisation of plastics by artificial metal catalysts is relatively recent as most of the earliest studies are related to biocatalytic systems. Metal salts are the conventional catalysts for these processes, wherein acetates, phosphates and chlorides of heavy metals ( $\mathrm{Ti}, \mathrm{Zn}, \mathrm{Mg}, \mathrm{Co}, \mathrm{Fe}$ ) or lead oxide are commonly used in the alcoholysis and glycolysis of polyesters $[127,128]$. Despite that these systems ensure high conversions and selectivity, shortcomings relate to the harsh reaction conditions, slow kinetics, cost of metals, toxicity, difficulty in catalyst reusing and need of downstream processing. Significant efforts have thus been made to develop greener and sustainable catalytic systems featuring high efficiency under mild conditions. The use of sodium carbonate or bicarbonate as ecofriendly catalyst replacements for zinc acetate in the glycolysis of PET are examples of this direction [129,130]. Recent studies focused on molecular complexes as homogeneous catalysts, whereas heterogeneous systems based on solid-supported metal nanoparticles (NPs) have been scarcely investigated.

\subsection{Polyolefins}

Due to the intrinsic chemical resistance of the hydrocarbon skeleton devoid of functional groups, polyolefins are neither prone to chemical recycling nor biodegradable [131,132] Hence, they are more commonly repurposed via mechanical recycling, burned or just discarded [133,134]. Depolymerisation of polyolefins usually requires thermal treatments at high temperature $[54,135]$.

3.1.1 Polyethylene (PE): PE is the most used thermoplastic material today, having a variety of uses in several fields. Applications of PE depend on the mechanical and physical properties (particularly the tensile strength, hardness and melting point $T_{\mathrm{m}}$ ), which are, in turn, ruled by the molecular weight and degree of branching [136,137]. Various types of PE exist, which are classified according to the density, the most common being high-density polyethylene (HDPE) and low-density polyethylene (LDPE). HDPE $\left(0.94-0.97 \mathrm{~g} \cdot \mathrm{cm}^{-3}, T_{\mathrm{m}} 130{ }^{\circ} \mathrm{C}\right)$ is a highly crystalline material with a low degree of short chain branching. Owing to the high stiffness, tensile strength, resistance to moisture and gas permeability, it is mainly used in the manufacture of water pipes, toys, beverage bottles, outdoor furniture, housewares and electrical cables $[138,139]$. LDPE $\left(0.91-0.94 \mathrm{~g} \cdot \mathrm{cm}^{-3}, T_{\mathrm{m}} 120^{\circ} \mathrm{C}\right)$ is a poorly crystalline material having a high degree of short chain and long chain branching. It is featured by a good flexibility, transparency and high impact strength, which make it suitable for short-term applications, such as films, food packaging, squeezable bottles, plastic bags and medical devices [140]. PEs (except cross-linked samples) are partially soluble in (hot) aromatic hydrocarbons or in chlorinated solvents [141].

Depolymerisation of PE by catalytic pyrolysis or cracking into liquid fuels was recently reviewed [67,142]. Most of these processes are promoted by heterogeneous acid catalysts (e.g., zeolites, alumina, silica) and are usually unselective, resulting in a broad distribution of gas $\left(\mathrm{C}_{3}\right.$ and $\mathrm{C}_{4}$ hydrocarbons), liquids (cycloparaffins, oligomers, aromatics) and solid products (char, coke) as a consequence of the random scission of $\mathrm{C}-\mathrm{C}$ bonds into radicals, which leads to a complex mixture of olefinic and cross-linked compounds [143].

In a few cases, good selectivity to a liquid fraction was achieved. For instance, nanostructured $\mathrm{BaTiO}_{3}$ doped with $\mathrm{Pb}$ provided a mixture of liquid products, which includes alkanes $(73.4 \%)$, olefins $(22.5 \%)$ and naphthalene $(4.1 \%)$ at total HDPE conversion at $350{ }^{\circ} \mathrm{C}$ [144]. In another example, hydrocracking of PE was performed over Pt NPs supported on $\mathrm{SrTiO}_{3}$ perovskite nanocuboids [145]. Virgin $\mathrm{PE}\left(M_{\mathrm{w}}=\right.$ 18000-420000 $\mathrm{g} \cdot \mathrm{mol}^{-1}$ ) or PE from single-use plastic bags $\left(M_{\mathrm{w}}=115000 \mathrm{~g} \cdot \mathrm{mol}^{-1}\right)$ was converted in $>97 \%$ yield into liquid hydrocarbon (alkane) products having a narrow distribution of the molecular weight (960-1130 $\mathrm{g} \cdot \mathrm{mol}^{-1}$ ) under $11.7 \mathrm{bar}$ $\mathrm{H}_{2}$ at $300{ }^{\circ} \mathrm{C}$ and solvent-free conditions [146]. The pyrolysis oils produced may be used as lubricants, waxes or further processed into detergents and cosmetics [147]. The catalyst could be recycled, however, with reduced performance due to Pt nanoparticle oxidation.

3.1.2 Polybutadiene (PBD): Partial depolymerisation of 1,4PBD (cis, trans, $M_{\mathrm{w}} 1800-500000 \mathrm{~g} \cdot \mathrm{mol}^{-1}$ ) was achieved by an unconventional tandem ring-opening-ring-closing metathesis route mediated by commercially available $\mathrm{Ru}$ homogeneous catalysts [148]. The process afforded $\mathrm{C}_{16}$ to $\mathrm{C}_{44}$ mixtures of macrocyclic oligobutadienes with up to $98 \%$ selectivity at moderate conversions (59-88\%) using first-generation Ru com- 
plexes bearing a tricyclohexylphosphine $\left(\mathrm{PCy}_{3}\right)$ ligand, mild reaction temperature $\left(35{ }^{\circ} \mathrm{C}\right)$ but toxic $\mathrm{CH}_{2} \mathrm{Cl}_{2}$ solvent (Scheme 1). The reaction using second-generation N-heterocyclic carbene ligands was faster and preferably yielded cyclododecatriene. Larger cyclic butadienes may be used in the production of flame retardants, lubricants and specialty polymers $[149,150]$.

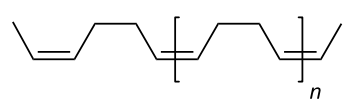

Ru cat.

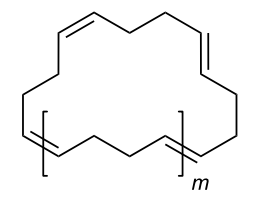

$\mathrm{L}^{1}=\mathrm{L}^{2}=\mathrm{PCy}_{3}, \mathrm{R}=\mathrm{CHPh}$

$\mathrm{L}^{1}=\mathrm{L}^{2}=\mathrm{PCy}_{3}, \mathrm{R}=$ indole

$\mathrm{L}^{1}=\mathrm{PCy}_{3}, \mathrm{~L}^{2}=\mathrm{R}=\mathrm{iPrOPh}$

Scheme 1: Simplified representation of the conversion of 1,4-PBD to $\mathrm{C}_{16}-\mathrm{C}_{44}$ macrocycles using Ru metathesis catalysts.

3.1.3 Polystyrene (PS): PS is a low-cost, hard and brittle plastic used both as a solid or foam in protective packaging, containers and trays [151]. It is a nonbiodegradable material accounting for about $10 \%$ of municipal solid waste [135]. It is soluble in benzene, carbon disulfide, chlorinated hydrocarbons, lower ethers and $\mathrm{N}$-methyl-2-pyrrolidone (NMP) and has a melting point around $240{ }^{\circ} \mathrm{C}$ [152]. Most methods for PS recycling are not economically advantageous [153]. Mechanical recycling, based on pelletizing and moulding, produces lowgrade plastics with poor mechanical strength and low market value. Solid PS products, such as coffee cups or take-away containers, can be recycled into videocassette cases or office equipment. Incineration at a temperature below $1000{ }^{\circ} \mathrm{C}$ and insufficient air is believed to produce a mixture of volatile compounds, including hazardous polycyclic aromatic hydrocarbons, alkylbenzenes and benzoperylene [154,155]. As for other polymers, pyrolytic methods end up to be poorly selective.

In some cases, metal-catalysed depolymerisation processes of PS were described, showing significant selectivity. In an earlier example, thermal treatment of PS waste over a Fe-K@ $\mathrm{Al}_{2} \mathrm{O}_{3}$ catalyst at $400{ }^{\circ} \mathrm{C}$ provided a hydrocarbon oil in $92 \%$ yield, $71.4 \%$ of which were attributable to styrene monomer [156]. A decrease of $56 \mathrm{~kJ} \mathrm{~mol}^{-1}$ for the activation energy of PS depolymerisation was calculated in the presence of the catalysts. More recently, high-porosity montmorillonite (Mt) was used to prepare $\mathrm{Mg}-, \mathrm{Zn}-, \mathrm{Al}-, \mathrm{Cu}$ - or Fe-decorated heterogeneous catalysts [157,158]. An oil yield around $89 \%$ was obtained at $450{ }^{\circ} \mathrm{C}$ over $20 \% \mathrm{Fe} @ \mathrm{Mt}$, composed by 51\%, 10\% and 6\% (wt) styrene, toluene and ethylbenzene, respectively, and additional oligomers.

\subsection{Polyesters}

3.2.1 PET: PET is one of the most widely used thermoplastic polyesters, particularly in the textile and food packaging industry (e.g., soft-drink and water bottles, food container, films) due to the excellent thermal and mechanical properties, durability, inertness and transparency. The global production of PET exceeds 50 million tons pear year, while PET accounts for around $8 \%$ by weight and $12 \%$ by volume of the world's solid waste $[159,160]$. PET is a copolymer of terephthalic acid (TPA) and EG [161]. It is best soluble in chlorophenol, tetrachloroethane, $m$-cresol, NMP, nitrobenzene and 1,1,1,3,3,3hexafluoro-2-propanol, insoluble in common alcohols and water and has a melting point of $250{ }^{\circ} \mathrm{C}$ and a glass transition temperature $T_{\mathrm{g}}$ of $76^{\circ} \mathrm{C}[162,163]$. It was suggested that under certain circumstances, PET may leach phthalates [164], which are known for potentially adverse health effects and subject to ECHA regulation restrictions $[165,166]$. Coupled with the fact that TPA is produced from petrochemical sources, bioderived 2,5-furandicarboxylic acid has been proposed as TPA replacement in the production of plastic bottles, representing one of the rare examples of industrial manufacture of biobased polymers $[167,168]$.

From the chemical recycling point of view, PET is one of the most studied plastics, so as to represent a case study in the field $[169,170]$. A variety of added-value, reusable chemicals and monomers can be recovered from PET via chemolytic depolymerisation, including 1,4-benzenedimethanol (BDM), TPA, dimethylterephthalate (DMT), bis(2-hydroxyethyl)terephthalate (BHET), terephthalamides (TPM [171]) and EG (Figure 3). Cat-

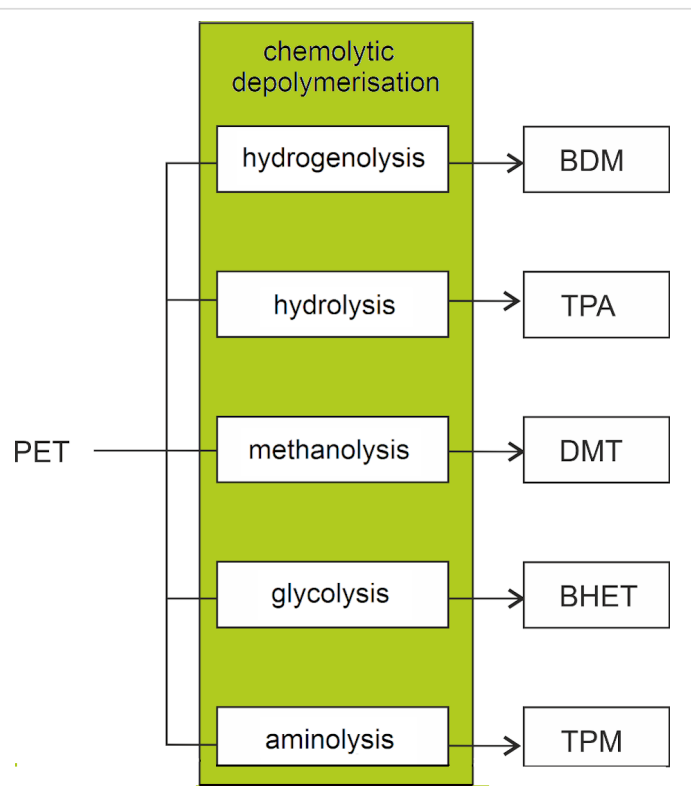

Figure 3: Main added-value monomers obtainable by catalytic depolymerisation of PET via chemolytic methods. 
alytic hydrogenolysis, hydrolysis, methanolysis and glycolysis reactions of (postconsumer) PET have been reviewed, each showing their own advantages and disadvantages $[172,173]$. For instance, glycolysis usually requires more problematic purifications than methanolysis, which, on the other hand, is generally more energy-intensive. Some solvolytic processes of PET are already in operation at the industrial or pilot scale [174,175] However, they often rely on the use of considerable amounts of strong alkali bases and chlorinated solvents [176,177], which makes them neither economically competitive nor environmentally friendly $[178,179]$. A survey of patents related to the chemical recycling of PET up to 2005 can be found in the literature [180].

Hydrogenolysis. In the recent years, hydrogenolysis reactions of PET were developed mostly using $\mathrm{Ru}$ metal-based catalysts, due to their higher affinity for $\mathrm{C}=\mathrm{O}$ bond (ester) hydrogenation compared to other metals (Scheme 2) [181,182]. Thus, a 73\% $\mathrm{BDM}$ yield was obtained using a soluble Ru(II)-PNN complex at $110^{\circ} \mathrm{C}$ in THF/anisole solvent, 50 bar of hydrogen and a 20:1 excess of strong base potassium tert-butoxide as cocatalyst (Table 1, entry 1) [183]. Although the reaction mechanism was not investigated in detail, it was suggested that cleavage of the ester linkage may occur in a concerted manner through the reported heterolytic route $[184,185]$. The role of butoxide was postulated to be the activation of the heterogeneous splitting of dihydrogen. BDM is an important building block for the production of resins and polyesters other than PET [186,187]. Analogously, a similar Milstein-type ruthenium-PNN complex, generated in situ by treatment of the chloride catalyst precursor with potassium butoxide in a 2:1 molar ratio, resulted in a nearly quantitative yield of BDM and EG at a slightly higher reaction temperature $\left(160{ }^{\circ} \mathrm{C}, 54\right.$ bar $\mathrm{H}_{2}$, Table 1 , entry 2$)$. Interestingly, PET flakes from postconsumer bottles could be used, showing the catalytic system to be resistant to the presence of contaminants and impurities (e.g., additives, pigments) [188]. More recently, effective PET depolymerisation was accomplished by a ruthenium molecular catalysts bearing the well-known tripodal phosphorous ligand 1,1,1-tri(diphenylphosphinomethyl)ethane (triphos) [189,190]. Thus, use of $\mathrm{Ru}($ triphos $) \mathrm{tmm}(\mathrm{tmm}=$ trimethylenemethane $)$ and acidic bis(trifluoromethane)sulfonimide $\left(\mathrm{HNTf}_{2}\right)$ cocatalyst $(1: 1)$ in noxious 1,4-dioxane solvent resulted in $41 \%$ PET conversion and $64 \%$ BDM selectivity at $140{ }^{\circ} \mathrm{C}$ and 100 bar $\mathrm{H}_{2}$ due to the formation of ether byproducts (Table 1, entry 3) [191]. No hypotheses for the reaction mechanism were formulated. Higher conversion (64\%) and selectivity (99\%) were observed using the bulkier xylyl derivative Ru(triphos-xyl)tmm (Table 1, entry 4), which was attributed to reduced catalyst degradation [192]. The catalyst could be employed for the depolymerisation of PET flakes from various sources (water bottles, dyed soda bottles, pillow filling, yoghurt pots). However, the role of HNTf $_{2}$ was unclear.

In a different approach, hydrogenolysis-like depolymerisation was achieved through a hydrosilylation strategy, using the pincer $\operatorname{Ir}(\mathrm{III})$ complex $[\operatorname{Ir}(\mathrm{POCOP}) \mathrm{H}(\mathrm{THF})]\left[\mathrm{B}\left(\mathrm{C}_{6} \mathrm{~F}_{5}\right)_{4}\right]$ (POCOP $\left.=1,3-\left(t-\mathrm{Bu}_{2} \mathrm{PO}\right)_{2} \mathrm{C}_{6} \mathrm{H}_{3}\right)$ as catalyst and an excess of $\mathrm{Et}_{3} \mathrm{SiH}$ as reagent (chlorobenzene solvent, $70^{\circ} \mathrm{C}$ ) [193]. BDM could be obtained in an overall 58\% yield from PET from fibres or bottles, after hydrolysis of the intermediate silyl ether using $\mathrm{Bu}_{4} \mathrm{NF} \cdot 3 \mathrm{H}_{2} \mathrm{O}$ in THF (Scheme 3).

Hydrolysis. Methods for the metal-catalysed hydrolysis of PET were developed, allowing for the recovery of costly TPA monomer (Scheme 4, top). TPA was obtained in $97.1 \%$ yield at full PET conversion, using $70 \mathrm{wt} \%$ aqueous $\mathrm{ZnCl}_{2}$ as catalyst at $180{ }^{\circ} \mathrm{C}$ and no organic solvent [194]. However, a high $\mathrm{ZnCl}_{2} /$ PET weight ratio of 35 was required. The catalyst could be reused, showing significant activity decrease starting from the fourth cycle due to biochar formation. A mechanism was hypothesised in which $\mathrm{Zn}^{2+}$ ions act as a Lewis acid activator for the carbonyl ester bond. In a previous work, complete depolymerisation of PET was achieved using zinc acetate as catalyst in hot compressed water [195]. A TPA yield of $90.5 \%$ was obtained at $240{ }^{\circ} \mathrm{C}$ after 30 min reaction time, using a $\mathrm{ZnAc}_{2} / \mathrm{PET}$ weight ratio as low as 0.015 . For this, a mechanism was speculated in which proton ions act as activators.

Methanolysis. To the best of our knowledge, only one example of a depolymerisation reaction of PET through alcoholysis was recently reported, which is however devoid of any catalysts [196]. Therein, a 97.3\% yield of DMT was obtained at full PET conversion, by treatment of PET with methanol at $200{ }^{\circ} \mathrm{C}$ for<smiles>CCCOC(=O)c1ccc(C(=O)OC)cc1</smiles>

PET

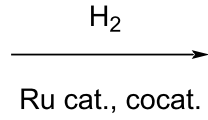

Ru cat., cocat.

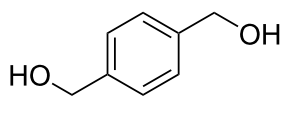

BDM<smiles>OCCO</smiles>

EG 
Table 1: Hydrogenolysis of PET by soluble Ru molecular catalysts

\begin{tabular}{|c|c|c|c|c|c|c|c|c|c|}
\hline \multirow[t]{2}{*}{ entry } & \multirow[t]{2}{*}{ catalyst } & \multirow[t]{2}{*}{ cocatalyst $^{a}$} & \multicolumn{3}{|c|}{ reaction conditions ${ }^{b}$} & \multirow{2}{*}{$\begin{array}{c}\text { conv. } \\
(\%)\end{array}$} & \multicolumn{2}{|r|}{ BDM } & \multirow[t]{2}{*}{ ref. } \\
\hline & & & $\begin{array}{c}T \\
\left({ }^{\circ} \mathrm{C}\right)\end{array}$ & $\begin{array}{c}\mathrm{H}_{2} \\
\text { (bar) }\end{array}$ & solvent & & $\begin{array}{c}\text { sel. }^{d} \\
(\%)\end{array}$ & $\begin{array}{c}\text { TOFe }^{\mathrm{e}} \\
\left.\text { (mol }_{\mathrm{BDM}} \cdot \mathrm{mol}_{\text {cat. }}{ }^{-1} \cdot \mathrm{h}^{-1}\right)\end{array}$ & \\
\hline 1 & & $\mathrm{~K} t-\mathrm{BuO}^{\mathrm{f}}$ & 110 & 50 & anisole/THF & 73 & 100 & 0.76 & [183] \\
\hline 2 & & $\mathrm{~K} t-\mathrm{BuO}$ & 160 & 54 & anisole/THF & 99 & 100 & 1.03 & [188] \\
\hline 3 & & HNTfh $^{h}$ & 140 & 100 & 1,4-dioxane & 42 & 64 & 1.68 & [191] \\
\hline 4 & & HNTfh & 140 & 100 & 1,4-dioxane & 64 & 99 & 3.96 & [191] \\
\hline
\end{tabular}

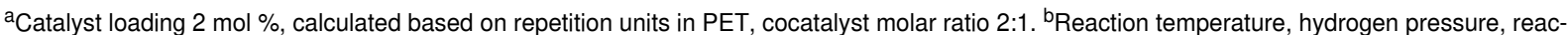

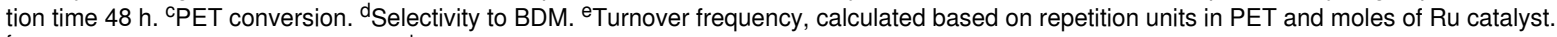
${ }^{f}$ Cocatalyst molar ratio 20:1. ${ }^{\mathrm{g}} 1: 1 \mathrm{v} / \mathrm{v}$. hCatalyst loading $1 \mathrm{~mol} \%$. Reaction time $16 \mathrm{~h}$.<smiles>CCOCCOCCOCCOCc1ccc(CO[Si]CC)cc1</smiles>

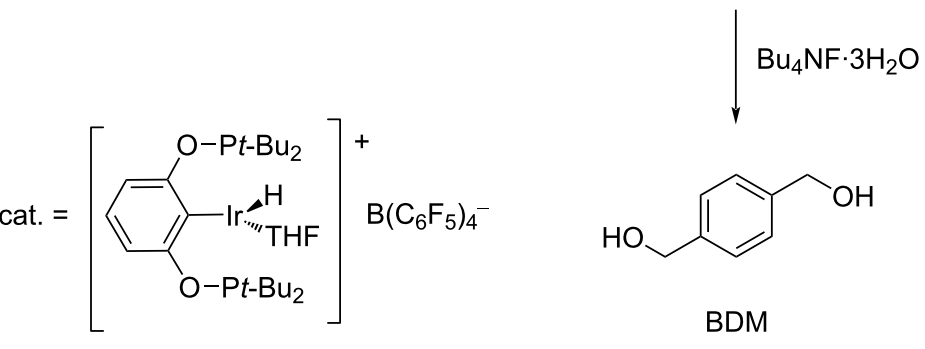

Scheme 3: Depolymerisation of PET via catalytic hydrosilylation by $\operatorname{Ir}(\mathrm{III})$ pincer complex. 


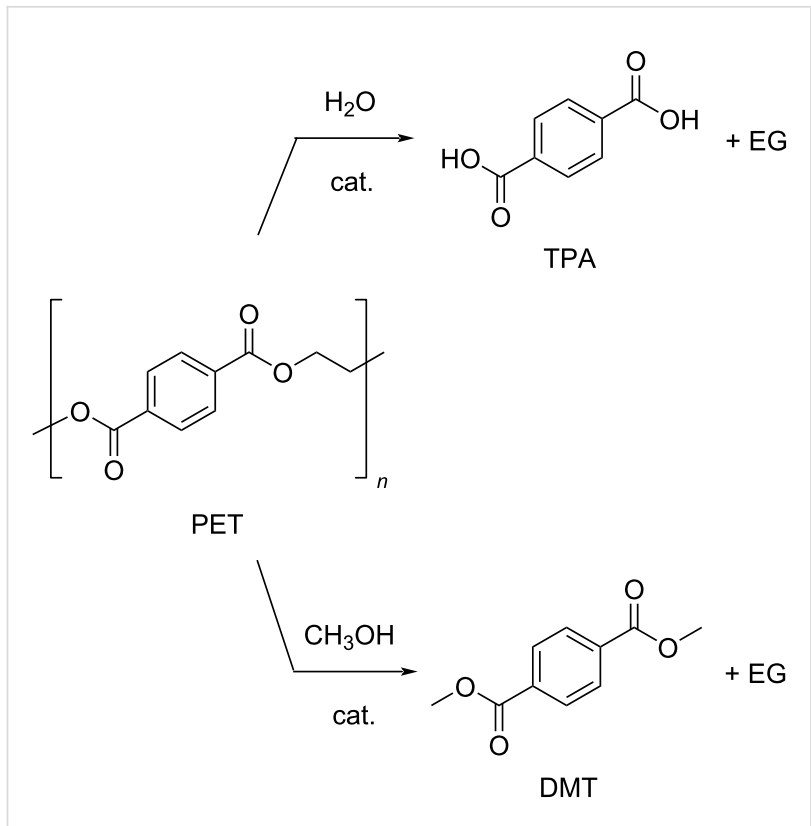

Scheme 4: Catalytic hydrolysis (top) and methanolysis (bottom) reactions of PET.

$3.5 \mathrm{~h}$ (Scheme 4, bottom). No details of byproducts were provided. Ethanol and butanol were much less reactive under identical reaction conditions. The as-prepared DMT could be used for the production of hydrocarbon jet fuels by catalytic hydrogenation. Metal-catalysed methanolysis of PET was described in previous years $[109,197]$.

Glycolysis. Glycolysis is a convenient process for PET chemical recycling, owing to the low cost, relatively mild reaction conditions and the potential for the production of useful monomers and oligomers. These compounds can be used in the synthesis of recycled polyesters, polyurethanes, polyisocyanurates and resins [43]. Among the various glycols, EG is the most popular, resulting in the formation of BHET, formally through a (reversible) transesterification reaction (Scheme 5) [198]. Drawbacks of this method are the difficulty of purification of BHET, the need of an excess of EG and the possible product contamination by homogeneous catalysts [199]. The conventional catalysts for this reaction are EG-soluble metal acetates, the activity of which showed a decrease in the order $\mathrm{Zn}^{2+}>$ $\mathrm{Mn}^{2+}>\mathrm{Co}^{2+}$, which was attributed to the diverse interaction between the metal cation promoter and the carbonyl group of polyester [200]. Indeed, several studies showed Zn-based catalysts to provide the best performances. A summary of recent findings and reaction conditions is reported in Table 2. In an earlier study, a 85.6\% BHET yield was obtained at $196{ }^{\circ} \mathrm{C}$, using an EG/PET ratio of 5:1 (w/w) and $1 \mathrm{wt} \% \mathrm{Zn}(\mathrm{OAc})_{2}$ loading (Table 2, entry 1) [201]. The system resulted in partial selectivity to BHET due to the formation of significant amounts of oligomers, mainly BHET dimers, which increased upon standing. The kinetic of the zinc acetate-promoted process was studied over a range of reaction conditions, showing the best combination to be $196{ }^{\circ} \mathrm{C}$, an EG/PET ratio of 2.45:1 (w/w) and a catalyst loading of $0.3 \mathrm{wt} \%$ (Table 2, entry 2) [129]. Under these conditions, an equilibrium yield of BHET around $65 \%$ was achieved within short reaction times $(1 \mathrm{~h})$, much faster than in the absence of catalysts or using alkali salt promoters $\left(\mathrm{Na}_{2} \mathrm{CO}_{3}, \mathrm{NaHCO}_{3}, \mathrm{Na}_{2} \mathrm{SO}_{4}\right.$ or $\mathrm{K}_{2} \mathrm{SO}_{4}$, Figure 4). PET wastes, including highly coloured and multilayered PET, could be used as substrate. More recently, it was demonstrated that the addition of a cosolvent for PET, such as dimethyl sulfoxide (DMSO), NMP, nitrobenzene or aniline to the conventional PET-insoluble EG system, greatly enhanced the depolymerisation kinetics, resulting in improved conversions (the solubility of PET at $T>130{ }^{\circ} \mathrm{C}$ was aniline $>$ NMP $>$ nitrobenzene $>$ DMSO) [202]. For instance, the use of a DMSO/EG 2:1, w/w solvent mixture resulted in an increase of PET conversion from $43.0 \%$ to $83.9 \%$ compared to pure EG $\left(190{ }^{\circ} \mathrm{C}, 5 \mathrm{wt} \%\right.$ catalyst loading, 5 min reaction time, Table 2, entry 4 vs entry 3). Using the same reaction conditions and solvent mixture, $\mathrm{Mn}, \mathrm{Co}, \mathrm{Cu}$ and $\mathrm{Ni}$ acetate catalysts were less active than $\mathrm{Zn}$ (Table 2, entries 5 and 6). In a further study, glycolysis of PET was performed under microwave heating in the presence of $\mathrm{Zn}(\mathrm{OAc})_{2}$, yielding BHET with an $80 \%$ selectivity at $97 \%$ conversion due to formation of dimers (Table 2, entry 7) [203,204]. Soluble metal chlorides (zinc, magnesium, iron, zirconium, cobalt, nickel) were also explored as catalysts in the glycolytic depolymerisation of PET [128,205]. The highest BHET yield (74.7\%) was achieved using zinc chloride $(0.5 \% \mathrm{w} / \mathrm{w})$, an EG/PET ratio of 14:1 and reflux conditions (Table 2, entry 8 ). The use of<smiles>CCCOC(=O)c1ccc(C(=O)OCC)cc1</smiles>

PET

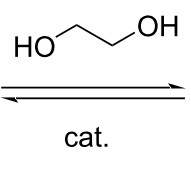

$\mathrm{HO}$<smiles>O=C(OCCO)c1ccc(C(=O)OCCO)cc1</smiles>

BHET 


\begin{tabular}{|c|c|c|c|c|c|c|c|c|}
\hline \multirow[t]{2}{*}{ entry } & \multirow[t]{2}{*}{ material } & \multirow[t]{2}{*}{ catalyst } & \multirow{2}{*}{$\begin{array}{c}\mathrm{EG} / \mathrm{PET}^{\mathrm{a}} \\
(\mathrm{w} / \mathrm{w})\end{array}$} & \multirow{2}{*}{$\begin{array}{l}T^{b} \\
\left({ }^{\circ} \mathrm{C}\right)\end{array}$} & \multirow{2}{*}{$\begin{array}{c}\text { conv. }^{c} \\
(\%)\end{array}$} & \multicolumn{2}{|r|}{ BHET } & \multirow[t]{2}{*}{ reference } \\
\hline & & & & & & $\begin{array}{l}\text { sel. }^{d} \\
(\%)\end{array}$ & $\begin{array}{c}\text { TOF }^{\mathrm{e}} \\
\left(\mathrm{mol}_{\mathrm{BHET}} \cdot \mathrm{mol}_{\left.\text {cat. }^{-1} \cdot \mathrm{h}^{-1}\right)}\right.\end{array}$ & \\
\hline 1 & $\begin{array}{l}\text { PET bottle } \\
\text { chips }\end{array}$ & $\mathrm{Zn}(\mathrm{OAc})_{2}$ & $5: 1$ & 196 & n.a. ${ }^{\dagger}$ & $85.6^{\mathrm{g}}$ & 27.0 & [201] \\
\hline 2 & PET waste & $\mathrm{Zn}(\mathrm{OAc})_{2}$ & $2.45: 1$ & 196 & 65 & 100 & 207.1 & [129] \\
\hline 3 & PET pellets & $\mathrm{Zn}(\mathrm{OAc})_{2}$ & $6: 1$ & 190 & 43.0 & 100 & 118.4 & [202] \\
\hline 4 & PET pellets & $\mathrm{Zn}(\mathrm{OAc})_{2}$ & $2: 1^{h}$ & 190 & 83.9 & 100 & 230.9 & [202] \\
\hline 5 & PET pellets & $\mathrm{Mn}(\mathrm{OAc})_{2}$ & $2: 1^{h}$ & 190 & 80.8 & 100 & 222.0 & [202] \\
\hline 6 & PET pellets & $\mathrm{Co}(\mathrm{OAc})_{2}$ & $2: 1^{h}$ & 190 & 78.7 & 100 & 216.3 & [202] \\
\hline 7 & $\begin{array}{l}\text { PET bottle } \\
\text { flakes }\end{array}$ & $\mathrm{Zn}(\mathrm{OAc})_{2}$ & $5: 1$ & $196^{i}$ & 97.1 & 80.3 & 73.7 & [203] \\
\hline 8 & PET & $\mathrm{ZnCl}_{2}$ & $14: 1$ & 196 & n.a. ${ }^{f}$ & $74.4^{\mathrm{g}}$ & n.a. ${ }^{f}$ & [128] \\
\hline 9 & PET pellets & Zn POMj & $4: 1$ & 185 & 100 & 84.1 & 1292.3 & [210] \\
\hline
\end{tabular}

${ }^{a} \mathrm{EEG}$ as solvent. ${ }^{\mathrm{b}}$ Reaction temperature. ${ }^{\mathrm{C}} \mathrm{PET}$ conversion. dSelectivity to BHET. ${ }^{\mathrm{e}}$ Turnover frequency calculated based on PET repetition units and moles of metal catalyst. ${ }^{\mathrm{f}} \mathrm{Not}$ available. ${ }^{\mathrm{B} B H E T}$ yield (\%). ${ }^{\mathrm{h}}$ Solvent DMSO/EG 2:1, w/w. ${ }^{i}$ Microwave irradiation $500 \mathrm{~W}$. ${ }^{\mathrm{i} Z n}$ polyoxometalate formula $\mathrm{K}_{6} \mathrm{SiW}_{11} \mathrm{ZnO}_{39}\left(\mathrm{H}_{2} \mathrm{O}\right)$.

preformed soluble Co(II) complexes bearing bidentate phosphorus ligands (e.g., 1,2-bis(dicyclophosphino)ethane) showed minimal improvements compared to the chloride salt catalyst [205]. The use of transition metal-substituted polyoxometallates (POMs), of the general formula $\mathrm{K}_{6} \mathrm{SiW}_{11} \mathrm{MO}_{39}\left(\mathrm{H}_{2} \mathrm{O}\right)$ $\left(\mathrm{M}=\mathrm{Zn}^{2+}, \mathrm{Mn}^{2+}, \mathrm{Co}^{2+}, \mathrm{Cu}^{2+}, \mathrm{Ni}^{2+}\right)[206,207]$, was also investigated [208]. The catalytic activity was found to decrease in the order $\mathrm{Zn}>\mathrm{Mn}>\mathrm{Co}>\mathrm{Cu}>\mathrm{Ni}$, consistent with previous reports [209]. The best catalyst afforded BHET in $84.1 \%$ yield (Table 2, entry 9), which was rather constant over eight catalyst reuses [210]. A stepwise depolymerisation mechanism was proposed, via intermediate oligomers, in which $\mathrm{Zn}$ ions act as Lewis acid activators for the $\mathrm{C}=\mathrm{O}$ ester bonds toward nucleophilic attack by EG.

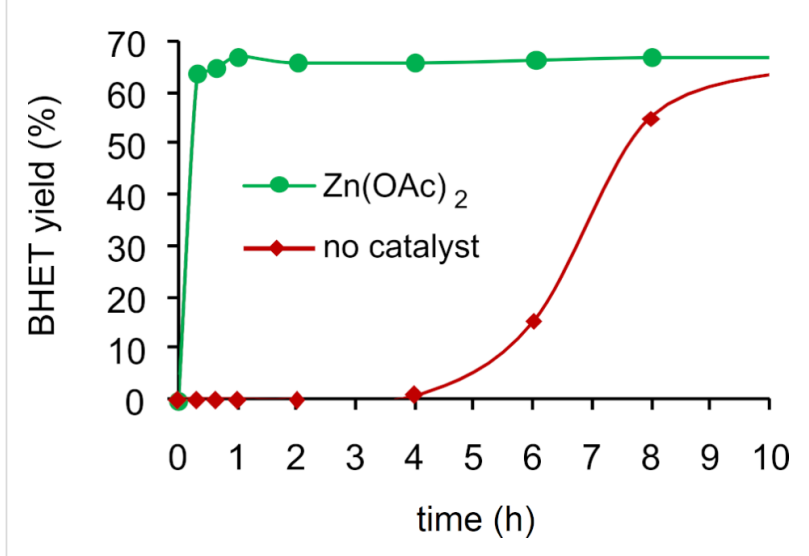

Figure 4: Glycolysis of PET: evolution of BHET yield over time, with and without zinc acetate catalyst $\left(196^{\circ} \mathrm{C}, \mathrm{EG} / \mathrm{PET}\right.$ ratio $2.45(\mathrm{w} / \mathrm{w})$. Data from reference [129].
In addition to soluble catalysts, metal-containing insoluble materials, namely solid acid catalysts, were developed for the glycolytic depolymerisation of PET by EG. Representative data are summarised in Table 3, wherein the catalyst productivity is reported for comparison as $\mathrm{mol}_{\mathrm{BHET}} \cdot \mathrm{g}_{\text {cat. }}{ }^{-1} \cdot \mathrm{h}^{-1}$. Despite that both catalyst and PET were insoluble in EG at the reaction temperature, most systems displayed substantial activity. Thus, sulfated titania, zinc oxide and mixed oxides $\left(\mathrm{SO}_{4}{ }^{2-} / \mathrm{TiO}_{2}\right.$, $\mathrm{SO}_{4}{ }^{2-} / \mathrm{ZnO}$ and $\mathrm{SO}_{4}{ }^{2-} / \mathrm{ZnO}-\mathrm{TiO}_{2}$ ) were prepared, showing the amount of Lewis acid sites and the high surface area of the solid material to be critical in affecting the catalytic efficiency [211]. Best results were obtained for the binary oxide $\mathrm{SO}_{4}{ }^{2-}$ / $\mathrm{ZnO}-\mathrm{TiO}_{2}$ calcined at $200-300{ }^{\circ} \mathrm{C}$ (surface area $192 \mathrm{~m}^{2} \cdot \mathrm{g}^{-1}$, density of acidic sites $4.34 \mathrm{mmol} \cdot \mathrm{g}^{-1}$ ), which provided BHET in $73 \%$ selectivity at full PET conversion at $180{ }^{\circ} \mathrm{C}$ reaction temperature and a moderate excess of EG $(5.5: 1, \mathrm{w} / \mathrm{w}$, Table 3 , entry 1). The formation of a significant amount of oligomers was detected. The catalyst could be recovered by centrifugation and reused over four cycles with no efficiency decay. Similar effects were reported for $\mathrm{Zn}$-substituted titanate nanotube (TiNT) catalysts [212,213]. Therein, a positive role of $\mathrm{Zn}^{2+}$ Lewis acid sites was demonstrated by the higher efficiency compared to the $\mathrm{Na}^{+}$catalyst counterpart (Table 3, entry 2 vs entry 3), whilst a high surface area around $150 \mathrm{~m}^{2} \cdot \mathrm{g}^{-1}$ was proposed to increase the number of exposed sites [214]. Zn@TiNT afforded BHET in $87 \%$ yield at $196{ }^{\circ} \mathrm{C}$ reaction temperature. TiNT have received significant general interest in heterogeneous catalysis because of the better active-site-accessibility compared to 2D materials, thanks to a typical 8-16 nm outer diameter tubular morphology $[215,216]$ and the potential for facile metal doping via ion-exchange of the solid support 


\begin{tabular}{|c|c|c|c|c|c|c|c|c|}
\hline \multirow[t]{2}{*}{ entry } & \multirow[t]{2}{*}{ material } & \multirow[t]{2}{*}{ catalyst } & \multirow{2}{*}{$\begin{array}{c}\text { EG/PET } \\
(w / w)\end{array}$} & \multirow{2}{*}{$\begin{array}{c}T^{\mathrm{a}} \\
\left({ }^{\circ} \mathrm{C}\right)\end{array}$} & \multirow{2}{*}{$\begin{array}{c}\text { conv. }^{\mathrm{b}} \\
(\%)\end{array}$} & \multicolumn{2}{|r|}{ BHET } & \multirow[t]{2}{*}{ reference } \\
\hline & & & & & & $\begin{array}{l}\text { sel. }^{c} \\
(\%)\end{array}$ & $\begin{array}{c}\text { productivity }^{\mathrm{d}} \\
\left.\text { (mol }_{\text {BHET }} \mathrm{g}_{\text {cat. }^{-1}} \cdot \mathrm{h}^{-1}\right)\end{array}$ & \\
\hline 1 & PET pellets & $\mathrm{SO}_{4}{ }^{2-} / \mathrm{ZnO}-\mathrm{TiO}_{2}$ & $5.5: 1$ & 180 & 100 & 73.0 & 0.42 & [211] \\
\hline 2 & PET bottle grains & Zn@TiNT & $4: 1$ & 196 & 99 & 87.0 & 0.45 & [214] \\
\hline 3 & PET bottle grains & Na@TiNT & $4: 1$ & 196 & 99 & 80.1 & 0.42 & [214] \\
\hline 4 & PET & $\mathrm{Y}-\mathrm{Fe}_{2} \mathrm{O}_{3} \mathrm{NPs}$ & $3.7: 1$ & 300 & 100 & 90 & 0.09 & [219] \\
\hline 5 & PET granules & $\mathrm{GO}-\mathrm{Mn}_{3} \mathrm{O}_{4}$ & $3.7: 1$ & 300 & 100 & 96.4 & 0.38 & [220] \\
\hline 6 & PET bottles & $\mathrm{ZnMn}_{2} \mathrm{O}_{4}$ & 5.5 & 260 & 100 & 92.2 & 0.48 & [222] \\
\hline 7 & PET pellets & $(\mathrm{Mg}-\mathrm{Zn})-\mathrm{Al} \mathrm{LDH}$ & $10: 1$ & 196 & 100 & 75.0 & 0.13 & [223] \\
\hline
\end{tabular}

${ }^{a}$ Reaction temperature. ${ }^{b}$ PET conversion. ${ }^{c}$ Selectivity to BHET. ${ }^{d}$ Catalyst productivity calculated based on PET repetition units, moles of BHET and grams of solid catalyst.

[217,218]. Lewis acid-type catalytic activity was also postulated for $\gamma-\mathrm{Fe}_{2} \mathrm{O}_{3} \mathrm{NPs}$, which provided BHET in $90 \%$ yield at $300{ }^{\circ} \mathrm{C}$ (Table 3, entry 4) [219]. Therein, thanks to the superparamagnetic properties, easy recovery of the highly dispersed solid catalyst (11 nm size) was possible by application of a magnetic field. The catalyst could be reused over ten cycles without significant activity loss. Other solid-supported nanostructured metal oxides were tested as catalysts for PET glycolysis. Thus, a graphene oxide (GO)- $\mathrm{Mn}_{3} \mathrm{O}_{4}$ nanocomposite (Table 3, entry 5) [220] and silica NPs-supported $\mathrm{Mn}_{3} \mathrm{O}_{4}$ [221] resulted in a good yield of BHET (>90\%), however, at a high reaction temperature. A zinc manganite spinel $\mathrm{ZnMn}_{2} \mathrm{O}_{4}$ gave BHET in $92 \%$ yield at $260{ }^{\circ} \mathrm{C}$ and 5 atm pressure (Table 3, entry 6) [222]. On the other hand, amphoteric solid catalysts have also shown usability in EG depolymerisation of PET. For instance, a BHET yield of $75 \%$ was achieved over $(\mathrm{Mg}-\mathrm{Zn})-\mathrm{Al}$-layered double hydroxides (LDH) catalysts at $196{ }^{\circ} \mathrm{C}$ (Table 2, entry 7) [223]. A cooperative mechanism was proposed in which Lewis acid sites $\left(\mathrm{Mg}^{2+}, \mathrm{Al}^{3+}, \mathrm{Zn}^{2+}\right)$ activate the $\mathrm{C}=\mathrm{O}$ ester bond, while the basic sites $\left(\mathrm{OH}^{-}\right)$deprotonate EG, enhancing the nucleophilic cleavage of the ester unit [224].

Notably, the depolymerisation of PET by EG was also reported using metal-containing catalysts in the form of ionic liquids (ILs) [209]. Advantages of metallated ILs include low flammability, high thermal stability and versatility. However, their "greenness" and toxicity are still debated [225,226]. Thus, $\operatorname{amim}\left[\mathrm{ZnCl}_{3}\right]$ (amin = 1-allyl-3-methylimidazolium, Table 4, entry 1) [227] and amim $\left[\mathrm{ZnCl}_{3}\right.$ ] (bmim = 1-butyl-3-methylimidazolium, Table 4, entry 2) [228] were recently studied, showing higher catalytic activity compared to metal-free ionic liquids (i.e., bmim chloride), the conventional catalysts (i.e., $\left.\mathrm{ZnCl}_{2}, \mathrm{Zn}(\mathrm{OAc})_{2}\right)$ or the analogous $\mathrm{Mn}$, $\mathrm{Co}$ and $\mathrm{Cu}$ ionic liquids. Typically, $80-85 \%$ BHET yields were observed for metallated ILs, while under the same experimental conditions,
$\mathrm{ZnCl}_{2}$ gave BHET in $\approx 70 \%$ yield (Table 4 , entry 5 ). Similar results were reported for the $\operatorname{bmim}_{2}\left[\mathrm{MCl}_{4}\right](\mathrm{M}=\mathrm{Cr}, \mathrm{Fe}, \mathrm{Co}, \mathrm{Zn}$, $\mathrm{Ni}, \mathrm{Cu}$ ) catalysts, wherein the cobalt derivative resulted in the best performance (Table 4, entry 3) [229]. Based on infrared studies, the higher catalytic activities of the metallated ILs was attributed to their higher Lewis acidity compared to both the metal-free catalysts and the metal salts. A mechanism was therefore proposed in which a synergistic effect of the metallated ILs takes place, based on the activation of the $\mathrm{C}=\mathrm{O}$ bond by the IL Lewis acid cation and of the hydroxy group in EG by the IL anion (Scheme 6). The IL catalysts could be easily separated by distillation and reused up to six times with no significant efficiency drop. Catalytic glycolysis by heterogenised, metallated ionic liquids was also investigated [230], however, showing a lower performance compared to the soluble systems. Thus, PET pellets were fully converted by a bmim[ $\left.\mathrm{Fe}(\mathrm{OAc})_{3}\right]$ catalyst immobilised onto bentonite, affording BHET in $44 \%$ yield (Table 4, entry 4) [231]. The solid catalyst could be recovered by filtration and reused.

As an alternative to ILs, metal-based deep eutectic solvent (DES) systems were also explored as catalysts for the glycolysis reaction of PET using EG. DES have similar properties to metallated ILs, but they are cheaper and less toxic [232,233]. Because of this, they have found application in many fields [234,235], though they cannot be considered inherently "green" [236]. In a recent work, the DES combination zinc acetate and 1,3-dimethylurea (1:4) showed the highest catalytic activity among a series of transition metal acetates ( $\mathrm{Zn}, \mathrm{Mn}, \mathrm{Co}, \mathrm{Ni}$, $\mathrm{Cu}$ ), affording BHET with $82 \%$ yield and noticeable productivity (TOF $=129 \mathrm{~h}^{-1}$, based on the moles of $\mathrm{Zn}$ ) at $190^{\circ} \mathrm{C}$, EG/ PET 4:1, w/w and 5 wt \% catalyst [237]. A mechanism was proposed analogous to that depicted in Scheme 6, but in which $\mathrm{Zn}^{2+}$ acts as Lewis acid and dimethylurea acts as base promoter for EG hydroxy deprotonation [238]. The remarkable activity 


\begin{tabular}{|c|c|c|c|c|c|c|c|c|}
\hline \multirow[t]{2}{*}{ entry } & \multicolumn{2}{|c|}{ catalyst } & \multirow{2}{*}{$\begin{array}{c}\mathrm{EG} / \mathrm{PET} \\
(\mathrm{w} / \mathrm{w})\end{array}$} & \multirow{2}{*}{$\begin{array}{l}T^{\mathrm{a}} \\
\left({ }^{\circ} \mathrm{C}\right)\end{array}$} & \multirow{2}{*}{$\begin{array}{c}\text { conv. } \\
(\%)\end{array}$} & \multicolumn{2}{|r|}{ BHET } & \multirow[t]{2}{*}{ reference } \\
\hline & formula & $\begin{array}{l}\text { loading } \\
\text { (wt \%) }\end{array}$ & & & & $\begin{array}{l}\text { sel. }^{\mathrm{c}} \\
(\%)\end{array}$ & $\begin{array}{c}\text { TOFd }^{\mathrm{d}} \\
\left(\mathrm{mol}_{\text {BHET }} \cdot \mathrm{mol}_{\left.\text {cat. }^{-1} \cdot \mathrm{h}^{-1}\right)}\right.\end{array}$ & \\
\hline 1 & $U_{3}$ & 10 & $4: 1$ & 175 & 100 & 80.1 & 9.8 & [227] \\
\hline 2 & $\mathrm{Cl}_{3}^{-}$ & 1.25 & $11: 1$ & 190 & 100 & 84.9 & 55.2 & [228] \\
\hline 3 & $\mathrm{Cl}_{4}{ }^{2-}$ & 17 & 12:1 & 175 & 100 & 81.1 & 8.5 & [229] \\
\hline 4 & $\mathrm{DAc})_{3}{ }^{-} @ \mathrm{~B}$ & $30^{e}$ & $7: 1$ & 190 & 100 & 44.0 & $2.9^{f}$ & [231] \\
\hline 5 & $\mathrm{ZnCl}_{2} \mathrm{~g}$ & 1.25 & $4: 1$ & 175 & 94 & 76.2 & 4.0 & [227] \\
\hline
\end{tabular}

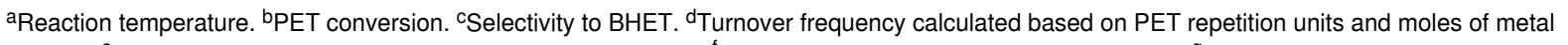

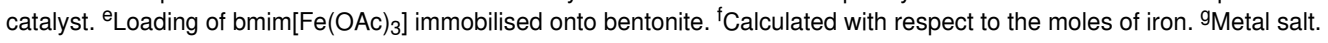

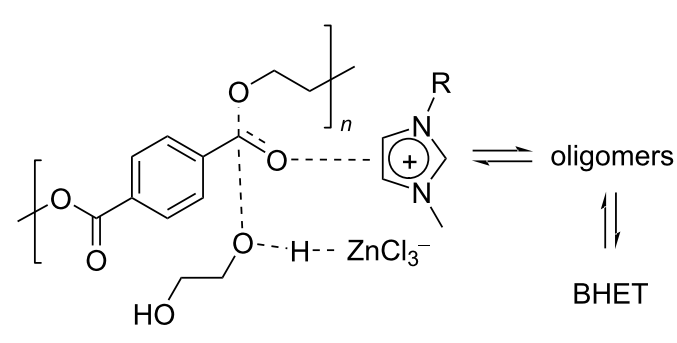

Scheme 6: Potential activated complex for the glycolysis reaction of PET catalysed by metallated ILs and evolution toward products.

was attributed to the dual effect of base and acid catalysis, in addition to the solubility of the catalyst in EG.

It is worth mentioning that, in addition to the recovery of chemicals via chemolytic processes, repurposing techniques of PET were developed based on one-pot, two-step glycolysis-reprocessing strategies, wherein the depolymerisation products are directly used in a polymerisation reaction, without intermediate purifications. In order to avoid the presence of free glycols in the polymerisation mixture, most of these processes were performed using (sub)stoichiometric amounts of diol cleaving agents, other than EG (for instance, PD [239], DEG [240,241]) As a consequence, the depolymerisation step usually results in complex mixtures of oligomers. Moreover, reacting diols may be unstable under the reaction conditions adopted. Hence, if used in excess, a significant formation of decomposition byproducts may be observed (i.e., dioxane and acetaldehyde for DEG [242]). Because of that, these metal-catalysed depolymerisations cannot be strictly considered as selective, although the overall processes are interesting from a practical and sustainability point of view. Some recent examples are cited herein. Postconsumer PET was depolymerised in the melt (at $250{ }^{\circ} \mathrm{C}$ ) using DEG and $\mathrm{Ca} / \mathrm{Zn}$ stearate as catalyst, and the product mixture was used in situ in conjunction with bis(2-ethylhexyl)phthalate and the same metal promoter for the production of flexible poly(vinyl chloride) compounds [243]. One-pot depolymerisation-polycondensation reactions were developed to produce random copolyesters poly(ethylene terephthalate-coadipate) from PET in the presence of EG and adipic acid [244]. The depolymerisation step was carried out using a zinc acetate catalyst ( 1 wt \%), with no need of excess of chemicals. Polymerisation was then achieved by raising the reaction temperature, without purification of the intermediate oligomers being required. An interesting one-pot process was developed that combines the use of bioderived chemicals, isosorbide and succinic acid, with PET chemical recycling to produce novel polyesters [245]. In this process, isosorbide was used as depolymerising diol to give a mixture of differently composed oligomers, whereas succinic acid was added in the second step as polymerising comonomer (Scheme 7). Both steps were efficiently catalysed by monobutyltin oxide, using substoichiometric amounts of isosorbide and succinic acid and no solvent at 


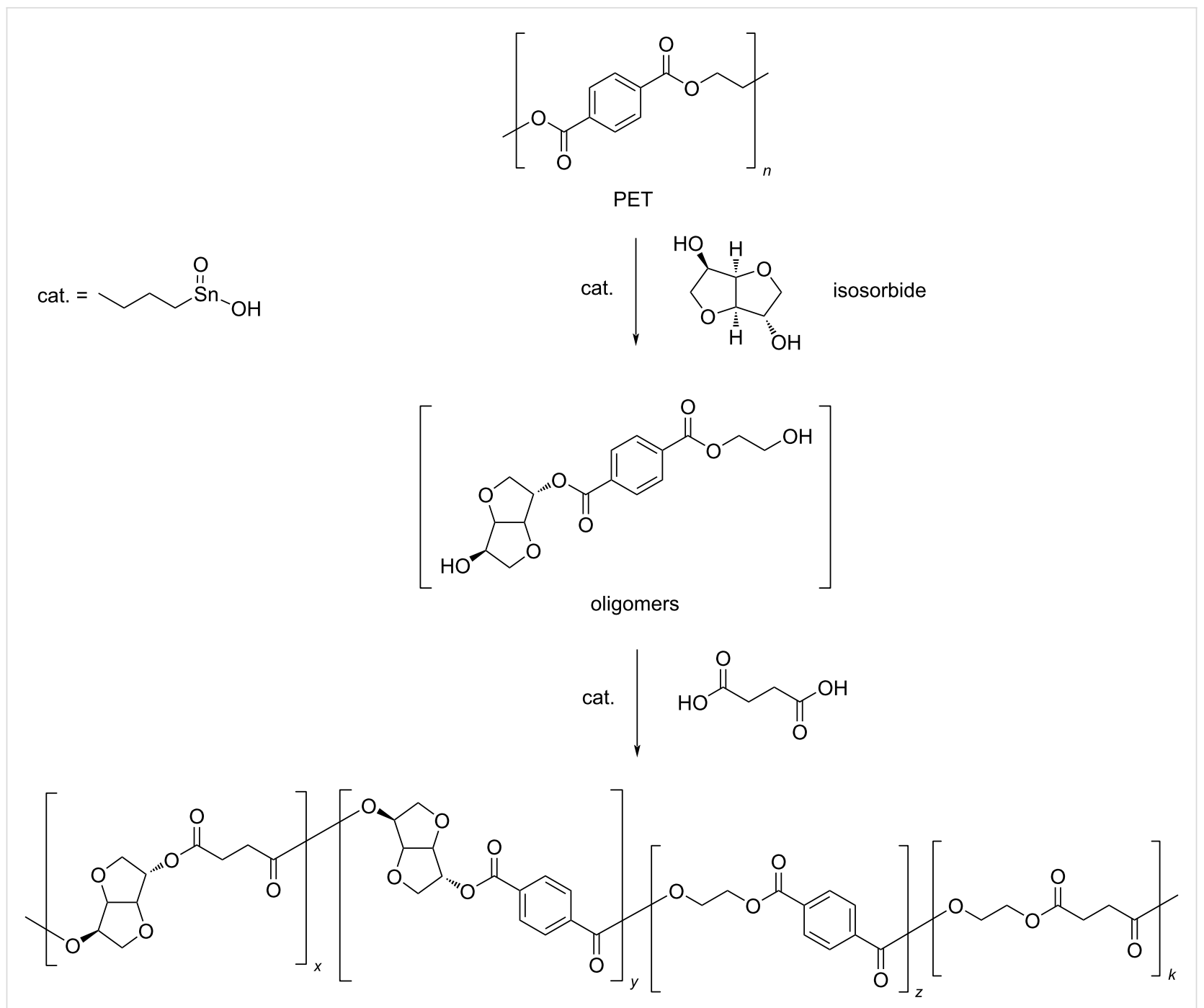

Scheme 7: One-pot, two-step process for PET repurposing via chemical recycling.

$230{ }^{\circ} \mathrm{C}$ reaction temperature. Isosorbide is a safe chemical [246] that is obtainable on the large scale from renewable glucose $[247,248]$. Because of this and due to the inherent rigid structure, conferring the resulting polymers with excellent mechanical properties (e.g., stiffness, toughness, hardness), isosorbide is used as monomer in the production of a variety of plastics $[249,250]$. By contrast, the rigidity results in a poor reactivity as depolymerising agent [251].

3.2.2 Polylactic acid (PLA): PLA is a bioderived plastic [252] that is manufactured on a 190 kton scale directly from lactic acid by condensation or from lactide by ring-opening polymerisation (Scheme 8) $[253,254]$. The main renewable raw material for lactic acid is starch, e.g., from corn, cassava, sugarcane or beet pulp [255]. Owing to the chirality of lactic acid, three forms of PLA (L, PLLA; D, PDLA; DL, PDLLA) with slightly different properties (crystallinity, $T_{\mathrm{g}} 60-65^{\circ} \mathrm{C}, T_{\mathrm{m}} 130-180^{\circ} \mathrm{C}$ )<smiles>CC(O)C(=O)O</smiles>

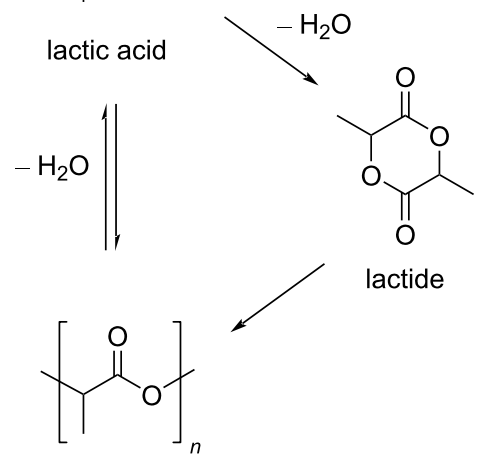

PLA 
exist [256]. PLA is soluble in benzene, tetrahydrofuran, ethyl acetate, propylene carbonate and dioxane [257], and it is biodegradable [258,259]. Because of these features, PLA is largely employed in several applications: microelectronics, biomedicine and food packaging [260].

Although chemical recycling of PLA is possible by thermal methods over metal catalysts [261,262], these often result in a poor selectivity and in a variety of volatile compounds, with the notable exception of calcium oxide, which gave L,L-lactide from PLLA in $\approx 98 \%$ yield at $250{ }^{\circ} \mathrm{C}$ [263].

Alcoholysis. The solvolytic depolymerisation of PLA was mostly reported using zinc-based catalysts, ethanol or methanol agents, wherein a higher reactivity of the latter was ascribed to the better nucleophilicity. Indeed, a methyl lactate (Me-La) and ethyl lactate yield of $70 \%$ and $21 \%$ was obtained, respectively, using soluble zinc acetate at reflux temperature [264]. Interestingly, under the same reaction conditions, PET was unreactive, thus enabling the selectively recycle of mixed PET/PLA plastic waste. It was suggested that the different reactivity between PLA and PET is attributable to the amorphous, less rigid structure of PLA and to the potential of forming five-membered chetate ring intermediates between $\mathrm{Zn}$ (II) ions and lactate units, which favour the transesterification process. More recently, the use of soluble $\mathrm{Zn}$ (II) molecular catalysts was investigated. An in-depth study of the methanolysis reaction of PLA was carried out via design of experiments technique, using a series of imino monophenolate-Zn complexes and THF solvent. Different commercial samples of PLA were examined, showing the critical operational parameters to be temperature and catalyst concentration, whereas the process was not significantly affected by particle size or stirring speed. Thus, up to $100 \%$ Me-La yield was obtained using the six-coordinated $\mathrm{Zn}$ (ligand) 2 complex sketched in Scheme 9a, either at $90{ }^{\circ} \mathrm{C}$ and $16 \mathrm{wt} \%$ catalyst or $130{ }^{\circ} \mathrm{C}$ and $8 \mathrm{wt} \%$ catalyst [265]. Higher efficiency was provided by the tetrahedral complex $\mathrm{ZnA}_{2}$ bearing a similar ligand, as shown in (Scheme 9b), which resulted in $81 \%$ Me-La selectivity at full PLA conversion at under $50{ }^{\circ} \mathrm{C}$ and $4 \mathrm{wt} \%$ catalyst loading [266]. However, in the absence of THF solvent, the latter catalysts gave a $98 \% \mathrm{Me}-\mathrm{La}$ yield at $130{ }^{\circ} \mathrm{C}$. The comparable complexes $\mathrm{ZnL}_{2}{ }_{2}, \mathrm{ZnL}^{2}{ }_{2}$ and $\mathrm{ZnL}^{3}{ }_{2}$ shown in Scheme $9 \mathrm{c}$ resulted in a lower catalytic efficiency (Me-La yield $41-88 \%$, $50{ }^{\circ} \mathrm{C}, 8 \mathrm{wt} \%$ catalyst loading, $18 \mathrm{~h}$ ), and thus indicating a significant steric and electronic effect of the ligand [267]. A reaction mechanism for PLA depolymerisation was proposed, consisting of two consecutive first-order steps, in which Me-La production follows the formation of chain-end groups intermediates [265]. A zinc-N-heterocyclic carbene complex was used as catalysts for the methanolysis reaction of PLLA via a twostep, one-pot procedure using $\mathrm{CH}_{2} \mathrm{Cl}_{2}$ solvent and an excess of methanol at room temperature (Scheme 10) [268]. At full sub- a)

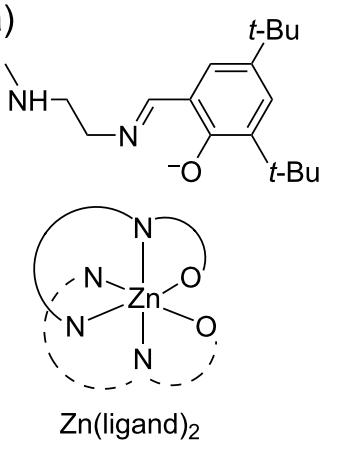

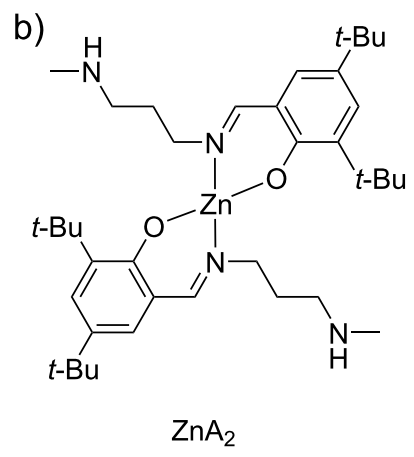

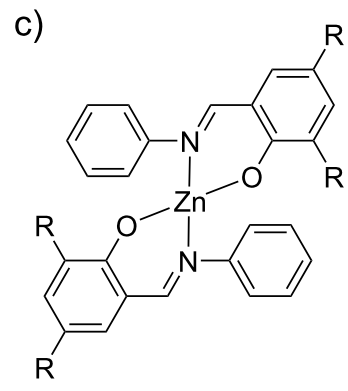

$$
\begin{aligned}
& \mathrm{ZnL}^{1}{ }_{2}, \mathrm{R}=t-\mathrm{Bu} \\
& \mathrm{ZnL}^{2}{ }_{2}, \mathrm{R}=\mathrm{Cl} \\
& \mathrm{ZnL}^{3}{ }_{2}, \mathrm{R}=\mathrm{H}
\end{aligned}
$$

Scheme 9: Structures of the zinc molecular catalysts used for PLA-methanolysis in various works. a) See [265], b) see [266], c) see [267].

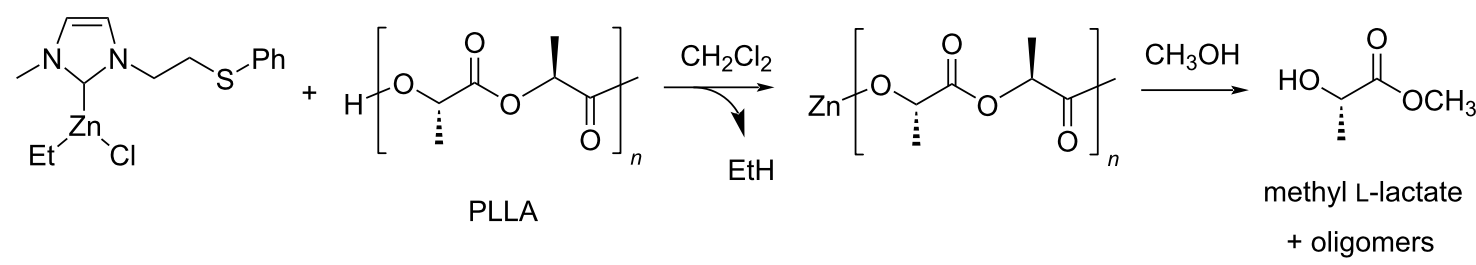


strate conversion, a Me-La/oligomers ratio around 10:1 was detected by GPC analysis. Notably, mutatis mutandis, almost all of the above described zinc complexes could be used as catalysts, both in PLA alcoholysis and in PLA synthesis via lactide polymerisation.

Metal species other than zinc were reported as effective catalysts for PLA methanolysis. Group 4 metal complexes with salalen ligands of the formula $\mathrm{M}($ ligand $)(\mathrm{OiPr})_{2}(\mathrm{M}=\mathrm{Ti}, \mathrm{Zr}$, Hf) were used in the methanolysis reaction of PLA at room temperature with an excess of methanol and $\mathrm{CH}_{2} \mathrm{Cl}_{2}$ cosolvent (Scheme 11) [269,270]. A 75\% yield of Me-La and residual oligomers with $M_{\mathrm{n}} 500 \mathrm{~g} \cdot \mathrm{mol}^{-1}$ were obtained by conversion of $M_{\mathrm{n}} 200000 \mathrm{~g} \cdot \mathrm{mol}^{-1}$ PLA using the hafnium derivative. As an alternative to expensive metal (complex) catalysts, methanolysis of PLA was recently described using alkali metal halides [271]. In an optimised experiment, PLA from various goods (cups, fork, spoons, containers, $M_{\mathrm{W}} 120000-260000 \mathrm{~g} \cdot \mathrm{mol}^{-1}$ ) was converted into $\mathrm{Me}-\mathrm{La}$ in up to $97 \%$ yield using $2.5 \mathrm{~mol} \%$ $\mathrm{KF}, 180{ }^{\circ} \mathrm{C}$ microwave heating and 23.1 equiv $\mathrm{CH}_{3} \mathrm{OH}$. The potassium fluoride catalyst could be reused in up to three runs with no change in performance, while a $50 \%$ drop of the yield was observed afterwards.

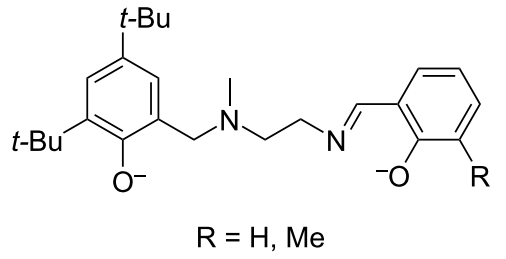

Scheme 11: Salalen ligands.

Me-La is a low-toxic chemical used as substitute for hydrocarbon solvents, with applications in the field of paints, lacquers and cleaning agents $[272,273]$. It should be finally mentioned that during the alcoholysis reaction of PLA using alkoxide catalysts, alkaline earth metal adducts (typically of $\mathrm{Ca}^{2+}$ ) were isolated, and thus suggesting a potential involvement of the metal centre in the depolymerisation mechanism [274,275].

Hydrogenolysis. The Ru(triphos)tmm/HNTf 2 catalytic system described above for the hydrogenolysis reaction of PET was also successfully applied in PLA hydrogenative depolymerisation (Scheme 12) [191]. PLA was directly converted to 1,2propanediol in $99 \%$ yield using $1 \mathrm{~mol} \%$ catalyst (with respect to lactic acid units) and 1,4-dioxane solvent at $140{ }^{\circ} \mathrm{C}$ and $100 \mathrm{bar} \mathrm{H}_{2}$. A TOF of $6.19 \mathrm{~mol}_{\mathrm{PD}} \cdot \mathrm{mol}_{\mathrm{Ru}}{ }^{-1} \cdot \mathrm{h}^{-1}$ can be calculated based on this. Scale-up using PLA granulates and beverage cups was also possible using a lower catalyst loading.
In addition, the method allowed for the selective recycle of equimolar mixtures of PET and PLA using the $[\mathrm{Ru}$ (triphosxyl)methylallyl] $\mathrm{NTf}_{2}$ catalyst congener at $45{ }^{\circ} \mathrm{C}$ reaction temperature, wherein insoluble PET was filtered out, while PLA was fully converted to PD. Similarly to PET, the ruthenium(II)-PNN complex sketched in Table 1, entry 2 was also used in PLA hydrogenolysis to give PD in $99 \%$ yield at $160{ }^{\circ} \mathrm{C}, 54$ bar $\mathrm{H}_{2}$ and in anisole/THF solvent [182,188]. PD is a safe chemical that is mainly produced from propylene oxide or catalytically from lactic acid intermediate, and it serves in the polymer and food industry or as antifreezing agent [276,277].<smiles>CC(C)OC(=O)C(C)(C)C</smiles>

PLA

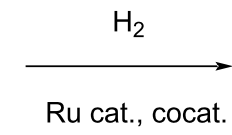

Ru cat., cocat.

$$
\text { rogenolysis of PLA. }
$$

Under milder reaction conditions, PLA could be converted to the corresponding silyl ether in $92 \%$ yield, propane and silicon byproducts $(8 \%)$ using the above mentioned Brookhart pincer complex $[\operatorname{Ir}(\mathrm{POCOP}) \mathrm{H}(\mathrm{THF})]\left[\mathrm{B}\left(\mathrm{C}_{6} \mathrm{~F}_{5}\right)_{4}\right]$ shown in Scheme 3, an excess of $\mathrm{Et}_{3} \mathrm{SiH}$ and chlorobenzene solvent at $90{ }^{\circ} \mathrm{C}$ (Scheme 13) [193]. The use of 6 equiv of 1,1,3,3-tetramethyldisiloxane (TMDS) led to the total conversion to propane and polydimethylsiloxane (PDMS), a silicon oil with several applications (lubricants, food-additives, breast implants).

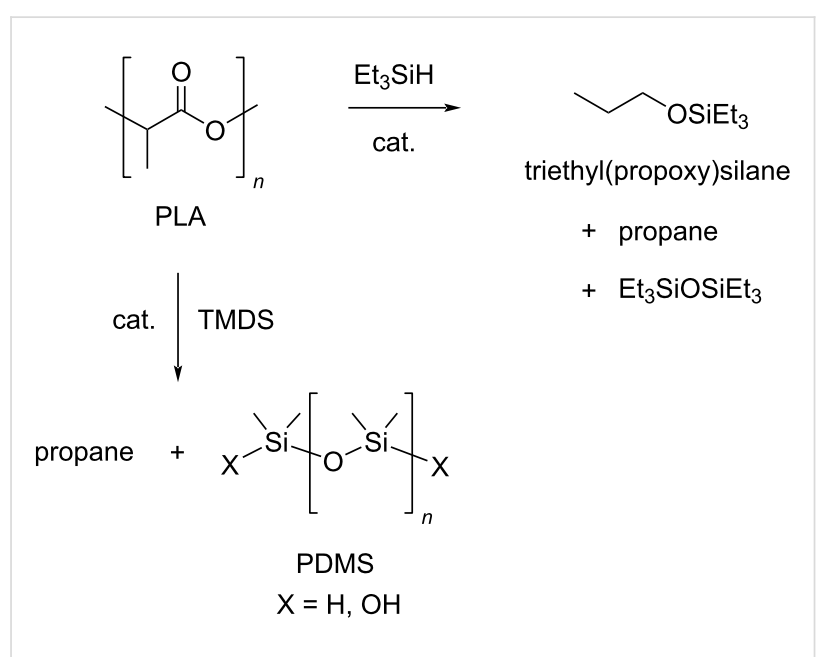

Scheme 13: Catalytic hydrosilylation of PLA.

3.2.3 Other polyesters: The hydrogenolysis reaction of esters other than PET and PLA was carried out using the above described soluble Ru(triphos)tmm/ $\mathrm{HNTf}_{2}$ catalytic system [191]. Thus, poly(butylene terephthalate) (PBT) and polycaprolactone 
(PCL) were depolymerised into the corresponding (co)monomeric diols at $140{ }^{\circ} \mathrm{C}$ and 100 bar $\mathrm{H}_{2}$ in 1,4-dioxane solvent (Scheme 14). A 99\% selectivity to 1,6-hexanediol was observed at full PCL conversion, whereas the selectivity to diols was only $22 \%$ for PBT (due to the formation of ethers byproducts), which could be raised to $99 \%$ by using the bulkier $\mathrm{Ru}($ triphos-xyl)tmm catalyst derivative.

PCL could be converted to 1,6 -hexanediol in $68 \%$ yield also through a two-step procedure involving hydrosilylation by the above mentioned cationic Ir catalyst complex $[\operatorname{Ir}(\mathrm{POCOP}) \mathrm{H}(\mathrm{THF})]\left[\mathrm{B}\left(\mathrm{C}_{6} \mathrm{~F}_{5}\right)_{4}\right]$ and TMDS reagent (chlorobenzene solvent, $\left.90{ }^{\circ} \mathrm{C}\right)$, followed by alkaline hydrolysis $(10 \%$ $\mathrm{NaOH}$ in $\left.\mathrm{CH}_{3} \mathrm{OH} / \mathrm{H}_{2} \mathrm{O}\right)$ [193]. PCL is a biodegradable polymer with a low melting point $\left(\approx 60^{\circ} \mathrm{C}\right)$ and glass transition temperature $\left(-60^{\circ} \mathrm{C}\right)$. It is commonly used in the manufacture of polyurethanes, to which it imparts improved solvent resistance, flexibility and toughness [278].
The glycolysis of poly(1,4-cyclohexylenedimethylene terephthalate) (PCT) was reported using DEG as reagent and zinc acetate as catalyst ( $0.12 \mathrm{~mol} \%$, Scheme 15) [279]. A 56\% yield of bis(2-hydroxydiethylene terephthalate) (BHDET) was obtained at $196{ }^{\circ} \mathrm{C}$ and a DEG/PCT $15: 1$, w/w ratio, which was five times lower than that using PET under the same reaction conditions. This finding was attributed to the steric hindrance of the 1,4-cyclohexanedimethanol (CHDM)-based chain that hampers the transesterification process. A 90\% BHDET yield was achieved using $\mathrm{Zn}\left(\mathrm{OCH}_{3}\right)_{2}$ catalysts under the same conditions.

Recently, a quantitatively and selectively depolymerisable novel polyester was developed based on a trans-fused six-membered $\gamma$-butyrolactone ring, 3,4-T6GBL (Scheme 16) [280]. This material joins the advantages of the ease of depolymerisation $(97 \%$ monomer yield, $180{ }^{\circ} \mathrm{C}$, toluene, $2 \mathrm{~mol} \% \mathrm{ZnCl}_{2}$ catalyst), rigid structure of the monomer (which provides the polymer with<smiles>CC(C)(C)CCCCCOC(C)(C)C</smiles>

PCL<smiles>[R4]C(CC)CC(C)(C)CCCOC(=O)c1ccc(C(=O)OC)cc1</smiles>

PBT<smiles>[R10]CC[NH3+]</smiles>

1,6-hexanediol

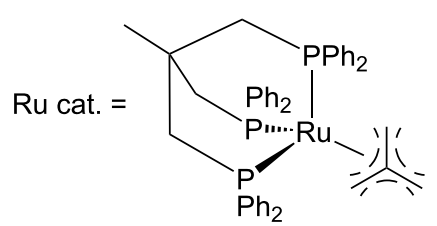<smiles>CC(C)(C)OCC1CCC(COC(=O)c2ccc(C(=O)OC(C)(C)C)cc2)CC1</smiles><smiles>OCCOCCO</smiles>
cat.<smiles>O=C(OCCOCCO)c1ccc(C(=O)OCCOCCO)cc1</smiles><smiles>[BH3-][TeH]</smiles><smiles>OCC1CCC(CO)CC1</smiles>

CHDM 
good thermal and mechanical properties) and facile synthesis (ring-opening polymerisation, solvent-free, room temperature, La, Y or Zn catalyst), significantly contributing to a closed-loop concept of plastics recycle. The approach enabled to perform the polymerisation-depolymerisation cycle over three times and on a multigram scale, using both linear and cyclic polymers. These advantages are not provided, for example, by more conventional poly $(\gamma$-butyrolactone) plastics, which require high depolymerisation temperatures $\left(260-300{ }^{\circ} \mathrm{C}\right)$ and undesirable synthetic conditions $\left(-40^{\circ} \mathrm{C}\right)$ [281].

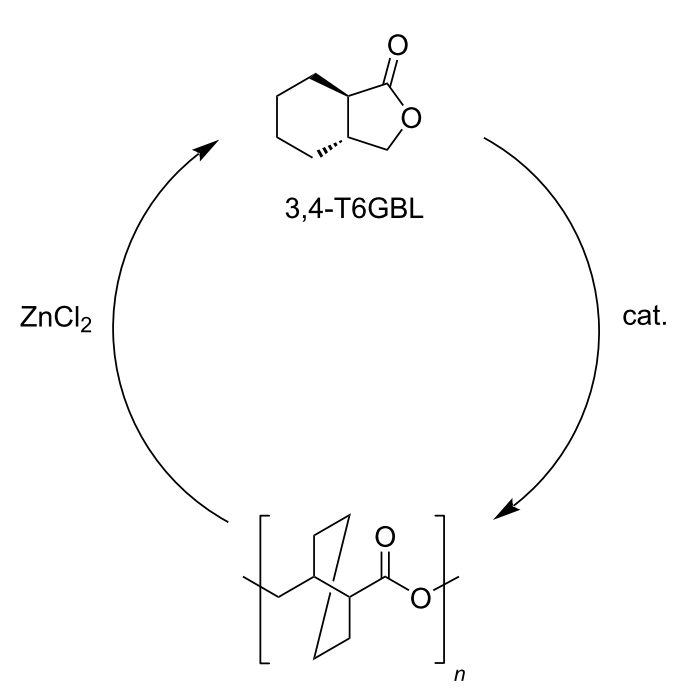

Scheme 16: Polymerisation-depolymerisation cycle of 3,4-T6GBL.

Following the same approach to purposely designed, chemically recyclable polymers, it was reported that poly(2-(2-hydroxyethoxybenzoate) (P2HEB) is reversibly depolymerised to 2,3dihydro-5H-1,4-benzodioxepin-5-one (2,3-DHB) in 94\% yield by an aluminium-salen catalyst at room temperature (Scheme 17) [282]. Thus, a polymerisation-depolymerisation cycle could be established using the same metal catalyst, simply by adjusting the initial monomer concentration in a one-pot process.

\subsection{Polycarbonates}

3.3.1 Poly(bisphenol A carbonate) (PBPAC): Bisphenol A (BPA) is a monomer for a variety of polymers widespread in our everyday life, namely polycarbonates, polyesters, polyethers, polysulphones and epoxy resins [249,283]. Particularly, PBPAC is used in the manufacture of plastics for food and beverage containers, safety helmets, optical lenses, electronic and medical equipment, phones, automotive components and toys $[284,285]$. This justifies for BPA to be one of the highestvolume chemicals produced worldwide, with a global market of around 6 million tons in 2017, $68 \%$ of which account for the

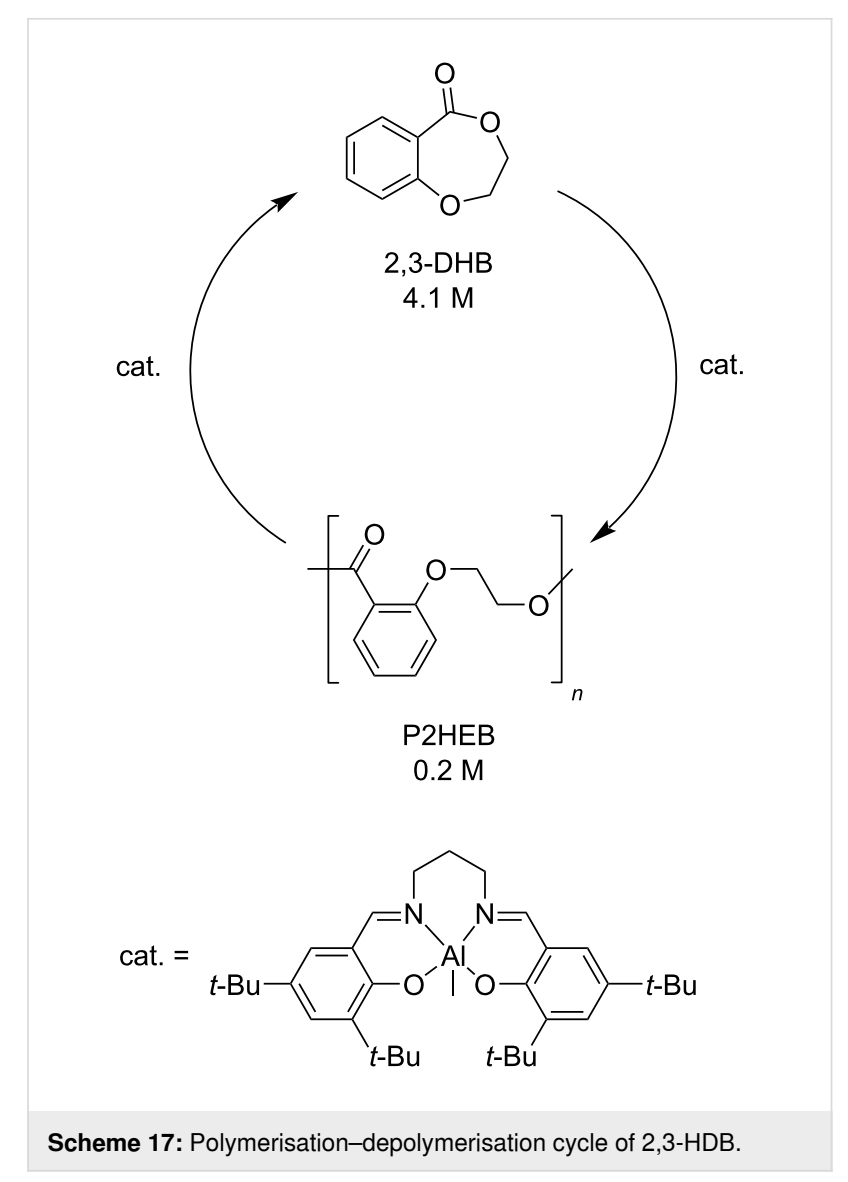

manufacture of polycarbonates [286,287]. However, BPA is considered a hazardous substance $[288,289]$ and an endocrine disrupting agent [290,291]. BPA can leach from the corresponding polymers, including water- and temperature-sensitive polycarbonates [292,293]. BPA is industrially obtained by the condensation reaction of phenol with acetone, using an excess of phenol [294]. All byproducts of the process, including unreacted phenol, are toxic [295,296], whereas a purity greater than $98 \%$ is required for most BPA applications [297,298]. PBPAC is then produced by the condensation of BPA and a carbonyl source, usually phosgene or diphenyl carbonate [299,300]. Commercial PBPAC is a tough material with an average $M_{\mathrm{w}}$ of $50000 \mathrm{~g} \cdot \mathrm{mol}^{-1}$ and $T_{\mathrm{g}}$ around $150{ }^{\circ} \mathrm{C}$. It is soluble in THF, hazardous NMP and chlorinated solvents and insoluble in alcohols and water [301]. A number of chemolytic processes have been developed in the recent years for the selective depolymerisation of PBPAC, including hydrogenolysis, hydrolysis, alcoholysis and aminolysis, some of which are metal-catalysed [302,303].

Hydrogenolysis. The hydrogenative depolymerisation of PBPAC was accomplished through the Ru-triphos molecular catalyst described above for PET, PLA, PBT and PCL polyesters [191]. Thus, use of the soluble Ru(triphos)tmm complex, 
in conjunction with acid $\mathrm{HNTf}_{2}$ cocatalyst (1:1) in 1,4-dioxane, resulted in complete conversion and selectivity to BPA and methanol under the moderate conditions of using $100 \mathrm{bar}_{2}$ at $140{ }^{\circ} \mathrm{C}$ (Scheme 18 and Table 5, entry 1). The protocol could be successfully extended to the depolymerisation of consumer goods, such as compact discs and beverage cups. Notably, pure BPA could be recovered in $>70 \%$ yield after simple $\mathrm{CH}_{2} \mathrm{Cl}_{2}$ extraction. A similar approach was recently reported using commercially available $\mathrm{Ru}(\mathrm{II})$ catalysts, namely the Milstein [304] and the Ru-MACHO-BH [305] complexes bearing tridentate PN ligands, as shown in Table 5, entries 2 and 3, which are known as efficient hydrogenation catalysts of organic carbonates [306,307]. High BPA yields were obtained in those experiments as well, though with lower hydrogen pressure and catalyst productivity in terms of turnover frequency $\left(\mathrm{mol}_{\mathrm{BPA}} \cdot \mathrm{mol}_{\mathrm{Ru} \text { cat. }}{ }^{-1} \cdot \mathrm{h}^{-1}\right)$. Potassium tert-butoxide was used as cocatalyst, the role of which was speculated to activate the carbonate group of the polymer [308]. The depolymerisa- tion of a digital versatile disc (DVD) using the latter catalyst afforded BPA in an estimated $97 \%$ yield after THF pretreatment.

Hydrolysis. The hydrolytic depolymerisation of PBPAC in hot compressed water was achieved via manganese acetate catalyst (Scheme 19, top) [309]. Under optimal conditions $\left(280{ }^{\circ} \mathrm{C}\right.$, catalyst loading $2 \mathrm{wt} \%$ ), the reaction resulted in $55 \%$ selectivity to BPA and $19 \%$ to phenol at full polymer conversion. A higher selectivity to BPA was obtained by simple Lewis acid treatment using rare earth metal triflate catalysts [310]. The process occurred in the homogeneous phase using a $\mathrm{THF} / \mathrm{H}_{2} \mathrm{O}$ solvent mixture and a $\mathrm{H}_{2} \mathrm{O} / \mathrm{PBPAC}$ weight ratio of $\leq 1$. The highest BPA yield $\left(97 \%\right.$ at $\left.160{ }^{\circ} \mathrm{C}\right)$ was observed for $\mathrm{La}\left(\mathrm{CF}_{3} \mathrm{SO}_{3}\right)_{3}$ due to the reduced decomposition of BPA to phenol, 4-isopropenylphenol and 4-isopropylphenol. A comparison with triflic acid catalyst ruled out the possibility of a proton-catalysed depolymerisation process.<smiles>CC(C)(C)Oc1ccc(C(C)(C)c2ccc(OC(C)(C)C)cc2)cc1</smiles>

PBPAC

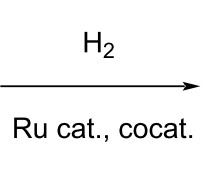

Ru cat., cocat.<smiles>CC(C)(c1ccc(O)cc1)c1ccc(O)cc1</smiles>

BPA

Scheme 18: Hydrogenative depolymerisation of PBPAC by molecular Ru catalysts.

Table 5: Hydrogenolysis of PBPAC by soluble Ru molecular catalysts.

\begin{tabular}{|c|c|c|c|c|c|c|c|c|c|}
\hline \multirow[t]{2}{*}{ entry } & \multirow[t]{2}{*}{ catalyst } & \multirow[t]{2}{*}{ cocatalyst $^{\mathrm{a}}$} & \multicolumn{3}{|c|}{ reaction conditions $^{b}$} & \multirow{2}{*}{$\begin{array}{l}\text { conv. }^{\mathrm{C}} \\
(\%)\end{array}$} & \multicolumn{2}{|r|}{ BPA } & \multirow[t]{2}{*}{ reference } \\
\hline & & & $\begin{array}{c}T \\
\left({ }^{\circ} \mathrm{C}\right)\end{array}$ & $\begin{array}{l}\mathrm{H}_{2} \\
\text { (bar) }\end{array}$ & solvent & & $\begin{array}{l}\text { sel.d }^{d} \\
(\%)\end{array}$ & $\begin{array}{c}\text { TOFe }^{\mathrm{e}} \\
\left.\text { (mol }_{\text {BPA }} \cdot \mathrm{mol}_{\text {cat. }}{ }^{-1} \cdot \mathrm{h}^{-1}\right)\end{array}$ & \\
\hline
\end{tabular}

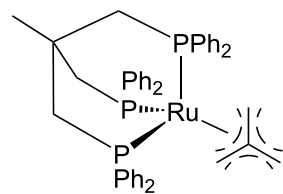

$\mathrm{HNTf}_{2}$

2

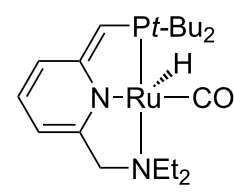

$\mathrm{K} t$-BuO

$140 \quad 45$

99

99

1.10

3

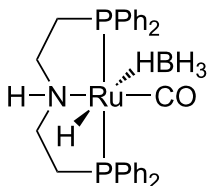

$\mathrm{K} t-\mathrm{BuO}$

140

45

THF

${ }^{\mathrm{a} C}$ Catalyst loading $5 \mathrm{~mol} \%$, calculated based on PBPAC repetition units, cocatalyst molar ratio $=1: 1$. ${ }^{\mathrm{b}}$ Reaction temperature, hydrogen pressure, $24 \mathrm{~h}$ reaction time. ${ }^{\mathrm{C} P B P A C}$ conversion. dSelectivity to BPA. ${ }^{\mathrm{e}}$ Turnover frequency, calculated based on PBPAC repetition units and moles of Ru catalyst. ${ }^{\mathrm{f}}$ Catalyst loading $1 \mathrm{~mol} \%$. 9Reaction time $16 \mathrm{~h}$. 
<smiles>CC(=O)Oc1ccc(C(C)(C)c2ccc(OC(C)(C)C)cc2)cc1</smiles>

PBPAC<smiles>CC(=O)Oc1ccc(C(C)(C)c2ccc(OC(C)(C)C)cc2)cc1</smiles>

PBPAC<smiles>CC(=O)Oc1ccc(C(C)(C)c2ccc(OC(C)(C)C)cc2)cc1</smiles>

PBPAC

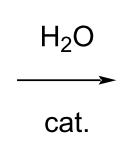

$\mathrm{ROH}$

cat.

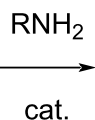<smiles>CC(C)(c1ccc(O)cc1)c1ccc(O)cc1</smiles>

BPA<smiles>[R]OC(=O)O[Na]</smiles>

BPA

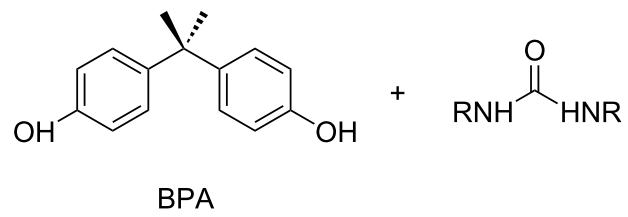

Scheme 19: Catalytic hydrolysis (top), alcoholysis (middle) and aminolysis (bottom) reactions of PBPAC.

Alcoholysis. A variety of metal-based catalytic systems was recently described for the alcoholysis reaction of PBPAC using diverse alcohols (Scheme 19, middle). Thus, a Lewis acid catalyst consisting of a soluble $\mathrm{FeCl}_{3}$-ionic liquid adduct, namely $\mathrm{BmimCl} \cdot 2 \mathrm{FeCl}_{3}$, was reported for the methanolysis of PBPAC, providing BPA in $97 \%$ yield at $120{ }^{\circ} \mathrm{C}$ [311]. Higher alcohols resulted in lower BPA yields. A mechanism was hypothesised in which the iron centre activates the carbonyl group of the polymer toward nucleophilic attack of methanol. The catalyst could be efficiently recovered and reused over six runs, after ethyl acetate/water extraction. On the other hand, $\mathrm{CeO}_{2}-\mathrm{CaO}$ particles onto hollow $\mathrm{ZrO}_{2}$ nanospheres were used as heterogeneous catalyst for the methanolysis of PBPAC, yielding around $95 \% \mathrm{BPA}$ at $100{ }^{\circ} \mathrm{C}$ in a THF/methanol mixture [312]. The basic sites, due to lattice $\mathrm{O}^{2-}$ of $\mathrm{CeO}_{2}$, were attributed to be responsible for the deprotonation of methanol, and thus initiating the solvolytic process in that reaction. Depolymerisation of PBPAC was reported using various alcohols (methanol, phenol, benzyl alcohol, 1-naphthol, PD, glycerol), a mechanical mixture of zinc oxide NPs and tetrabutylammonium chloride as catalyst as well as THF cosolvent to give BPA and the corresponding carbonates in $>98 \%$ yield at $100{ }^{\circ} \mathrm{C}$ reaction temperature (Scheme 19) [313]. The insoluble Lewis acid $\mathrm{ZnO}$ catalyst could be removed from the reaction mixture by centrifugation and reused five times with a minor loss of activity. However, $\mathrm{Bu}_{4} \mathrm{NCl}$ was only partially recovered and had to be integrated with fresh cocatalyst after each run. Remarkably, the reaction with glycerol enabled the recycling of two industrial wastes (PBPAC and glycerol) into the valuable chemicals BPA and glycerol carbonate in one process only, with the latter compound being industrially used as synthetic intermediate, solvent and in the formulation of cosmetics [314].

Aminolysis. The $\mathrm{ZnO}-\mathrm{Bu}_{4} \mathrm{NCl}$ Lewis acid catalytic mixture was also successfully used in the aminolytic depolymerisation of PBPAC by different amines (cyclohexylamine, aniline, imidazole, 1,2-diaminopropane, 1,3-diaminopropane) to give the corresponding substituted (cyclic) ureas in $>97 \%$ yield (Scheme 19, bottom) [313]. The reaction with 2-amino-1propanol gave 4-methyloxazolidin-2-one. Despite the complications due to separation from BPA, the process provides ureas of industrial relevance as anticancer or antiviral agents $[315,316]$.

3.3.2 Poly(propylene carbonate) (PPC) and poly(ethylene carbonate) (PEC): PPC is a thermoplastic material obtained by the copolymerisation of $\mathrm{CO}_{2}$ with propylene oxide or propylenediol, which is mainly used as a packing material and in binder applications [317]. It has a low thermal stability, with a decomposition temperature around $200{ }^{\circ} \mathrm{C}$ and a $T_{\mathrm{g}}$ around $40{ }^{\circ} \mathrm{C}$, depending on the molecular weight. PPC may be readily dissolved in many solvents (e.g., chlorinated hydrocarbons, THF, benzene, ethyl acetate and lower ketones), but it is insoluble in longer-chain alkanes, alcohols and water [318].

Hydrogenative depolymerisation of PPC and PEC to methanol and the respective glycols (PD and EG, respectively) was achieved using the soluble Milstein ruthenium catalysts described above for the hydrogenolysis of PET (Scheme 20) [188]. Thus, more than $91 \%$ glycol yield was obtained using a 
<smiles>CCC(=O)OC(C)COC(C)(C)C</smiles>

PPC<smiles>CC(C)(C)OCCOC(=O)C(C)(C)C</smiles>
PEC

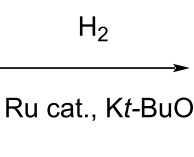

$\mathrm{HO} \sim \mathrm{OH}$

PD

$+\mathrm{CH}_{3} \mathrm{OH}$

$$
\begin{array}{cc}
\underset{\text { Ru cat., } \mathrm{Kt}-\mathrm{BuO}}{\mathrm{EG}} & \mathrm{H}_{2}^{\mathrm{OH}} \\
+\mathrm{CH}_{3} \mathrm{OH}
\end{array}
$$

Scheme 20: Hydrogenative depolymerisation of PPC (top) and PEC (bottom) by molecular Ru catalysts.
1:2 Ru catalyst/butoxide molar ratio, $160{ }^{\circ} \mathrm{C}$ reaction temperature, 55 bar $\mathrm{H}_{2}$ pressure and an anisole/THF 1:1 solvent mixture (Table 6, entries 1 and 2). The same approach was adopted using a Ru(II)-PNP pincer complex, showing higher catalytic activity (TOF $41.3 \mathrm{~h}^{-1}$ ) under similar reaction conditions (Table 6, entry 3) [319]. The role of butoxide was proposed to be the conversion of the staring molecular complex in the catalytically active species by elimination of $\mathrm{HCl}$. Similarly, a nonprecious PNN-manganese carbonyl complex was reported to afford PD from PPC in 91\% yield (Table 6, entry 4) [320]. By contrast, use of a comparable Mn complex and $\mathrm{KH}$ as activator resulted in a much lower selectivity to PD (68\%) at full PPC conversion $\left(110^{\circ} \mathrm{C}, 50\right.$ bar $\mathrm{H}_{2}$, in toluene), resulting in the formation of a propylene carbonate byproduct [321].

Table 6: Hydrogenolysis of PPC by molecular metal catalysts.

entry catalyst $\quad$ cocatalyst $^{\mathrm{a}} \quad$ reaction conditions $^{\mathrm{b}} \quad$ conv

$(\%)$

reference

$T \quad \mathrm{H}_{2} \quad$ solvent

TOFe

$\left({ }^{\circ} \mathrm{C}\right) \quad($ bar $) \quad(\%) \quad\left(\right.$ mol $\left._{\mathrm{PD}} \cdot \mathrm{mol}_{\text {cat. }}{ }^{-1} \cdot \mathrm{h}^{-1}\right)$

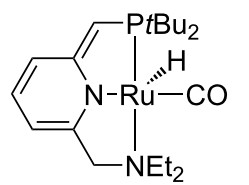

160

55

anisole/THF

99

100

4.12

[188]<smiles>[R16][R]([H])(C)N1C2=CC=CC1=C1C=CC=CN1C2=O</smiles>

$\mathrm{Kt}$-BuO

160

5

anisole/THF

99

100

4.12

[188]<smiles>P[P+]1CCN2CCP(c3ccccc3)[Pb]1C[Ge]2(Cl)Cl</smiles>

$\mathrm{Kt}$-BuOg

140

50

THF

99

99

41.25

[319]

4
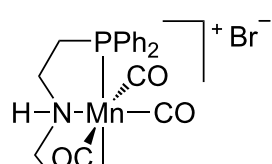

$\sum \mathrm{N}$

$\mathrm{Kt}$-BuO

50

1,4-dioxane

91

100

$2.84^{i}$

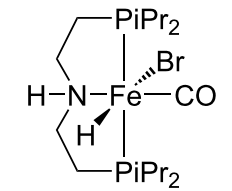

$\mathrm{Kt}$-BuOj

140

iPrOH/THF

65

0.43

${ }^{a}$ Catalyst loading $1 \mathrm{~mol} \%$, calculated based on PPC repetition units, cocatalyst molar ratio $=2: 1$. ${ }^{b}$ Reaction temperature, hydrogen pressure, $24 \mathrm{~h}$ reaction time. ${ }^{C}$ PPC conversion. ${ }^{d}$ Selectivity to PD. ${ }^{e}$ Turnover frequency, calculated based on PPC repetition units and moles of Ru catalyst. ${ }^{f} 1: 1, v / v$. gCatalyst loading $0.1 \mathrm{~mol} \%$, cocatalyst molar ratio $=1: 1$. hCatalyst loading $0.2 \mathrm{~mol} \%$, cocatalyst molar ratio $=2: 1$. ${ }^{\mathrm{i}}$ Reaction time $16 \mathrm{~h}$. ${ }^{\mathrm{j} C a t a l y t i c}$ hydrogen transfer. Catalyst loading $5 \mathrm{~mol} \%$, cocatalyst molar ratio $=1: 1$, reaction time $30 \mathrm{~h} . \mathrm{k} 4: 1$, v/v. 
In the search of safer and "greener" alternatives, a slightly different approach to controlled PPC depolymerisation was recently proposed, based on catalytic hydrogen transfer rather than hydrogenation reaction, and thus to avoid involvement of high $\mathrm{H}_{2}$ pressures [322]. Thus, hydrogen transfer from isopropanol to PPC using a soluble iron pincer-type catalyst resulted in a $65 \% \mathrm{PD}$ yield at $140{ }^{\circ} \mathrm{C}$ (Table 6, entry 5). However, a relatively high amount of catalyst was required. Potassium butoxide and THF were used as precatalyst activator and cosolvent, respectively.

3.3.3 Other carbonates: A polycarbonate suitable for smooth chemical recycle was engineered based on 1-benzyloxycarbonyl-3,4-epoxypyrrolidine (BEP) units [323]. In fact, a onepot copolymerisation-depolymerisation cycle was enabled using a dinuclear salen-chromium complex in the presence of a bis(triphenylphosphine)iminium cocatalyst (Scheme 21). Therein, the BEP monomer was fully converted to the polycarbonate at $60{ }^{\circ} \mathrm{C}$ reaction temperature, while complete and selective depolymerisation back to BEP was achieved at $100{ }^{\circ} \mathrm{C}$. The
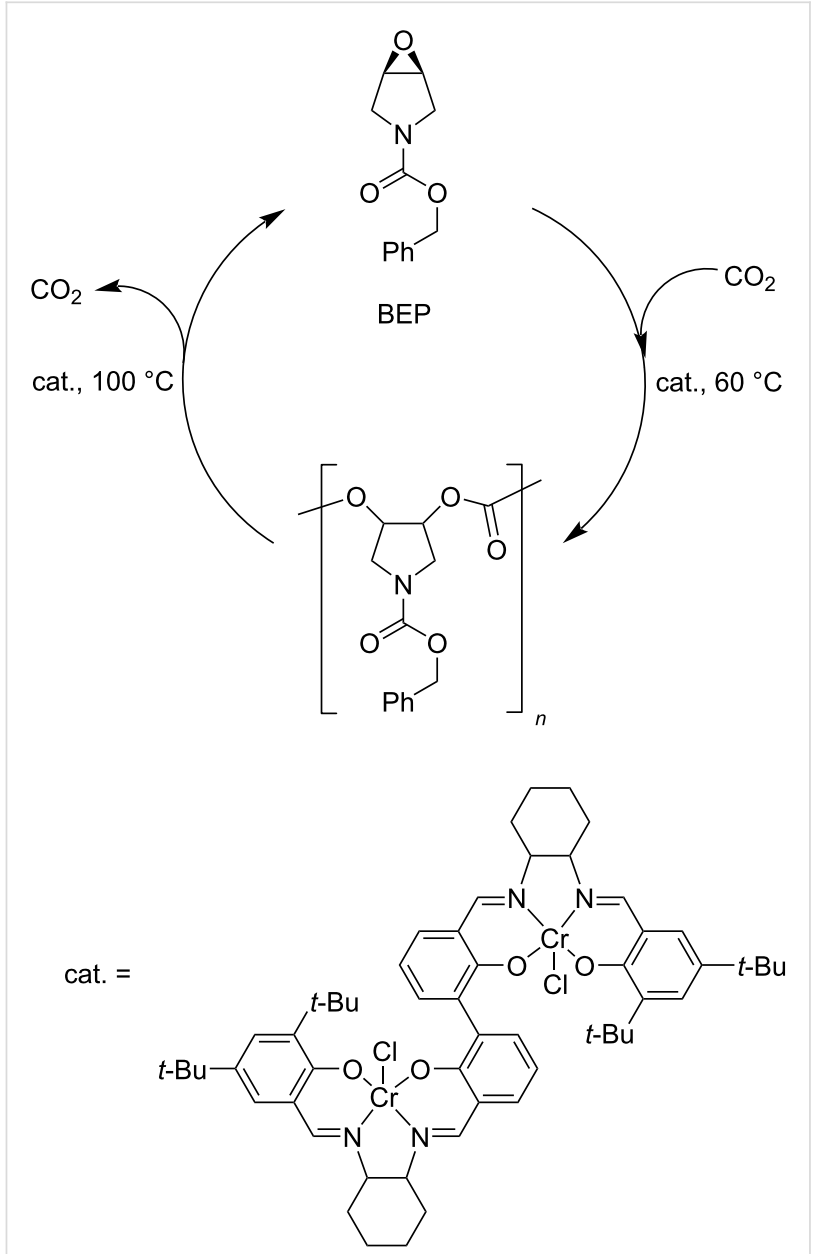

Scheme 21: Polymerisation-depolymerisation cycle of BEP. process could be repeated several times with no changes in either the monomer or the copolymer structure. After removing the catalyst, the polymer was stable at $200{ }^{\circ} \mathrm{C}$ for $10 \mathrm{~h}$.

\subsection{Polyamides (PA)}

Polyamides may be natural (e.g., silk, wool) or synthetic polymers (e.g., nylons, aramids, polyaspartates) that are largely used in the manufacture of fibres and automotive components as well as in biomedicine, due to their excellent mechanical and thermal properties [324,325]. The widespread use of polyamides and the high price of the starting monomers, such as $\varepsilon$-caprolactam, have led to the development of several methods for their chemical recycling. Most of these are based on mineral acid [326], organic base (e.g., 4-dimethylaminopyridine, triethylenetetramine) [327,328] or organic acid (e.g., glycolic, lactic, benzoic acid) [329] catalysis, using supercritical methanol or ionic liquids as solvent [330]. Few literature reports exist on the depolymerisation of polyamides using metal catalysts. In an earlier paper, the hydrolysis of nylon- 6 was achieved by a combination of zinc chloride (40 wt \%) and phosphoric acid (20 wt \%) under microwave irradiation, however, resulting in a mixture of linear and cyclic oligomers at $89 \%$ polymer conversion [121,331]. While drafting the present review, the first example of catalytic hydrogenative depolymerisation of polyamides and polyurethanes was described, using soluble Milstein-type Ru-pincer complexes (2 mol \%), DMSO solvent and $\mathrm{K} t$ - $\mathrm{BuO}$ cocatalyst at $150{ }^{\circ} \mathrm{C}$ and 70 bar $\mathrm{H}_{2}$ [332]. Typically, a selectivity to the corresponding diols/diamines/amino alcohols in the range of $20-80 \%$ was observed at $60-99 \%$ conversion, depending on the polymeric substrate. For instance, 6-amino-hexan-1-ol and BDM were obtained in $24 \%$ and $80 \%$ yield, respectively, from nylon- 6 and the polyamide shown in Scheme 22.

\subsection{Other plastics}

3.5.1 Epoxy resins (EP): EP are thermosetting polymers featuring high thermal and chemical resistance. They are widely used in the manufacture of paints, metal coatings, electronic components and adhesives [333]. EP are usually reinforced with fibres to give composite materials for the aeronautical, automotive and sport industries. Actually, recycling efforts of EP were mainly focused on the recovery of valuable (expensive) carbon fibres rather than the polymers themselves. Recently, a metalcatalysed route was reported for the degradation of the epoxy resin of bisphenol A diglycidyl ether (BADGE)-carbon fibres composites [334]. Therein, low-coordinated aquo ions of zinc enabled the selective cleavage of the $\mathrm{R}_{2} \mathrm{CH}-\mathrm{N}$ bond while keeping intact $\mathrm{RCH}_{2}-\mathrm{N}, \mathrm{C}-\mathrm{C}$ and $\mathrm{C}-\mathrm{O}$ bonds (Scheme 23). The method was previously adopted for the conversion of cellulose to hydroxymethylfurfural and required the use of highly soluble zinc chloride to obtain a concentrated aqueous solution of metal 
<smiles>CC(C)NCCCCCC(=O)C(C)(C)C</smiles><smiles>CC(C)(C)NCc1ccc(CNC(=O)c2ccc(C(C)(C)C)cc2)cc1</smiles>

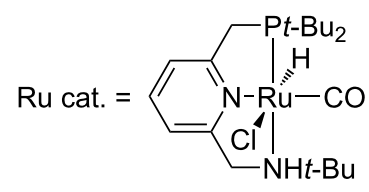

Scheme 22: Hydrogenolysis of polyamides using soluble Ru catalysts.

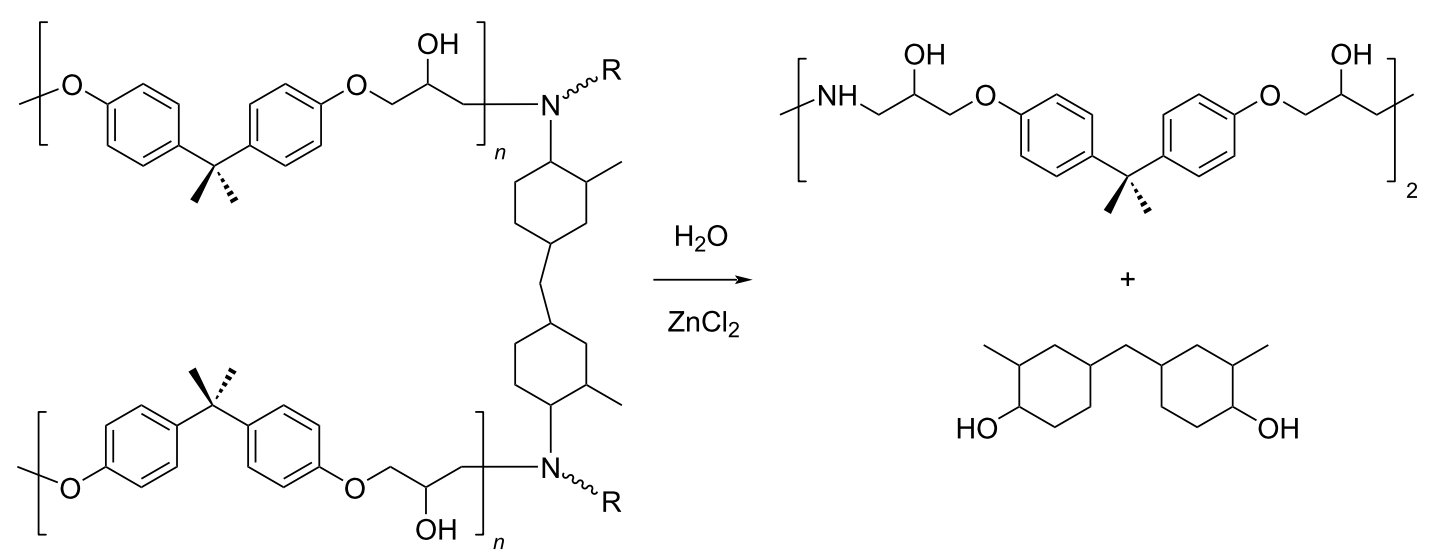

Scheme 23: Catalytic depolymerisation of epoxy resin/carbon fibres composite.

(60 wt \% $\mathrm{ZnCl}_{2}$ ) [335]. On this basis, the small, incompletely coordinated $\mathrm{Zn}^{2+}$ ions were proposed to activate the selective cleavage of $\mathrm{C}-\mathrm{N}$ bonds, acting as Lewis acid centres. The process carried out at $220{ }^{\circ} \mathrm{C}$ led to carbon fibres, a dimer of DGEBA reused for the synthesis of new EP, and 4,4'-methylenebis(2-methylcyclohexanol). The concentrated $\mathrm{ZnCl}_{2}$ solution showed good reusability, and thus adding some advantages to common highly energy-consuming methods.

3.5.2 Polyethers: Polyethers are polymers with a solubility that depends heavily on the solvent used, including water, and they find applications in the cosmetic, pharmacy or paint industries [336]. Thermal decomposition or disposal into landfills are consolidated management systems of "end-of-life" polyethers [337,338], whereas very few studies cope with the catalytic depolymerisation through selective $\mathrm{C}-\mathrm{O}$ bond cleavage into specific low-molecular-weight chemicals.

The group of Enthaler reported a number of research with a common strategy for polyethers depolymerisation [339-341]: Basically, the solvent-free reaction of a polyether with an acyl chloride in the presence of a catalytic amount $(5 \mathrm{~mol} \%$ ) of zinc or iron salts as Lewis acid catalysts results in monomeric chloroesters, which are valuable chemicals reprocessable into other polymers (Scheme 24). A deep study was carried out investigating the effect of key reaction parameters: metal salt, 


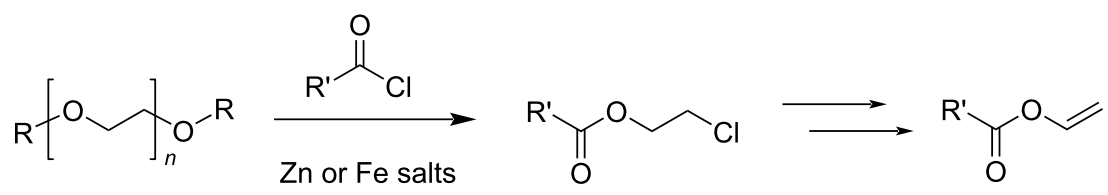

Scheme 24: Depolymerisation of polyethers with metal salt catalysts and acyl chlorides.

catalyst loading, temperature, depolymerisation agent and the applicability to a variety of polyethers. Successful examples include depolymerisation of polyethylene glycol (PEG) and polytetrahydrofuran (polyTHF) to chloroesters in 70-78\% and $92 \%$ yield, respectively, using $\mathrm{ZnCl}_{2}$ at $130{ }^{\circ} \mathrm{C}$ or $\mathrm{Zn}(\mathrm{OTf})_{2}$ catalyst when acetic anhydride was used as depolymerising agent $[339,340]$. Chloroester yields in the range $89-95 \%$ were obtained for PEG depolymerisation at $100{ }^{\circ} \mathrm{C}$ using $\mathrm{FeCl}_{2}$ as catalyst [341]. A mechanism was postulated in which the ether bond is cleaved via formation of an iron alkoxide intermediate (Scheme 25). Sustainability issues relate to the hazardous properties of low-molecular-weight acyl chlorides, which could be partially circumvented by the use of bioderived fatty acid chlorides [340].

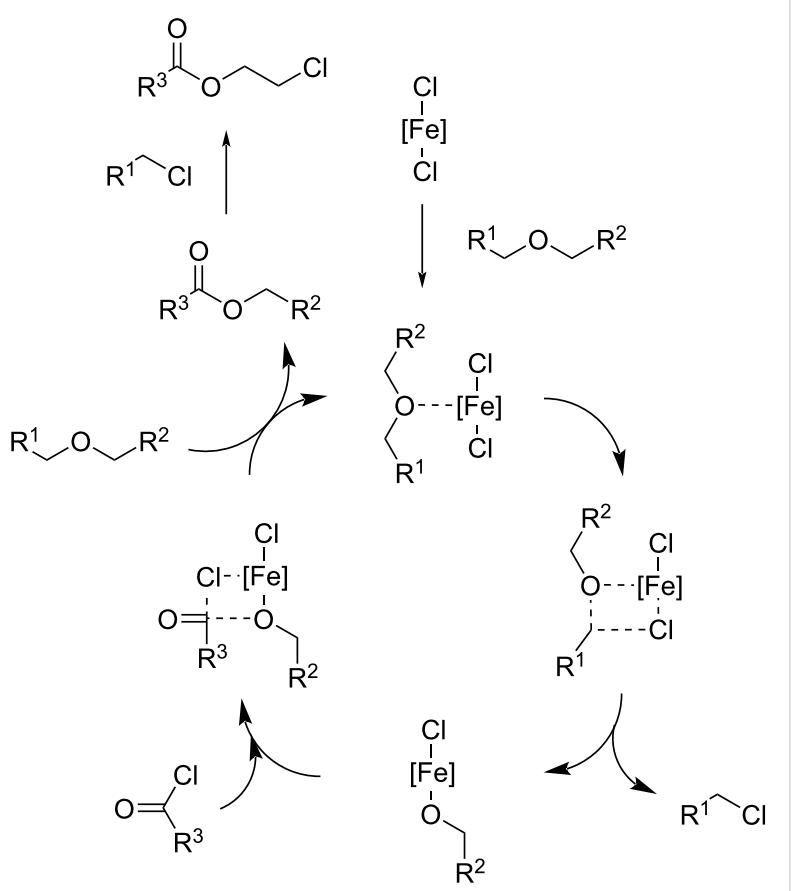

Scheme 25: Proposed mechanism for the iron-catalysed depolymerisation reaction of polyethers. Adapted with permission from [341], Copyright (c) 2012 WILEY-VCH Verlag GmbH \& Co. KGaA, Weinheim. Used with permission from Stephan Enthaler and Maik Weidauer, "Low-Temperature Iron-Catalysed Depolymerization of Polyethers", ChemSusChem, John Wiley and Sons.
In a different approach, selective ring-closing depolymerisation of polyTHF to THF was achieved in $92 \%$ and $95 \%$ yield, respectively, using Lewis acid catalysis by $\mathrm{FeCl}_{3}(5 \mathrm{~mol} \%$, $\left.180{ }^{\circ} \mathrm{C}\right)\left[342\right.$ ] or phosphotungstic acid $\left(10 \mathrm{wt} \%, 130{ }^{\circ} \mathrm{C}\right)$ [343].

\section{Conclusion}

The implementation of a value chain for plastics, in which design is coupled with production, use, depolymerisation and reprocessing, may substantially contribute to the development of a truly circular economy model for plastic materials, wherein scraps are converted into useful chemicals and reusable building blocks [344]. This model addresses three grand challenges of our century: pollution of the habitat, carbon dioxide emissions and dependence on fossil sources. However, performing plastics recycling via chemical processing is not enough. This must be achieved at competitive economic and environmental costs [345]. A perusal of the recent literature indicates that, despite their urgency and significance, strategies for sustainable chemical recycling are surprisingly still rather underdeveloped. Most methods for controlled and selective depolymerisation rely on harsh reaction conditions, use of an excess of reagents, toxic solvents and troublesome downstream treatments often generating a considerable amount of waste. Metal catalysis may represent a useful tool to overcome these issues, provided that significant improvements are achieved in relation to key challenges.

\section{Catalysts}

Most processes, particularly if based on solvolysis reactions, are carried out using traditional metal salt-based catalysts (e.g., zinc chloride, zinc acetate), the role of which is merely to act as Lewis acid centres, and they are often needed in a large amount with respect to the plastic to be depolymerised (i.e., $>2$ and up to $60 \mathrm{wt} \%$ ). In some cases, toxic metals (e.g., $\mathrm{Co}, \mathrm{Ni}$ ) result in the highest catalytic efficiency. A significant improvement is represented by the use of molecular complex catalysts, particularly based on ruthenium for use in hydrogenolysis. These systems, typically used in up to $2 \mathrm{wt} \%$, are quite efficient under relatively mild reaction conditions, although a strong acid or basic cocatalyst is usually required. On the other hand, soluble catalysts were mainly investigated so far, with clear limitations in terms of catalyst separation and reuse, purification, scale-up 
and cost. The use of meal-based ionic liquids and deep eutectic solvents has also been explored; however, their viability for practical application at large is uncertain [346]. Thus, inventive catalysts shall be developed with particular attention to heterogeneous systems, for instance, solid-supported metal species based on low-cost metals and solid materials featured by enhanced mass transfer and thermal resistance properties. Bifunctional solid catalysts bearing arrays of metal and acid singlesites may be useful in the same instances and processes [347,348]

\section{Polymers}

Easily and selectively depolymerisable plastics are relatively uncommon, owing to the poor mechanical and physical properties and to the low temperature required to achieve their polymerisation [280]. Specifically designed, chemically recyclable polymers have been developed in some cases, which may offer an affordable solution to this regard (see, e.g., Section 3.2.3). These materials are indeed usable in closed polymerisation-depolymerisation loops, and hence appropriate to extend the life cycle of plastics. Excellent reviews describe the recent developments in the field [71].

\section{Processes}

Large-scale chemical recycling of plastics is thus far hampered by the higher costs compared to mechanical recycling. A reason for this lays in the scarce development of effective catalysts. On the other hand, most processes for chemical recycling are still based on conventional organic reactions, requiring an excess of (unstable) decomposing agents or high temperature (e.g., for transesterifications). Moreover, performing the reactions in the homogeneous phase improves their kinetics, which, however, is limited by the usual poor solubility of polymers, and thus often ending up in the use of toxic solvents (e.g., chlorinated ones). Hence, besides the need for more efficient catalysts, the use of renewable and safer reagents and solvents is certainly desirable $[349,350]$. More importantly, novel processes and depolymerisation strategies have to be designed. Whereas glycolysis and methanolysis methods have reached commercial maturity (e.g., for PET), at high energy costs, however, in other instances (e.g., for polyolefins), no efficient processes for selective depolymerisation are in place yet. Hydrogenative depolymerisation represents a promising contribution to this end, owing to the use of the clean reducing agent $\mathrm{H}_{2}$, no need for organic reactants, reduced amount of metal catalyst, milder reaction conditions and limited formation of byproducts. Issues related to hydrogen supply may be circumvented, e.g., by in situ-generated hydrogen. Novel processes have thus to be developed, with special emphasis on those based on reaction sequences in one-pot or depolymerisation-polymerisation cycles as they clearly benefit from reduced energy inputs, reactor volumes and units, no need for intermediate purification/separation steps and better automation. Notably, methods for the direct reprocessing of plastics into valuable chemicals or polymers take advantage of metal catalysts (see Sections 3.2.3 and 3.3.3). Finally, coupling onepot techniques with the use of lytic agents other than the conventional ones may remarkably enlarge the scenario of depolymerisation products beyond that of the simple plastic components. Table 7 summarises the most common monomers obtainable in the metal-catalysed depolymerisation of plastics described in the present review. It is predictable that a greater variety of added-value products, such as monomers, oligomers and the chemically derived, functionalised compounds thereof, may be obtained by developing alternative depolymerisation pathways and reprocessing strategies.

In conclusion, as it was previously outlined, circular chemistry is a precondition for a truly circular economy, particularly in the field of production of goods and materials [351]. Chemical recycling via metal catalysts may effectively contribute to a circular recycling vision for postconsumer plastics, provided that the strategy is further developed and improved, aiming to reduce costs and environmental impact of selective depolymerisation processes. The design of novel versatile catalysts and more sustainable processes are key in this direction.

Table 7: Common monomeric products of metal-catalysed chemolytic depolymerisation reactions of plastics. ${ }^{\mathrm{a}}$ polymer type chemolytic method

\begin{tabular}{|c|c|c|c|c|c|}
\hline & hydrogenolysis & hydrolysis & alcoholysis & glycolysis & aminolysis \\
\hline polyolefins & hydrocarbons ${ }^{b}$ & - & - & - & - \\
\hline polyesters & diols & acids (+ diols) & esters (+ diols) & esters & amides + diols \\
\hline polycarbonates & diols $+\mathrm{CH}_{3} \mathrm{OH}$ & diols $+\mathrm{CO}_{2}$ & diols + carbonates ${ }^{c}$ & $\begin{array}{l}\text { diols + cyclic } \\
\text { carbonates }^{c}\end{array}$ & diols + ureas $^{d}$ \\
\hline polyamides & amines, alcohols & amines, acids & - & - & - \\
\hline
\end{tabular}

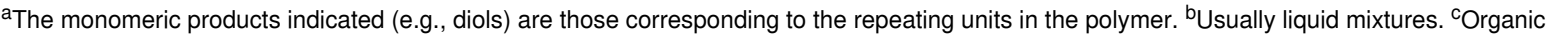
carbonates. ${ }^{\mathrm{N}} \mathrm{N}$-substituted ureas. 


\section{ORCID ${ }^{\circledR}$ iDs}

Francesca Liguori - https://orcid.org/0000-0002-5520-1550 Carmen Moreno-Marrodán - https://orcid.org/0000-0003-0805-0726 Pierluigi Barbaro - https://orcid.org/0000-0002-7298-5756

\section{References}

1. Circular Economy Action Plan, European Commission, Brussels, Belgium, 2020.

https://ec.europa.eu/environment/circular-economy/pdf/new_circular_ economy_action_plan.pdf (accessed Jan 27, 2021).

2. Towards a circular economy - Waste management in the EU, PE 581.913, European Parliamentary Research Service, Brussels, Belgium, 2017. https://www.europarl.europa.eu/RegData/etudes/STUD/2017/581913/ EPRS_STU\%282017\%29581913_EN.pdf (accessed Jan 27, 2021).

3. Heidbreder, L. M.; Bablok, I.; Drews, S.; Menzel, C. Sci. Total Environ. 2019, 668, 1077-1093. doi:10.1016/j.scitotenv.2019.02.437

4. Narancic, T.; O'Connor, K. E. Microbiology (London, U. K.) 2019, 165, 129-137. doi:10.1099/mic.0.000749

5. Moharir, R. V.; Kumar, S. J. Cleaner Prod. 2019, 208, 65-76. doi:10.1016/j.jclepro.2018.10.059

6. Raddadi, N.; Fava, F. Sci. Total Environ. 2019, 679, 148-158. doi:10.1016/j.scitotenv.2019.04.419

7. Sardon, H.; Dove, A. P. Science 2018, 360, 380-381. doi:10.1126/science.aat4997

8. Thomas, P.; Rumjit, N. P.; Lai, C. W.; Johan, M. R. B.; Saravanakumar, M. P. Polymer-Recycling of Bulk Plastics. Encyclopedia of Renewable and Sustainable Materials; Elsevier: Amsterdam, Netherlands, 2020; Vol. 2, pp 432-454. doi:10.1016/b978-0-12-803581-8.10765-9

9. Wright, S. L.; Kelly, F. J. Environ. Sci. Technol. 2017, 51, 6634-6647. doi:10.1021/acs.est.7b00423

10. Lehner, R.; Weder, C.; Petri-Fink, A.; Rothen-Rutishauser, B. Environ. Sci. Technol. 2019, 53, 1748-1765. doi:10.1021/acs.est.8b05512

11. Plastics - the Facts 2019, Plastics Europe, Association of Plastics Manufacturers, Brussels, Belgium, 2019. https://www.plasticseurope.org/application/files/9715/7129/9584/FINA L_web_version_Plastics_the_facts2019_14102019.pdf (accessed Jan 27, 2021).

12. Geyer, R.; Jambeck, J. R.; Law, K. L. Sci. Adv. 2017, 3, e1700782. doi:10.1126/sciadv.1700782

13. The New Plastics Economy: Rethinking the future of plastics \& catalysing action, Ellen MacArthur Foundation, 2017. https://www.ellenmacarthurfoundation.org/assets/downloads/publicati ons/NPEC-Hybrid_English_22-11-17_Digital.pdf (accessed Jan 27, 2021).

14. Li, J.; Song, Y.; Cai, Y. Environ. Pollut. 2020, 257, 113570. doi:10.1016/j.envpol.2019.113570

15. Wang, J.; Liu, X.; Li, Y.; Powell, T.; Wang, X.; Wang, G.; Zhang, P. Sci. Total Environ. 2019, 691, 848-857. doi:10.1016/j.scitotenv.2019.07.209

16. Peng, L.; Fu, D.; Qi, H.; Lan, C. Q.; Yu, H.; Ge, C. Sci. Total Environ 2020, 698, 134254. doi:10.1016/j.scitotenv.2019.134254

17. Jambeck, J. R.; Geyer, R.; Wilcox, C.; Siegler, T. R.; Perryman, M.; Andrady, A.; Narayan, R.; Law, K. L. Science 2015, 347, 768-771. doi:10.1126/science.1260352

18. Iannilli, V.; Pasquali, V.; Setini, A.; Corami, F. Environ. Res. 2019, 179, 108811. doi:10.1016/j.envres.2019.108811
19. Brahney, J.; Hallerud, M.; Heim, E.; Hahnenberger, M.; Sukumaran, S. Science 2020, 368, 1257-1260. doi:10.1126/science.aaz5819

20. Zheng, J.; Suh, S. Nat. Clim. Change 2019, 9, 374-378. doi:10.1038/s41558-019-0459-z

21. Dormer, A.; Finn, D. P.; Ward, P.; Cullen, J. J. Cleaner Prod. 2013, 51, 133-141. doi:10.1016/j.jclepro.2013.01.014

22. Hopewell, J.; Dvorak, R.; Kosior, E. Philos. Trans. R. Soc., B 2009, 364, 2115-2126. doi:10.1098/rstb.2008.0311

23. Kiser, B. Nature 2016, 531, 443-446. doi:10.1038/531443a

24. A European Strategy for Plastics in a Circular Economy, European Commission, Brussels, Belgium, 2018. https://ec.europa.eu/environment/circular-economy/pdf/plastics-strate gy-brochure.pdf (accessed Jan 27, 2021).

25. Xu, C.; Nasrollahzadeh, M.; Selva, M.; Issaabadi, Z.; Luque, R. Chem. Soc. Rev. 2019, 48, 4791-4822. doi:10.1039/c8cs00543e

26. Maschmeyer, T.; Luque, R.; Selva, M. Chem. Soc. Rev. 2020, 49, 4527-4563. doi:10.1039/c9cs00653b

27. Kanani, F.; Heidari, M. D.; Gilroyed, B. H.; Pelletier, N. J. Cleaner Prod. 2020, 262, 121129. doi:10.1016/j.jclepro.2020.121129

28. Cavani, F.; Albonetti, S.; Basile, F.; Gandini, A., Eds. Chemicals and Fuels from Bio-Based Building Blocks; Wiley-VCH: Weinheim, Germany, 2016. doi:10.1002/9783527698202

29. Jérôme, F.; Chatel, G.; De Oliveira Vigier, K. Green Chem. 2016, 18, 3903-3913. doi:10.1039/c6gc00814c

30. Breakthrough Innovations Enabling Waste-to-Product, Report ID 4900532, Research and Markets, Dublin, Ireland, Dec 2019.

31. Müller, R. J. In Biodegradability of Polymers: Regulations and Methods for Testing; Steinbüchel, A., Ed.; Biopolymers Online; John Wiley \& Sons: Hoboken, NJ, USA, 2005. doi:10.1002/3527600035.bpola012

32. Niaounakis, M. Biopolymers: Applications and Trends; Elsevier: Amsterdam, Netherlands, 2015. doi:10.1016/c2014-0-00936-7

33. Vert, M.; Doi, Y.; Hellwich, K.-H.; Hess, M.; Hodge, P.; Kubisa, P.; Rinaudo, M.; Schué, F. Pure Appl. Chem. 2012, 84, 377-410. doi:10.1351/pac-rec-10-12-04

34. Rudnik, E. Compostable Polymer Materials: Definitions, Structures, and Methods of Preparation. Handbook of Biopolymers and Biodegradable Plastics; Elsevier: Amsterdam, Netherlands, 2013; pp 189-211. doi:10.1016/b978-1-4557-2834-3.00010-0

35. Commission Decision of 28 June 2001 relating to the publication of references for standards EN 13428:2000, EN 13429:2000, EN 13430:2000, EN 13431:2000 and EN 13432:2000 in the Official Journal of the European Communities in connection with Directive 94/62/EC on packaging and packaging waste, L 190, 12/07/2001, 21-23, 2001/524/EC, European Commission, Brussels, Belgium, 2001. https://op.europa.eu/en/publication-detail/-/publication/17d5b3cd-42a7 -45ef-a821-2f773d551f1f (accessed Jan 27, 2021).

36. EN 13432 Certified bioplastic performance in industrial composting, European Bioplastics e.V., Berlin, Germany, 2015. https://docs.european-bioplastics.org/publications/bp/EUBP_BP_En_1 3432.pdf (accessed Jan 27, 2021).

37. Datta, J.; Kopczyńska, P. Crit. Rev. Environ. Sci. Technol. 2016, 46, 905-946. doi:10.1080/10643389.2016.1180227

38. The APR Design ${ }^{\circledR}$ Guide for Plastics Recyclability, Association of Plastic Recyclers, Washington, DC, 2018. https://plasticsrecycling.org/apr-design-guide (accessed Jan 27, 2021). 
39. Plastic Recyclers Europe, Brussels, Belgium. https://www.plasticsrecyclers.eu/design-recycling (accessed June 1, 2020).

40. Merrington, A. Recycling of Plastics. Applied Plastics Engineering Handbook, 2nd ed.; Elsevier: Amsterdam, Netherlands, 2017; pp 167-189. doi:10.1016/b978-0-323-39040-8.00009-2

41. Guide for Waste Reduction, Resource Recovery, and Use of Recycled Polymeric Materials and Products, ASTM D7209-06; ASTM International: West Conshohocken, PA, U.S.A.. doi:10.1520/d7209-06

42. Sahajwalla, V.; Gaikwad, V. Curr. Opin. Green Sustainable Chem. 2018, 13, 102-107. doi:10.1016/j.cogsc.2018.06.006

43. Nikles, D. E.; Farahat, M. S. Macromol. Mater. Eng. 2005, 290, 13-30. doi:10.1002/mame.200400186

44. Hamad, K.; Kaseem, M.; Deri, F. Polym. Degrad. Stab. 2013, 98, 2801-2812. doi:10.1016/j.polymdegradstab.2013.09.025

45. Directive 2008/98/EC of the European Parliament and of the Council of 19 November 2008 on waste and repealing certain Directives, European Commission, Brussels, Belgium, 2008. https://eur-lex.europa.eu/legal-content/EN/TXT/?uri=celex\%3A32008L 0098 (accessed Jan 27, 2021).

46. Reuse - Rethinking Packaging, Ellen MacArthur Foundation, 2019. https://www.ellenmacarthurfoundation.org/assets/downloads/Reuse.p df (accessed Jan 27, 2021).

47. Al-Salem, S. M.; Lettieri, P.; Baeyens, J. Waste Manage. (Oxford, U. K.) 2009, 29, 2625-2643. doi:10.1016/j.wasman.2009.06.004

48. Chandrasekaran, S. R.; Sharma, B. K. From Waste to Resources: How to Integrate Recycling Into the Production Cycle of Plastics. Plastics to Energy; Elsevier: Amsterdam, Netherlands, 2019; pp 345-364. doi:10.1016/b978-0-12-813140-4.00013-3

49. Ignatyev, I. A.; Thielemans, W.; Vander Beke, B. ChemSusChem 2014, 7, 1579-1593. doi:10.1002/cssc.201300898

50. Vilaplana, F.; Karlsson, S. Macromol. Mater. Eng. 2008, 293, 274-297. doi:10.1002/mame.200700393

51. Kaminsky, W.; Hartmann, F. Angew. Chem., Int. Ed. 2000, 39 331-333. doi:10.1002/(sici)1521-3773(20000117)39:2<331::aid-anie331>3.0.co; 2-h

52. Welle, F. Food Law Compliance of Poly(ethylene Terephthalate) (PET) Food Packaging Materials. In Food Additives and Packaging; Komolprasert, V.; Turowski, P., Eds.; ACS Symposium Series, Vol. 1162; American Chemical Society: Washington, DC, USA, 2014; pp 167-195. doi:10.1021/bk-2014-1162.ch016

53. Sethi, B. Methods of Recycling. In Recycling of Polymers - Methods, Characterization and Applications; Francis, R., Ed.; Wiley-VCH: Weinheim, Germany, 2017; pp 55-114. doi:10.1002/9783527689002.ch3

54. Thiounn, T.; Smith, R. C. J. Polym. Sci. (Hoboken, NJ, U. S.) 2020, 58, 1347-1364. doi:10.1002/pol.20190261

55. Al-Salem, S. M.; Antelava, A.; Constantinou, A.; Manos, G.; Dutta, A. J. Environ. Manage. 2017, 197, 177-198. doi:10.1016/j.jenvman.2017.03.084

56. Serrano, D. P.; Aguado, J.; Escola, J. M. ACS Catal. 2012, 2, 1924-1941. doi:10.1021/cs3003403

57. Panda, A. K.; Singh, R. K. J. Fuel Chem. Technol. (Beijing, China) 2011, 39, 198-202. doi:10.1016/s1872-5813(11)60017-0

58. Butler, E.; Devlin, G.; McDonnell, K. Waste Biomass Valorization 2011, 2, 227-255. doi:10.1007/s12649-011-9067-5
59. Ciesielski, P. N.; Pecha, M. B.; Bharadwaj, V. S.; Mukarakate, C.; Leong, G. J.; Kappes, B.; Crowley, M. F.; Kim, S.; Foust, T. D.; Nimlos, M. R. Wiley Interdiscip. Rev.: Energy Environ. 2018, 7, e297. doi:10.1002/wene.297

60. Munir, D.; Irfan, M. F.; Usman, M. R. Renewable Sustainable Energy Rev. 2018, 90, 490-515. doi:10.1016/j.rser.2018.03.034

61. Al-Salem, S. M.; Lettieri, P.; Baeyens, J. Prog. Energy Combust. Sci. 2010, 36, 103-129. doi:10.1016/j.pecs.2009.09.001

62. Verma, R.; Vinoda, K. S.; Papireddy, M.; Gowda, A. N. S. Procedia Environ. Sci. 2016, 35, 701-708. doi:10.1016/j.proenv.2016.07.069

63. Gente, V.; La Marca, F. Study on the Feasibility of Hazardous Waste Recycling: The Case of Pharmaceutical Packaging. In Material Recycling-Trends and Perspectives; Achilias, D. S., Ed.; IntechOpen: Rijeka, Croatia, 2012; pp 237-264. doi:10.5772/34389

64. Keane, M. A. ChemSusChem 2009, 2, 207-214. doi:10.1002/cssc.200900001

65. Veethahavya, K. S.; Rajath, B. S.; Noobia, S.; Kumar, B. M. Procedia Environ. Sci. 2016, 35, 709-713. doi:10.1016/j.proenv.2016.07.072

66. Brems, A.; Baeyens, J.; Dewil, R. Therm. Sci. 2012, 16, 669-685. doi:10.2298/tsci120111121b

67. Burange, A. S.; Gawande, M. B.; Lam, F. L. Y.; Jayaram, R. V.; Luque, R. Green Chem. 2015, 17, 146-156. doi:10.1039/c4gc01760a

68. Ma, C.; Yu, J.; Wang, B.; Song, Z.; Xiang, J.; Hu, S.; Su, S.; Sun, L. Renewable Sustainable Energy Rev. 2016, 61, 433-450. doi:10.1016/j.rser.2016.04.020

69. Pathak, V. M.; Navneet. Bioresour. Bioprocess. 2017, 4, 15. doi:10.1186/s40643-017-0145-9

70. Urbanek, A. K.; Mirończuk, A. M.; García-Martín, A.; Saborido, A.; de la Mata, I.; Arroyo, M. Biochim. Biophys. Acta, Proteins Proteomics 2020, 1868, 140315. doi:10.1016/j.bbapap.2019.140315

71. Hong, M.; Chen, E. Y.-X. Green Chem. 2017, 19, 3692-3706. doi:10.1039/c7gc01496a

72. Circular economy in Europe - Developing the knowledge base, Report No. 2/2016, European Environment Agency, 2016. https://www.eea.europa.eu/publications/circular-economy-in-europe (accessed Jan 27, 2021).

73. Carey, J. Proc. Natl. Acad. Sci. U. S. A. 2017, 114, 612-616. doi:10.1073/pnas.1620655114

74. Haider, T. P.; Völker, C.; Kramm, J.; Landfester, K.; Wurm, F. R. Angew. Chem., Int. Ed. 2019, 58, 50-62. doi:10.1002/anie.201805766

75. Webb, H. K.; Arnott, J.; Crawford, R. J.; Ivanova, E. P. Polymers (Basel, Switz.) 2013, 5, 1-18. doi:10.3390/polym5010001

76. Schneiderman, D. K.; Hillmyer, M. A. Macromolecules 2017, 50, 3733-3749. doi:10.1021/acs.macromol.7b00293

77. Wei, R.; Zimmermann, W. Microb. Biotechnol. 2017, 10, 1308-1322. doi:10.1111/1751-7915.12710

78. Zhang, X.; Fevre, M.; Jones, G. O.; Waymouth, R. M. Chem. Rev. 2018, 118, 839-885. doi:10.1021/acs.chemrev.7b00329

79. Fiorentino, G.; Ripa, M.; Ulgiati, S. Biofuels, Bioprod. Biorefin. 2017, 11, 195-214. doi:10.1002/bbb.1729

80. Achilias, D. S.; Antonakou, E.; Roupakias, C.; Megalokonomos, P.; Lappas, A. Global NEST J. 2008, 10, 114-122. doi:10.30955/gnj.000468

81. Ragaert, K.; Delva, L.; Van Geem, K. Waste Manage. (Oxford, U. K.) 2017, 69, 24-58. doi:10.1016/j.wasman.2017.07.044

82. Pardal, F.; Tersac, G. Polym. Degrad. Stab. 2007, 92, 611-616. doi:10.1016/j.polymdegradstab.2007.01.008 
83. Achilias, D. S.; Karayannidis, G. P. Water, Air, Soil Pollut.: Focus 2004, 4, 385-396. doi:10.1023/b:wafo.0000044812.47185.0f

84. El Dorado of Chemical Recycling -State of play and policy challenges, Zero Waste Europe, Aug 2019.

https://zerowasteeurope.eu/library/el-dorado-of-chemical-recycling-sta te-of-play-and-policy-challenges/ (accessed Jan 27, 2021).

85. Sudarsanam, P.; Peeters, E.; Makshina, E. V.; Parvulescu, V. I.; Sels, B. F. Chem. Soc. Rev. 2019, 48, 2366-2421. doi: $10.1039 / \mathrm{c} 8 \mathrm{cs} 00452 \mathrm{~h}$

86. George, N.; Kurian, T. Ind. Eng. Chem. Res. 2014, 53, 14185-14198. doi:10.1021/ie501995m

87. Sabu, T.; Ajay, V. R.; Krishnan, K.; Abitha, V. K.; Martin, G. T., Eds. Recycling of Polyurethane Foams; Elsevier: Amsterdam, Netherlands, 2018. doi:10.1016/c2016-0-01054-9

88. Carta, D.; Cao, G.; D'Angeli, C. Environ. Sci. Pollut. Res. 2003, 10, 390-394. doi:10.1065/espr2001.12.104.8

89. Di Serio, M.; Tesser, R.; Ferrara, A.; Santacesaria, E. J. Mol. Catal. A: Chem. 2004, 212, 251-257. doi:10.1016/j.molcata.2003.10.032

90. Awaja, F.; Pavel, D. Eur. Polym. J. 2005, 41, 1453-1477. doi:10.1016/j.eurpolymj.2005.02.005

91. Lorenzetti, C.; Manaresi, P.; Berti, C.; Barbiroli, G. J. Polym. Environ. 2006, 14, 89-101. doi:10.1007/s10924-005-8711-1

92. Pardal, F.; Tersac, G. Polym. Degrad. Stab. 2006, 91, 2567-2578. doi:10.1016/j.polymdegradstab.2006.05.016

93. Kandasamy, S.; Samudrala, S. P.; Bhattacharya, S. Catal. Sci. Technol. 2019, 9, 567-577. doi:10.1039/c8cy02035c

94. McElvery, R. Chem. Eng. News 2019, 97, No. 10.

95. Kim, S.; Kwon, E. E.; Kim, Y. T.; Jung, S.; Kim, H. J.; Huber, G. W.; Lee, J. Green Chem. 2019, 21, 3715-3743. doi:10.1039/c9gc01210a

96. De, S.; Saha, B.; Luque, R. Bioresour. Technol. 2015, 178, 108-118. doi:10.1016/j.biortech.2014.09.065

97. Espro, C.; Gumina, B.; Paone, E.; Mauriello, F. Catalysts 2017, 7, 78. doi:10.3390/catal7030078

98. Van den Bosch, S.; Koelewijn, S.-F.; Renders, T.; Van den Bossche, G.; Vangeel, T.; Schutyser, W.; Sels, B. F. Top. Curr. Chem. 2018, 376, 36. doi:10.1007/s41061-018-0214-3

99. Kärkäs, M. D. ChemSusChem 2017, 10, 2111-2115. doi:10.1002/cssc.201700436

100.Cheng, C.; Shen, D.; Gu, S.; Luo, K. H. Catal. Sci. Technol. 2018, 8, 6275-6296. doi:10.1039/c8cy00845k

101.Xin, H.; Hu, X.; Cai, C.; Wang, H.; Zhu, C.; Li, S.; Xiu, Z.; Zhang, X.; Liu, Q.; Ma, L. Front. Chem. (Lausanne, Switz.) 2020, 8, 333. doi:10.3389/fchem.2020.00333

102. Farmer, T. J.; Mascal, M. Platform Molecules. Introduction to Chemicals from Biomass, 2nd ed.; John Wiley \& Sons: Hoboken, NJ, USA, 2015; pp 89-155. doi:10.1002/9781118714478.ch4

103.Fang, Z.; Smith, R. L., Jr.; Qi, X., Eds. Production of Platform Chemicals from Sustainable Resources; Springer Nature Singapore Pte, Ltd.: Singapore, 2017. doi:10.1007/978-981-10-4172-3

104.Tang, X.; Chen, H.; Hu, L.; Hao, W.; Sun, Y.; Zeng, X.; Lin, L.; Liu, S. Appl. Catal., B 2014, 147, 827-834. doi:10.1016/j.apcatb.2013.10.021

105. Margellou, A.; Triantafyllidis, K. S. Catalysts 2019, 9, 43. doi:10.3390/catal9010043

106. Cole-Hamilton, D. J.; Tooze, R. P., Eds. Catalyst Separation, Recovery and Recycling - Chemistry and Process Design; Catalysis by Metal Complexes, Vol. 30; Springer: Dordrecht, Netherlands, 2006. doi:10.1007/1-4020-4087-3
107.Sheldon, R. A.; van Bekkum, H., Eds. Fine Chemicals Through Heterogeneous Catalysis; Wiley-VCH: Weinheim, Germany, 2001. doi:10.1002/9783527612963

108. Yoshioka, T.; Sato, T.; Okuwaki, A. J. Appl. Polym. Sci. 1994, 52, 1353-1355. doi:10.1002/app.1994.070520919

109. Paszun, D.; Spychaj, T. Ind. Eng. Chem. Res. 1997, 36, 1373-1383. doi:10.1021/ie960563c

110. Aguado, J.; Serrano, D. P.; Escola, J. M. Ind. Eng. Chem. Res. 2008, 47, 7982-7992. doi:10.1021/ie800393w

111.Sinha, V.; Patel, M. R.; Patel, J. V. J. Polym. Environ. 2010, 18, 8-25. doi:10.1007/s10924-008-0106-7

112. Taniguchi, I.; Yoshida, S.; Hiraga, K.; Miyamoto, K.; Kimura, Y.; Oda, K. ACS Catal. 2019, 9, 4089-4105. doi:10.1021/acscatal.8b05171

113. Kawai, F.; Kawabata, T.; Oda, M. Appl. Microbiol. Biotechnol. 2019, 103, 4253-4268. doi:10.1007/s00253-019-09717-y

114. Witt, U.; Yamamoto, M.; Seeliger, U.; Müller, R.-J.; Warzelhan, V. Angew. Chem., Int. Ed. 1999, 38, 1438-1442. doi:10.1002/(sici)1521-3773(19990517)38:10<1438::aid-anie1438>3.0 .co;2-u

115. Koshti, R.; Mehta, L.; Samarth, N. J. Polym. Environ. 2018, 26 , 3520-3529. doi:10.1007/s10924-018-1214-7

116. Kumar Sen, S.; Raut, S. J. Environ. Chem. Eng. 2015, 3, 462-473. doi:10.1016/j.jece.2015.01.003

117. Bornscheuer, U. T. Science 2016, 351, 1154-1155. doi:10.1126/science.aaf2853

118. Verma, R.; Singh, S.; Dalai, M. K.; Saravanan, M.; Agrawal, V. V.; Srivastava, A. K. Mater. Des. 2017, 133, 10-18. doi:10.1016/j.matdes.2017.07.042

119.Devi, R. S. K.; Natarajan, K.; Nivas, D.; Kannan, K.; Chandra, S.; Antony, A. R. The Role of Microbes in Plastic Degradation. In Environmental waste management; Chandra, R., Ed.; CRC Press: Boca Raton, FL, USA, 2015; pp 341-370. doi:10.1201/b19243

120. Hadad, D.; Geresh, S.; Sivan, A. J. Appl. Microbiol. 2005, 98, 1093-1100. doi:10.1111/j.1365-2672.2005.02553.x

121.Jehanno, C.; Pérez-Madrigal, M. M.; Demarteau, J.; Sardon, H.; Dove, A. P. Polym. Chem. 2019, 10, 172-186. doi:10.1039/c8py01284a

122. Fukushima, K.; Coulembier, O.; Lecuyer, J. M.; Almegren, H. A.; Alabdulrahman, A. M.; Alsewailem, F. D.; Mcneil, M. A.; Dubois, P.; Waymouth, R. M.; Horn, H. W.; Rice, J. E.; Hedrick, J. L. J. Polym. Sci., Part A: Polym. Chem. 2011, 49, 1273-1281. doi:10.1002/pola.24551

123. Liu, M.; Guo, J.; Gu, Y.; Gao, J.; Liu, F.; Yu, S. ACS Sustainable Chem. Eng. 2018, 6, 13114-13121. doi:10.1021/acssuschemeng.8b02650

124. McKeown, P.; Kamran, M.; Davidson, M. G.; Jones, M. D.; Román-Ramírez, L. A.; Wood, J. Green Chem. 2020, 22, 3721-3726. doi:10.1039/d0gc01252a

125.Wang, Q.; Yao, X.; Tang, S.; Lu, X.; Zhang, X.; Zhang, S. Green Chem. 2012, 14, 2559-2566. doi:10.1039/c2gc35696a

126. Quaranta, E.; Minischetti, C. C.; Tartaro, G. ACS Omega 2018, 3, 7261-7268. doi:10.1021/acsomega.8b01123

127.Troev, K.; Grancharov, G.; Tsevi, R.; Gitsov, I. J. Appl. Polym. Sci. 2003, 90, 1148-1152. doi:10.1002/app.12711

128. Pingale, N. D.; Palekar, V. S.; Shukla, S. R. J. Appl. Polym. Sci. 2010, 115, 249-254. doi:10.1002/app.31092

129. López-Fonseca, R.; Duque-Ingunza, I.; de Rivas, B.; Arnaiz, S.; Gutiérrez-Ortiz, J. I. Polym. Degrad. Stab. 2010, 95, 1022-1028. doi:10.1016/j.polymdegradstab.2010.03.007 
130.Pingale, N. D.; Shukla, S. R. Eur. Polym. J. 2008, 44, 4151-4156. doi:10.1016/j.eurpolymj.2008.09.019

131. Mukherjee, S.; RoyChaudhuri, U.; Kundu, P. P. J. Chem. Technol. Biotechnol. 2018, 93, 1300-1311. doi:10.1002/jctb.5489

132. Yang, J.; Yang, Y.; Wu, W.-M.; Zhao, J.; Jiang, L. Environ. Sci. Technol. 2014, 48, 13776-13784. doi:10.1021/es504038a

133.Yin, S.; Tuladhar, R.; Shi, F.; Shanks, R. A.; Combe, M.; Collister, T. Polym. Eng. Sci. 2015, 55, 2899-2909. doi:10.1002/pen.24182

134.Grigore, M. E. Recycling 2017, 2, 24. doi:10.3390/recycling2040024

135. Achilias, D. S.; Andriotis, L.; Koutsidis, I. A.; Louka, D. A.; Nianias, N. P.; Siafaka, P.; Tsagkalias, I.; Tsintzou, G. Recent Advances in the Chemical Recycling of Polymers (PP, PS, LDPE, HDPE, PVC, PC, Nylon, PMMA). Material Recycling - Trends and Perspectives; IntechOpen Ltd.: Rijeka, Croatia, 2012. doi: $10.5772 / 33457$

136. Peacock, A. Handbook of Polyethylene: Structures: Properties, and Applications; CRC Press: Boca Raton, FL, USA, 2000. doi:10.1201/9781482295467

137. Ugbolue, S. C. O., Ed. Polyolefin Fibres: Structure, Properties and Industrial Applications, 2nd ed.; Elsevier: Amsterdam, Netherlands, 2017.

138. Emblem, A. Plastics properties for packaging materials. Packaging Technology Fundamentals, Materials and Processes; Elsevier: Amsterdam, Netherlands, 2012; pp 287-309. doi:10.1533/9780857095701.2.287

139. Rahimi, A.; García, J. M. Nat. Rev. Chem. 2017, 1, 0046. doi:10.1038/s41570-017-0046

140.Jordan, J. L.; Casem, D. T.; Bradley, J. M.; Dwivedi, A. K.; Brown, E. N.; Jordan, C. W. J. Dyn. Behav. Mater. 2016, 2, 411-420. doi:10.1007/s40870-016-0076-0

141. Whiteley, K. S.; Heggs, T. G.; Koch, H.; Mawer, R. L.; Immel, W. Polyolefins. Ullmann's Encyclopedia of Industrial Chemistry; Wiley-VCH: Weinheim, Germany, 2000. doi:10.1002/14356007.a21_487

142.Kumar, S.; Panda, A. K.; Singh, R. K. Resour., Conserv. Recycl. 2011, 55, 893-910. doi:10.1016/j.resconrec.2011.05.005

143.Jin, H.; Gonzalez-Gutierrez, J.; Oblak, P.; Zupančič, B.; Emri, I. Polym. Degrad. Stab. 2012, 97, 2262-2272. doi:10.1016/j.polymdegradstab.2012.07.039

144.Ahmad, I.; Khan, M. I.; Ishaq, M.; Khan, H.; Gul, K.; Ahmad, W. Polym. Degrad. Stab. 2013, 98, 2512-2519. doi:10.1016/j.polymdegradstab.2013.09.009

145. Christensen, S. T.; Elam, J. W.; Rabuffetti, F. A.; Ma, Q.; Weigand, S. J.; Lee, B.; Seifert, S.; Stair, P. C.; Poeppelmeier, K. R.; Hersam, M. C.; Bedzyk, M. J. Small 2009, 5, 750-757. doi:10.1002/smll.200801920

146. Celik, G.; Kennedy, R. M.; Hackler, R. A.; Ferrandon, M.; Tennakoon, A.; Patnaik, S.; LaPointe, A. M.; Ammal, S. C.; Heyden, A.; Perras, F. A.; Pruski, M.; Scott, S. L.; Poeppelmeier, K. R.; Sadow, A. D.; Delferro, M. ACS Cent. Sci. 2019, 5, 1795-1803. doi:10.1021/acscentsci.9b00722

147.Liang, Z.; Chen, L.; Alam, M. S.; Zeraati Rezaei, S.; Stark, C.; Xu, H.; Harrison, R. M. Fuel 2018, 220, 792-799. doi:10.1016/j.fuel.2017.11.142

148.Dewaele, A.; Renders, T.; Yu, B.; Verpoort, F.; Sels, B. F. Catal. Sci. Technol. 2016, 6, 7708-7717. doi:10.1039/c6cy00933f
149.Bahr, S.; Doyle, N.; Wang, J.; Winckler, S.; Takekoshi, T.; Wang, Y. F. Macrocyclic polyster oligomers as carriers and/or flow modifier additives for thermoplastics. W.O. Pat. Appl. WO2007011684 A2, Jan 25, 2007.

150.Laurent, B. A.; Grayson, S. M. J. Am. Chem. Soc. 2011, 133, 13421-13429. doi:10.1021/ja2024355

151.Scheirs, J.; Priddy, D. B., Eds. Modern Styrenic Polymers: Polystyrenes and Styrenic Copolymers; John Wiley \& Sons: Hoboken, NJ, USA, 2003. doi:10.1002/0470867213

152. Wypych, G. PS polystyrene. Handbook of Polymers; Elsevier: Amsterdam, Netherlands, 2012; pp 541-547. doi:10.1016/b978-1-895198-47-8.50162-4

153.Samper, M. D.; Garcia-Sanoguera, D.; Parres, F.; López, J. Prog. Rubber, Plast. Recycl. Technol. 2010, 26, 83-92. doi:10.1177/147776061002600202

154. Hawley-Fedder, R. A.; Parsons, M. L.; Karasek, F. W. J. Chromatogr. 1984, 315, 201-210. doi:10.1016/s0021-9673(01)90737-x

155. Ergut, A.; Levendis, Y. A.; Carlson, J. Fuel 2007, 86, 1789-1799. doi:10.1016/j.fuel.2007.01.009

156. Kim, J.-S.; Lee, W.-Y.; Lee, S.-B.; Kim, S.-B.; Choi, M.-J. Catal. Today 2003, 87, 59-68. doi:10.1016/j.cattod.2003.10.004

157. Adnan; Shah, J.; Jan, M. R. J. Anal. Appl. Pyrolysis 2014, 109, 196-204. doi:10.1016/j.jaap.2014.06.013

158.Shah, J.; Jan, M. R.; Adnan. J. Taiwan Inst. Chem. Eng. 2017, 80, 391-398. doi:10.1016/j.jtice.2017.07.026

159. Yoshida, S.; Hiraga, K.; Takehana, T.; Taniguchi, I.; Yamaji, H.; Maeda, Y.; Toyohara, K.; Miyamoto, K.; Kimura, Y.; Oda, K. Science 2016, 351, 1196-1199. doi:10.1126/science.aad6359

160. Atta, A. M.; El-Kafrawy, A. F.; Aly, M. H.; Abdel-Azim, A.-A. A. Prog. Org. Coat. 2007, 58, 13-22. doi:10.1016/j.porgcoat.2006.11.001

161. Köpnick, H.; Schmidt, M.; Brügging, W.; Rüter, J.; Kaminsky, W. Polyesters. Ullmann's Encyclopedia of Industrial Chemistry; Wiley-VCH: Weinheim, Germany, 2000; pp 623-649. doi:10.1002/14356007.a21_227

162. Mahalingam, S.; Raimi-Abraham, B. T.; Craig, D. Q. M.; Edirisinghe, M. Chem. Eng. J. 2015, 280, 344-353. doi:10.1016/j.cej.2015.05.114

163. Weisskopf, K. J. Polym. Sci., Part A: Polym. Chem. 1988, 26 , 1919-1935. doi:10.1002/pola.1988.080260718

164.Sax, L. Environ. Health Perspect. 2010, 118, 445-448. doi:10.1289/ehp.0901253

165. Sathyanarayana, S. Curr. Probl. Pediatr. Adolesc. Health Care 2008, 38, 34-49. doi:10.1016/j.cppeds.2007.11.001

166. Commission Regulation (EU) 2018/2005 of 17 December 2018 amending Annex XVII to Regulation (EC) No 1907/2006 of the European Parliament and of the Council concerning the Registration, Evaluation, Authorisation and Restriction of Chemicals (REACH) as regards bis(2-ethylhexyl) phthalate (DEHP), dibutyl phthalate (DBP), benzyl butyl phthalate (BBP) and diisobutyl phthalate (DIBP). https://eur-lex.europa.eu/legal-content/EN/TXT/PDF/?uri=CELEX:320 18R2005\&from=EN (accessed Jan 27, 2021).

167. De Clercq, R.; Dusselier, M.; Sels, B. F. Green Chem. 2017, 19, 5012-5040. doi:10.1039/c7gc02040f

168. Liguori, F.; Barbaro, P.; Calisi, N. ChemSusChem 2019, 12, 2558-2563. doi:10.1002/cssc.201900833

169.Al-Sabagh, A. M.; Yehia, F. Z.; Eshaq, G.; Rabie, A. M.; EIMetwally, A. E. Egypt. J. Pet. 2016, 25, 53-64. doi:10.1016/j.ejpe.2015.03.001

170. Garcia, J. M.; Robertson, M. L. Science 2017, 358, 870-872. doi:10.1126/science.aaq0324 
171.Hoang, C. N.; Dang, Y. H. Polym. Degrad. Stab. 2013, 98, 697-708. doi:10.1016/j.polymdegradstab.2012.12.026

172.Sabu, T.; Ajay, V. R.; Krishnan, K.; Abitha, V. K.; Martin, G. T., Eds. Recycling of Polyethylene Terephthalate Bottles; Elsevier: Amsterdam, Netherlands, 2018. doi:10.1016/c2016-0-01084-7

173. Raheem, A. B.; Noor, Z. Z.; Hassan, A.; Abd Hamid, M. K.; Samsudin, S. A.; Sabeen, A. H. J. Cleaner Prod. 2019, 225, 1052-1064. doi:10.1016/j.jclepro.2019.04.019

174. Vilaplana Artigas, M.; Mestrom, L.; De Groot, R.; Philipp, V.; Guerreo Sanchez, C.; Hooghoudt, T. Polymer Degradation. U.S. Pat. Appl. US2019185406A1, June 20, 2019.

175. Inada, S.; Sato, K. Methods for the preparation or purification of bis-beta-hydroxythethyl terephthalate. W.O. Pat. Appl. WO2001010812 A1, Feb 15, 2001.

176. Essaddam, H.; Hostetler, M. J. Polyethylene terephthalate depolymerisation. W.O. Pat. Appl. WO2017007965 A1, Jan 12, 2017.

177.Parravicini, M.; Crippa, M.; Bertelè, M. V. Method and apparatus for the recycling of polymeric materials via depolymerization process. W.O. Pat. Appl. WO2013014650 A1, Jan 31, 2013.

178.Barla, F. G.; Showalter, T.; Su, H. C.; Jones, J.; Bobe, I. Methods for recycling cotton and polyester fibers from waste textiles. W.O. Pat Appl. WO2019140245 A1, July 18, 2019

179. Cornell, D. D. Recycling Polyesters by Chemical Depolymerization. Modern Polyesters: Chemistry and Technology of Polyesters and Copolyesters; John Wiley \& Sons: Hoboken, NJ, USA, 2003; pp 563-590. doi:10.1002/0470090685.ch16

180. Han, M. Depolymerization of PET Bottle via Methanolysis and Hydrolysis. In Recycling of Polyethylene Terephthalate Bottles; Sabu, T.; Ajay, V. R.; Krishnan, K.; Abitha, V. K.; Martin, G. T., Eds.; Elsevier: Amsterdam, Netherlands, 2019; pp 85-108. doi:10.1016/b978-0-12-811361-5.00005-5

181. Michel, C.; Gallezot, P. ACS Catal. 2015, 5, 4130-4132. doi:10.1021/acscatal.5b00707

182. Balaraman, E.; Fogler, E.; Milstein, D. Chem. Commun. 2012, 48 , 1111-1113. doi:10.1039/c1cc15778g

183. Fuentes, J. A.; Smith, S. M.; Scharbert, M. T.; Carpenter, I.; Cordes, D. B.; Slawin, A. M. Z.; Clarke, M. L. Chem. - Eur. J. 2015, 21, 10851-10860. doi:10.1002/chem.201500907

184. Takebayashi, S.; Bergens, S. H. Organometallics 2009, 28 , 2349-2351. doi:10.1021/om9002076

185. Hasanayn, F.; Baroudi, A. Organometallics 2013, 32, 2493-2496. doi:10.1021/om400122n

186. Martello, M. T.; Hillmyer, M. A. Macromolecules 2011, 44, 8537-8545. doi:10.1021/ma201063t

187.Luo, Y.; Zhang, S.; Ma, Y.; Wang, W.; Tan, B. Polym. Chem. 2013, 4, 1126-1131. doi:10.1039/c2py20914d

188. Krall, E. M.; Klein, T. W.; Andersen, R. J.; Nett, A. J.; Glasgow, R. W.; Reader, D. S.; Dauphinais, B. C.; Mc Ilrath, S. P.; Fischer, A. A.; Carney, M. J.; Hudson, D. J.; Robertson, N. J. Chem. Commun. 2014, 50, 4884-4887. doi:10.1039/c4cc00541d

189. Ghilardi, C. A.; Midollini, S.; Orlandini, A.; Sacconi, L. Inorg. Chem. 1980, 19, 301-306. doi:10.1021/ic50204a005

190.Phanopoulos, A.; Miller, P. W.; Long, N. J. Coord. Chem. Rev. 2015, 299, 39-60. doi:10.1016/j.ccr.2015.04.001

191. Westhues, S.; Idel, J.; Klankermayer, J. Sci. Adv. 2018, 4, eaat9669. doi:10.1126/sciadv.aat9669

192.vom Stein, T.; Meuresch, M.; Limper, D.; Schmitz, M.; Hölscher, M.; Coetzee, J.; Cole-Hamilton, D. J.; Klankermayer, J.; Leitner, W. J. Am. Chem. Soc. 2014, 136, 13217-13225. doi:10.1021/ja506023f
193.Monsigny, L.; Berthet, J.-C.; Cantat, T. ACS Sustainable Chem. Eng. 2018, 6, 10481-10488. doi:10.1021/acssuschemeng.8b01842

194.Wang, Y.; Zhang, Y.; Song, H.; Wang, Y.; Deng, T.; Hou, X. J. Cleaner Prod. 2019, 208, 1469-1475.

doi:10.1016/j.jclepro.2018.10.117

195.Liu, Y.; Wang, M.; Pan, Z. J. Supercrit. Fluids 2012, 62, 226-231. doi:10.1016/j.supflu.2011.11.001

196. Tang, H.; Li, N.; Li, G.; Wang, A.; Cong, Y.; Xu, G.; Wang, X.; Zhang, T. Green Chem. 2019, 21, 2709-2719. doi:10.1039/c9gc00571d

197.Kurokawa, H.; Ohshima, M.-a.; Sugiyama, K.; Miura, H. Polym. Degrad. Stab. 2003, 79, 529-533. doi:10.1016/s0141-3910(02)00370-1

198. López-Fonseca, R.; Duque-Ingunza, I.; de Rivas, B.; Flores-Giraldo, L.; Gutiérrez-Ortiz, J. I. Chem. Eng. J. 2011, 168, 312-320. doi:10.1016/j.cej.2011.01.031

199. Commission regulation No 10/2011 of 14 January 2011 on plastic materials and articles intended to come into contact with food, European Commission, Brussels, Belgium, 2011. https://eur-lex.europa.eu/legal-content/EN/TXT/PDF/?uri=CELEX:320 11R0010\&from=EN (accessed Jan 27, 2021).

200. Ghaemy, M.; Mossaddegh, K. Polym. Degrad. Stab. 2005, 90 , 570-576. doi:10.1016/j.polymdegradstab.2005.03.011

201.Xi, G.; Lu, M.; Sun, C. Polym. Degrad. Stab. 2005, 87, 117-120. doi:10.1016/j.polymdegradstab.2004.07.017

202.Liu, B.; Lu, X.; Ju, Z.; Sun, P.; Xin, J.; Yao, X.; Zhou, Q.; Zhang, S. Ind. Eng. Chem. Res. 2018, 57, 16239-16245. doi:10.1021/acs.iecr.8b03854

203. Chen, F.; Wang, G.; Shi, C.; Zhang, Y.; Zhang, L.; Li, W.; Yang, F. J. Appl. Polym. Sci. 2013, 127, 2809-2815. doi:10.1002/app.37608

204. Chaudhary, S.; Surekha, P.; Kumar, D.; Rajagopal, C.; Roy, P. K. J. Appl. Polym. Sci. 2013, 129, 2779-2788. doi:10.1002/app.38970

205. Esquer, R.; García, J. J. J. Organomet. Chem. 2019, 902, 120972. doi:10.1016/j.jorganchem.2019.120972

206. Ammam, M. J. Mater. Chem. A 2013, 1, 6291-6312. doi:10.1039/c3ta01663c

207. Kamata, K.; Sugahara, K. Catalysts 2017, 7, 345. doi:10.3390/catal7110345

208.Zhang, L.; Gao, J.; Zou, J.; Yi, F. J. Appl. Polym. Sci. 2013, 130, 2790-2795. doi:10.1002/app.39497

209.Zhou, X.; Lu, X.; Wang, Q.; Zhu, M.; Li, Z. Pure Appl. Chem. 2012, 84, 789-801. doi:10.1351/pac-con-11-06-10

210.Geng, Y.; Dong, T.; Fang, P.; Zhou, Q.; Lu, X.; Zhang, S. Polym. Degrad. Stab. 2015, 117, 30-36. doi:10.1016/j.polymdegradstab.2015.03.019

211.Zhu, M.; Li, S.; Li, Z.; Lu, X.; Zhang, S. Chem. Eng. J. 2012, 185-186, 168-177. doi:10.1016/j.cej.2012.01.068

212. Ritter Lima, G.; Monteiro, W. F.; Ligabue, R.; Campomanes Santana, R. M. Mater. Res. (Sao Carlos, Braz.) 2017, 20 (Suppl. 2), 588-595. doi:10.1590/1980-5373-mr-2017-0645

213.Monteiro, W. F.; Vieira, M. O.; Aquino, A. S.; de Souza, M. O.; de Lima, J.; Einloft, S.; Ligabue, R. Appl. Catal., A 2017, 544, 46-54. doi:10.1016/j.apcata.2017.07.011

214.Lima, G. R.; Monteiro, W. F.; Toledo, B. O.; Ligabue, R. A.; Santana, R. M. C. Macromol. Symp. 2019, 383, 1800008. doi:10.1002/masy.201800008

215. Kitano, M.; Nakajima, K.; Kondo, J. N.; Hayashi, S.; Hara, M. J. Am. Chem. Soc. 2010, 132, 6622-6623. doi:10.1021/ja100435w 216. Yang, X.; Wu, L.; Ma, L.; Li, X.; Wang, T.; Liao, S. Catal. Commun. 2015, 59, 184-188. doi:10.1016/j.catcom.2014.10.031 
217. Linares, N.; Moreno-Marrodan, C.; Barbaro, P. ChemCatChem 2016, 8, 1001-1011. doi:10.1002/cctc.201501126

218.Jiao, S.; Chen, Y.; Xu, M.; Zhang, Y.; Wang, D.; Pang, G.; Feng, S. Mater. Lett. 2010, 64, 1704-1706. doi:10.1016/j.matlet.2010.05.007

219.Bartolome, L.; Imran, M.; Lee, K. G.; Sangalang, A.; Ahn, J. K.; Kim, D. H. Green Chem. 2014, 16, 279-286. doi:10.1039/c3gc41834k

220.Park, G.; Bartolome, L.; Lee, K. G.; Lee, S. J.; Kim, D. H.; Park, T. J. Nanoscale 2012, 4, 3879-3885. doi:10.1039/c2nr30168g

221. Imran, M.; Lee, K. G.; Imtiaz, Q.; Kim, B.-K.; Han, M.; Cho, B. G.; Kim, D. H. J. Nanosci. Nanotechnol. 2011, 11, 824-828. doi:10.1166/jnn.2011.3201

222.Imran, M.; Kim, D. H.; Al-Masry, W. A.; Mahmood, A.; Hassan, A.; Haider, S.; Ramay, S. M. Polym. Degrad. Stab. 2013, 98, 904-915. doi:10.1016/j.polymdegradstab.2013.01.007

223. Eshaq, G.; EIMetwally, A. E. J. Mol. Liq. 2016, 214, 1-6. doi:10.1016/j.molliq.2015.11.049

224.Di Cosimo, J. I.; Dıez, V. K.; Xu, M.; Iglesia, E.; Apesteguıa, C. R. J. Catal. 1998, 178, 499-510. doi:10.1006/jcat.1998.2161

225. Deetlefs, M.; Seddon, K. R. Green Chem. 2010, 12, 17-30. doi:10.1039/b915049h

226. Thuy Pham, T. P.; Cho, C.-W.; Yun, Y.-S. Water Res. 2010, 44, 352-372. doi:10.1016/j.watres.2009.09.030

227.Wang, Q.; Lu, X.; Zhou, X.; Zhu, M.; He, H.; Zhang, X. J. Appl. Polym. Sci. 2013, 129, 3574-3581. doi:10.1002/app.38706

228.Yue, Q. F.; Xiao, L. F.; Zhang, M. L.; Feng Bai, X. F. Polymers (Basel, Switz.) 2013, 5, 1258-1271. doi:10.3390/polym5041258

229. Wang, Q.; Geng, Y.; Lu, X.; Zhang, S. ACS Sustainable Chem. Eng. 2015, 3, 340-348. doi:10.1021/sc5007522

230.Valkenberg, M. H.; deCastro, C.; Hölderich, W. F. Green Chem. 2002, 4, 88-93. doi:10.1039/b107946h

231.Al-Sabagh, A. M.; Yehia, F. Z.; Eshaq, G.; ElMetwally, A. E. Ind. Eng. Chem. Res. 2015, 54, 12474-12481. doi:10.1021/acs.iecr.5b03857

232.Abbott, A. P.; Ahmed, E. I.; Harris, R. C.; Ryder, K. S. Green Chem. 2014, 16, 4156-4161. doi:10.1039/c4gc00952e

233. Wagle, D. V.; Zhao, H.; Baker, G. A. Acc. Chem. Res. 2014, 47, 2299-2308. doi:10.1021/ar5000488

234.Paiva, A.; Craveiro, R.; Aroso, I.; Martins, M.; Reis, R. L.; Duarte, A. R. C. ACS Sustainable Chem. Eng. 2014, 2, 1063-1071. doi:10.1021/sc500096j

235.Pena-Pereira, F.; Namieśnik, J. ChemSusChem 2014, 7, 1784-1800. doi:10.1002/cssc.201301192

236.Smith, E. L.; Abbott, A. P.; Ryder, K. S. Chem. Rev. 2014, 114, 11060-11082. doi:10.1021/cr300162p

237.Liu, B.; Fu, W.; Lu, X.; Zhou, Q.; Zhang, S. ACS Sustainable Chem. Eng. 2019, 7, 3292-3300. doi:10.1021/acssuschemeng.8b05324

238.Wang, Q.; Yao, X.; Geng, Y.; Zhou, Q.; Lu, X.; Zhang, S. Green Chem. 2015, 17, 2473-2479. doi:10.1039/c4gc02401j

239. Cakić, S. M.; Ristić, I. S.; M-Cincović, M.; Nikolić, N. Č.; llić, O. Z.; Stojiljković, D. T.; B-Simendić, J. K. Prog. Org. Coat. 2012, 74, 115-124. doi:10.1016/j.porgcoat.2011.11.024

240. Essawy, H. A.; Tawfik, M. E.; Elsayed, N. H. J. Appl. Polym. Sci. 2012, 123, 2377-2383. doi:10.1002/app.34750

241. Chaudhary, S.; Surekha, P.; Kumar, D.; Rajagopal, C.; Roy, P. K. J. Appl. Polym. Sci. 2013, 129, 2779-2788. doi:10.1002/app.38970

242.Hoang, C. N.; Le, T. T. N.; Hoang, Q. D. Polym. Bull. 2019, 76, 23-34. doi:10.1007/s00289-018-2369-Z
243. Amaro, L. P.; Coiai, S.; Ciardelli, F.; Passaglia, E. Waste Manage. (Oxford, U. K.) 2015, 46, 68-75. doi:10.1016/j.wasman.2015.09.005

244. Kárpáti, L.; Fogarassy, F.; Kovácsik, D.; Vargha, V. J. Polym. Environ. 2019, 27, 2167-2181. doi:10.1007/s10924-019-01490-3

245.Gioia, C.; Vannini, M.; Marchese, P.; Minesso, A.; Cavalieri, R.; Colonna, M.; Celli, A. Green Chem. 2014, 16, 1807-1815. doi:10.1039/c3gc42122h

246. Substance Infocard 1,4:3,6-dianhydro-D-glucitol, European Chemicals Agency.

https://echa.europa.eu/it/substance-information/-/substanceinfo/100.0 10.449 (accessed Sept 1, 2020).

247. Dussenne, C.; Delaunay, T.; Wiatz, V.; Wyart, H.; Suisse, I.; Sauthier, M. Green Chem. 2017, 19, 5332-5344. doi:10.1039/c7gc01912b

248. Delbecq, F.; Khodadadi, M. R.; Rodriguez Padron, D.; Varma, R.; Len, C. Mol. Catal. 2020, 482, 110648. doi:10.1016/j.mcat.2019.110648

249. Liguori, F.; Moreno-Marrodan, C.; Barbaro, P. Chem. Soc. Rev. 2020, 49, 6329-6363. doi:10.1039/d0cs00179a

250.Saxon, D. J.; Luke, A. M.; Sajjad, H.; Tolman, W. B.; Reineke, T. M. Prog. Polym. Sci. 2020, 101, 101196. doi:10.1016/j.progpolymsci.2019.101196

251.Feng, X.; East, A. J.; Hammond, W. B.; Zhang, Y.; Jaffe, M. Polym. Adv. Technol. 2011, 22, 139-150. doi:10.1002/pat.1859

252.Jem, K. J.; Tan, B. Adv. Ind. Eng. Polym. Res. 2020, 3, 60-70. doi:10.1016/j.aiepr.2020.01.002

253. Auras, R.; Lim, L.-T.; Selke, S. E. M.; Tsuji, H., Eds. Poly(Lactic Acid): Synthesis, Structures, Properties, Processing, and Applications; John Wiley \& Sons: Hoboken, NJ, USA, 2010. doi:10.1002/9780470649848

254. Lunt, J. Polym. Degrad. Stab. 1998, 59, 145-152. doi:10.1016/s0141-3910(97)00148-1

255. Datta, R.; Henry, M. J. Chem. Technol. Biotechnol. 2006, 81, 1119-1129. doi:10.1002/jctb.1486

256. Garlotta, D. J. Polym. Environ. 2001, 9, 63-84. doi:10.1023/a:1020200822435

257. Sato, S.; Gondo, D.; Wada, T.; Kanehashi, S.; Nagai, K. J. Appl. Polym. Sci. 2013, 129, 1607-1617. doi:10.1002/app.38833

258. Castro-Aguirre, E.; Iñiguez-Franco, F.; Samsudin, H.; Fang, X.; Auras, R. Adv. Drug Delivery Rev. 2016, 107, 333-366. doi:10.1016/j.addr.2016.03.010

259. Anderson, J. M.; Shive, M. S. Adv. Drug Delivery Rev. 2012, 64, 72-82. doi:10.1016/j.addr.2012.09.004

260. Niaounakis, M. Biopolymers: Processing and Products; Elsevier: Amsterdam, Netherlands, 2014. doi:10.1016/c2013-0-09982-3

261. Garg, M.; White, S. R.; Sottos, N. R. ACS Appl. Mater. Interfaces 2019, 11, 46226-46232. doi:10.1021/acsami.9b17599

262. Lizundia, E.; Ruiz-Rubio, L.; Vilas, J. L.; León, L. M. RSC Adv. 2016, 6, 15660-15669. doi:10.1039/c5ra24604k

263. Fan, Y.; Nishida, H.; Mori, T.; Shirai, Y.; Endo, T. Polymer 2004, 45, 1197-1205. doi:10.1016/j.polymer.2003.12.058

264. Carné Sánchez, A.; Collinson, S. R. Eur. Polym. J. 2011, 47, 1970-1976. doi:10.1016/j.eurpolymj.2011.07.013

265. Román-Ramírez, L. A.; Mckeown, P.; Jones, M. D.; Wood, J. ACS Catal. 2019, 9, 409-416. doi:10.1021/acscatal.8b04863

266. McKeown, P.; Román-Ramírez, L. A.; Bates, S.; Wood, J.; Jones, M. D. ChemSusChem 2019, 12, 5233-5238. doi:10.1002/cssc.201902755 
267.Payne, J.; McKeown, P.; Mahon, M. F.; Emanuelsson, E. A. C.; Jones, M. D. Polym. Chem. 2020, 11, 2381-2389. doi:10.1039/d0py00192a

268. Fliedel, C.; Vila-Viçosa, D.; Calhorda, M. J.; Dagorne, S.; Avilés, T. ChemCatChem 2014, 6, 1357-1367. doi:10.1002/cctc.201301015

269. Whitelaw, E. L.; Davidson, M. G.; Jones, M. D. Chem. Commun. 2011, 47, 10004-10006. doi:10.1039/c1cc13910j

270.Chmura, A. J.; Cousins, D. M.; Davidson, M. G.; Jones, M. D.; Lunn, M. D.; Mahon, M. F. Dalton Trans. 2008, 1437-1443. doi:10.1039/b716304e

271.Alberti, C.; Damps, N.; Meißner, R. R. R.; Hofmann, M.; Rijono, D.; Enthaler, S. Adv. Sustainable Syst. 2020, 4, 1900081. doi:10.1002/adsu.201900081

272.Bowmer, C. T.; Hooftman, R. N.; Hanstveit, A. O.; Venderbosch, P. W. M.; van der Hoeven, N. Chemosphere 1998, 37, 1317-1333. doi:10.1016/s0045-6535(98)00116-7

273. Calvo-Flores, F. G.; Monteagudo-Arrebola, M. J.; Dobado, J. A.; Isac-García, J. Top. Curr. Chem. 2018, 376, 18. doi:10.1007/s41061-018-0191-6

274.Petrus, R.; Bykowski, D.; Sobota, P. ACS Catal. 2016, 6, 5222-5235. doi:10.1021/acscatal.6b01009

275.Bykowski, D.; Grala, A.; Sobota, P. Tetrahedron Lett. 2014, 55, 5286-5289. doi:10.1016/j.tetlet.2014.07.103

276.Dusselier, M.; Van Wouwe, P.; Dewaele, A.; Makshina, E.; Sels, B. F. Energy Environ. Sci. 2013, 6, 1415-1442. doi:10.1039/c3ee00069a

277.Sullivan, C. J.; Kuenz, A.; Vorlop, K. D. Propanediols. Ullmann's Encyclopedia of Industrial Chemistry; Wiley-VCH: Weinheim, Germany, 2018. doi:10.1002/14356007.a22_163.pub2

278.Guarino, V.; Gentile, G.; Sorrentino, L.; Ambrosio, L. Polycaprolactone: Synthesis, Properties, and Applications. Encyclopedia of Polymer Science and Technology, 4th ed.; John Wiley \& Sons: Hoboken, NJ, USA, 2017. doi:10.1002/0471440264.pst658

279. Nguyet Thi Ho, L.; Minh Ngo, D.; Cho, J.; Jung, H. M. Polym. Degrad. Stab. 2018, 155, 15-21. doi:10.1016/j.polymdegradstab.2018.07.003

280.Zhu, J.-B.; Watson, E. M.; Tang, J.; Chen, E. Y.-X. Science 2018, 360 398-403. doi:10.1126/science.aar5498

281. Hong, M.; Chen, E. Y.-X. Angew. Chem., Int. Ed. 2016, 55, 4188-4193. doi:10.1002/anie.201601092

282. MacDonald, J. P.; Shaver, M. P. Polym. Chem. 2016, 7, 553-559. doi:10.1039/c5py01606a

283. Czub, P. Bisphenol-A. In Handbook of Engineering and Specialty Thermoplastics, Polyethers and Polyesters; Sabu, T.; Visakh, P. M., Eds.; John Wiley \& Sons: Hoboken, NJ, USA, 2011; Vol. 3 , pp 221-269. doi:10.1002/9781118104729.ch7

284. Fukuoka, S.; Fukawa, I.; Adachi, T.; Fujita, H.; Sugiyama, N.; Sawa, T. Org. Process Res. Dev. 2019, 23, 145-169. doi:10.1021/acs.oprd.8b00391

285. Morgan, S. E.; Li, J. Polycarbonate (PC). In Encyclopedia of Chemical Processing; Lee, S., Ed.; CRC Press: Boca Raton, FL, USA, 2005; Vol. 4, pp 2277-2290. doi:10.1201/noe0824755638

286. Bisphenol A (BPA) Market - Growth, Trends, and Forecast (2019 2024), Report ID 4520075, Research and Markets, Dublin, Ireland, Apr 2019.

287.http://bisphenol-a-europe.org/ (accessed July 18, 2020).
288. Bisphenol A (BPA) hazard assessment protocol, EFSA supporting publication 2017:EN-1354, European Food Safety Authority (EFSA), 2017.

https://pdfs.semanticscholar.org/baa6/8fcf927e969202d76ce06d43d4 e4a9576d33.pdf (accessed Jan 27, 2021).

289. Ma, Y.; Liu, H.; Wu, J.; Yuan, L.; Wang, Y.; Du, X.; Wang, R.; Marwa, P. W.; Petlulu, P.; Chen, X.; Zhang, H. Environ. Res. 2019, 176, 108575. doi:10.1016/j.envres.2019.108575

290. Giulivo, M.; Lopez de Alda, M.; Capri, E.; Barceló, D. Environ. Res. 2016, 151, 251-264. doi:10.1016/j.envres.2016.07.011

291. Alonso-Magdalena, P.; Ropero, A. B.; Soriano, S.; García-Arévalo, M.; Ripoll, C.; Fuentes, E.; Quesada, I.; Nadal, Á. Mol. Cell. Endocrinol. 2012, 355, 201-207. doi:10.1016/j.mce.2011.12.012

292. Mercea, P. J. Appl. Polym. Sci. 2009, 112, 579-593. doi:10.1002/app.29421

293. Kang, J.-H.; Kito, K.; Kondo, F. J. Food Prot. 2003, 66, 1444-1447. doi:10.4315/0362-028x-66.8.1444

294.de Angelis, A.; Ingallina, P.; Perego, C. Ind. Eng. Chem. Res. 2004, 43, 1169-1178. doi:10.1021/ie030429+

295. Eco-profiles and Environmental Product Declarations of the European Plastics Manufacturers - Bisphenol A (BPA), Plastics Europe, Brussels, Belgium, Jan 2019. https://www.plasticseurope.org/en/resources/eco-profiles (accessed Jan 27, 2021).

296. Toxicological profile for phenol, U.S. Department of Health and Human Services, Agency for Toxic Substances and Disease Registry, Atlanta, GA, Sept 2008.

https://www.atsdr.cdc.gov/toxprofiles/tp115.pdf (accessed Jan 27, 2021).

297.Belfadhel, H. W.; de Brouwer, J.; Vieveen, M.; Wold, C.; Brander, E. Process for producing Bisphenol A with reduced sulfur content, polycarbonate made from the Bisphenol $A$, and containers formed from the polycarbonate. W.O. Pat. Appl. WO2013061274 A1, May 2, 2013.

298. Kissinger, G. M.; Wynn, N. P. Process and composition. U.S. Pat. Appl. US5362900A, Nov 8, 1994.

299. Brunelle, D. J. ACS Symp. Ser. 2005, 898, 1-5. doi:10.1021/bk-2005-0898.ch001

300. Serini, V. Polycarbonates. Ullmann's Encyclopedia of Industrial Chemistry; Wiley-VCH: Weinheim, Germany, 2000. doi:10.1002/14356007.a21_207

301.Samperi, F.; Montaudo, M. S.; Montaudo, G. Polycarbonates. In Handbook of Engineering and Specialty Thermoplastics, Polyethers and Polyesters; Sabu, T.; Visakh, P. M., Eds.; John Wiley \& Sons: Hoboken, NJ, USA, 2011; Vol. 3, pp 493-528. doi:10.1002/9781118104729.ch12

302. Kim, J. G. Polym. Chem. 2020, 11, 4830-4849. doi:10.1039/c9py01927h

303. Antonakou, E. V.; Achilias, D. S. Waste Biomass Valorization 2013, 4, 9-21. doi:10.1007/s12649-012-9159-x

304. Alberti, C.; Eckelt, S.; Enthaler, S. ChemistrySelect 2019, 4, 12268-12271. doi:10.1002/slct.201903549

305. Kindler, T.-O.; Alberti, C.; Sundermeier, J.; Enthaler, S. ChemistryOpen 2019, 8, 1410-1412. doi:10.1002/open.201900319 306. Balaraman, E.; Gunanathan, C.; Zhang, J.; Shimon, L. J. W.; Milstein, D. Nat. Chem. 2011, 3, 609-614. doi:10.1038/nchem.1089 307.Dixneuf, P. H. Nat. Chem. 2011, 3, 578-579. doi:10.1038/nchem.1103 308. Alberti, C.; Scheliga, F.; Enthaler, S. ChemistrySelect 2019, 4, 2639-2643. doi:10.1002/slct.201900556 
309.Pan, Z.; Hu, Z.; Shi, Y.; Shen, Y.; Wang, J.; Chou, I.-M. RSC Adv. 2014, 4, 19992-19998. doi:10.1039/c4ra00680a

310. Quaranta, E. Appl. Catal., B 2017, 206, 233-241. doi:10.1016/j.apcatb.2017.01.007

311.Guo, J.; Liu, M.; Gu, Y.; Wang, Y.; Gao, J.; Liu, F. Ind. Eng. Chem. Res. 2018, 57, 10915-10921. doi:10.1021/acs.iecr.8b02201

312.Liu, F.; Xiao, Y.; Sun, X.; Qin, G.; Song, X.; Liu, Y. Chem. Eng. J. 2019, 369, 205-214. doi:10.1016/j.cej.2019.03.048

313. Iannone, F.; Casiello, M.; Monopoli, A.; Cotugno, P.; Sportelli, M. C.; Picca, R. A.; Cioffi, N.; Dell'Anna, M. M.; Nacci, A. J. Mol. Catal. A: Chem. 2017, 426, 107-116. doi:10.1016/j.molcata.2016.11.006

314.de Caro, P.; Bandres, M.; Urrutigoïty, M.; Cecutti, C.; Thiebaud-Roux, S. Front. Chem. (Lausanne, Switz.) 2019, 7, 308. doi:10.3389/fchem.2019.00308

315.Adams, J. L.; Meek, T. D.; Mong, S. M.; Johnson, R. K.; Metcalf, B. W. J. Med. Chem. 1988, 31, 1355-1359. doi:10.1021/jm00402a018

316. Katritzky, A. R.; Oliferenko, A.; Lomaka, A.; Karelson, M. Bioorg. Med. Chem. Lett. 2002, 12, 3453-3457. doi:10.1016/s0960-894x(02)00741-2

317. Luinstra, G. A. Polym. Rev. (Philadelphia, PA, U. S.) 2008, 48, 192-219. doi:10.1080/15583720701834240

318. Luinstra, G. A.; Borchardt, E. Material Properties of Poly(Propylene Carbonates). In Synthetic Biodegradable Polymers; Rieger, B.; Künkel, A.; Coates, G.; Reichardt, R.; Dinjus, E.; Zevaco, T., Eds.; Advances in Polymer Science, Vol. 245; Springer: Berlin, Heidelberg, 2011; pp 29-48. doi:10.1007/12_2011_126

319. Han, Z.; Rong, L.; Wu, J.; Zhang, L.; Wang, Z.; Ding, K. Angew. Chem., Int. Ed. 2012, 51, 13041-13045. doi:10.1002/anie.201207781

320.Zubar, V.; Lebedev, Y.; Azofra, L. M.; Cavallo, L.; El-Sepelgy, O.; Rueping, M. Angew. Chem., Int. Ed. 2018, 57, 13439-13443. doi:10.1002/anie.201805630

321. Kumar, A.; Janes, T.; Espinosa-Jalapa, N. A.; Milstein, D. Angew. Chem., Int. Ed. 2018, 57, 12076-12080. doi:10.1002/anie.201806289

322.Liu, X.; de Vries, J. G.; Werner, T. Green Chem. 2019, 21, 5248-5255. doi:10.1039/c9gc02052g

323.Liu, Y.; Zhou, H.; Guo, J.-Z.; Ren, W.-M.; Lu, X.-B. Angew. Chem., Int. Ed. 2017, 56, 4862-4866. doi:10.1002/anie.201701438

324.Palmer, R. J. Polyamides, Plastics. Encyclopedia of Polymer Science and Technology; John Wiley \& Sons: Hoboken, NJ, USA, 2001. doi:10.1002/0471440264.pst251

325.Zhang, C. e-Polym. 2018, 18, 373-408. doi:10.1515/epoly-2018-0094 326.Shukla, S. R.; Harad, A. M.; Mahato, D. J. Appl. Polym. Sci. 2006, 100, 186-190. doi:10.1002/app.22775

327. Alberti, C.; Figueira, R.; Hofmann, M.; Koschke, S.; Enthaler, S. ChemistrySelect 2019, 4, 12638-12642. doi:10.1002/slct.201903970

328. Datta, J.; Błażek, K.; Włoch, M.; Bukowski, R. J. Polym. Environ. 2018, 26, 4415-4429. doi:10.1007/s10924-018-1314-4

329. Matsumoto, H.; Akinari, Y.; Kaiso, K.; Kamimura, A. J. Mater. Cycles Waste Manage. 2017, 19, 326-331. doi:10.1007/s10163-015-0425-4

330. Kamimura, A.; Shiramatsu, Y.; Kawamoto, T. Green Energy Environ. 2019, 4, 166-170. doi:10.1016/j.gee.2019.01.002

331. Klun, U.; Kržan, A. Polym. Adv. Technol. 2002, 13, 817-822. doi:10.1002/pat.250
332.Kumar, A.; von Wolff, N.; Rauch, M.; Zou, Y.-Q.; Shmul, G.; Ben-David, Y.; Leitus, G.; Avram, L.; Milstein, D. J. Am. Chem. Soc. 2020, 142, 14267-14275. doi:10.1021/jacs.0c05675

333. May, C. A., Ed. Epoxy Resins: Chemistry and Technology, 2nd ed.; Taylor \& Francis: Boca Raton, FL, USA, 1988. doi:10.1201/9780203756713

334.Deng, T.; Liu, Y.; Cui, X.; Yang, Y.; Jia, S.; Wang, Y.; Lu, C.; Li, D.; Cai, R.; Hou, X. Green Chem. 2015, 17, 2141-2145. doi:10.1039/c4gc02512a

335.Deng, T.; Cui, X.; Qi, Y.; Wang, Y.; Hou, X.; Zhu, Y. Chem. Commun. 2012, 48, 5494-5496. doi:10.1039/c2cc00122e

336. Ensing, B.; Tiwari, A.; Tros, M.; Hunger, J.; Domingos, S. R.; Pérez, C.; Smits, G.; Bonn, M.; Bonn, D.; Woutersen, S. Nat. Commun. 2019, 10, 2893. doi:10.1038/s41467-019-10783-z

337.Maeno, Z.; Torii, H.; Yamada, S.; Mitsudome, T.; Mizugaki, T.; Jitsukawa, K. RSC Adv. 2016, 6, 89231-89233. doi:10.1039/c6ra20864a

338. Maeno, Z.; Yamada, S.; Mitsudome, T.; Mizugaki, T.; Jitsukawa, K. Green Chem. 2017, 19, 2612-2619. doi:10.1039/c7gc00817a

339. Enthaler, S.; Weidauer, M. Chem. - Eur. J. 2012, 18, 1910-1913. doi:10.1002/chem.201103677

340. Enthaler, S. Catal. Lett. 2014, 144, 850-859. doi:10.1007/s10562-014-1214-8

341. Enthaler, S.; Weidauer, M. ChemSusChem 2012, 5, 1195-1198. doi:10.1002/cssc.201200125

342. Enthaler, S.; Trautner, A. ChemSusChem 2013, 6, 1334-1336. doi:10.1002/cssc.201300380

343.Wang, Y.; Hou, Y.; Song, H. Polym. Degrad. Stab. 2017, 144, 17-23. doi:10.1016/j.polymdegradstab.2017.08.001

344.Vollmer, I.; Jenks, M. J. F.; Roelands, M. C. P.; White, R. J.; van Harmelen, T.; de Wild, P.; van der Laan, G. P.; Meirer, F.; Keurentjes, J. T. F.; Weckhuysen, B. M. Angew. Chem., Int. Ed. 2020, 59, 15402-15423. doi:10.1002/anie.201915651

345.Sheldon, R. A.; Norton, M. Green Chem. 2020, 22, 6310-6322. doi:10.1039/d0gc02630a

346. Plechkova, N. V.; Seddon, K. R. Chem. Soc. Rev. 2008, 37, 123-150. doi:10.1039/b006677j

347. Climent, M. J.; Corma, A.; Iborra, S. ChemSusChem 2009, 2 , 500-506. doi:10.1002/cssc.200800259

348. Felpin, F.-X.; Fouquet, E. ChemSusChem 2008, 1, 718-724. doi:10.1002/cssc.200800110

349. Moreno-Marrodan, C.; Liguori, F.; Barbaro, P. Mol. Catal. 2019, 466, 60-69. doi:10.1016/j.mcat.2019.01.014

350.Clarke, C. J.; Tu, W.-C.; Levers, O.; Bröhl, A.; Hallett, J. P. Chem. Rev. 2018, 118, 747-800. doi:10.1021/acs.chemrev.7b00571

351.Keijer, T.; Bakker, V.; Slootweg, J. C. Nat. Chem. 2019, 11, 190-195. doi:10.1038/s41557-019-0226-9 


\section{License and Terms}

This is an Open Access article under the terms of the Creative Commons Attribution License (https://creativecommons.org/licenses/by/4.0). Please note that the reuse, redistribution and reproduction in particular requires that the author(s) and source are credited and that individual graphics may be subject to special legal provisions.

The license is subject to the Beilstein Journal of Organic Chemistry terms and conditions:

(https://www.beilstein-journals.org/bjoc/terms)

The definitive version of this article is the electronic one which can be found at:

https://doi.org/10.3762/bjoc.17.53 